Dottorato in "Frutticoltura Mediterranea"

Dipartimento di Scienze Agrarie e Forestali

AGR/03 - Arboricoltura generale e Coltivazioni arboree

\title{
Evaluation of antioxidant properties and assessment of genetic diversity of Capparis spinosa cultivated in Pantelleria Island.
}

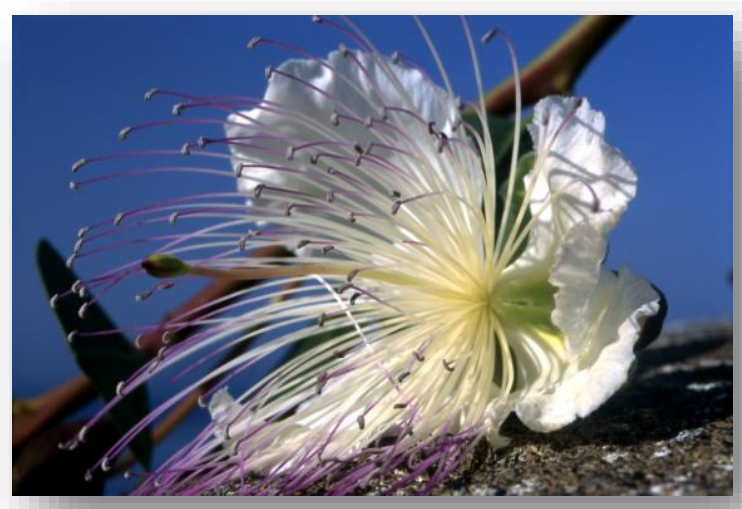

PhD STUDENT

Dr. FABRIZIA LO BOSCO

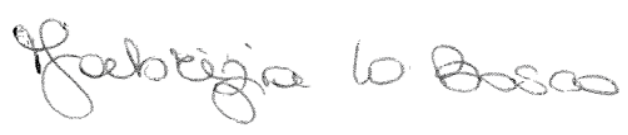

SUPERVISOR

Prof. MARIA ANTONIETTA GERMANÀ

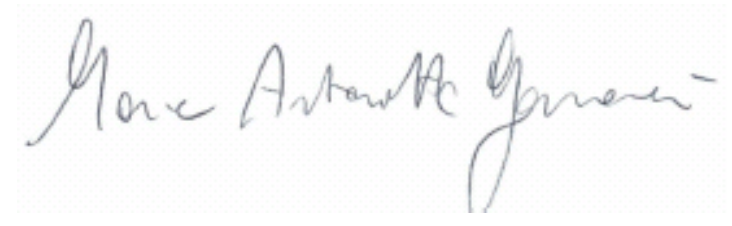

PhD COORDINATOR Prof. MARIA ANTONIETTA GERMANÀ

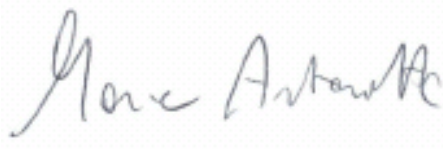

CO SUPERVISOR

Dr. PIER LUIGI SAN BIAGIO

Dr. VALERIA GUARRASI

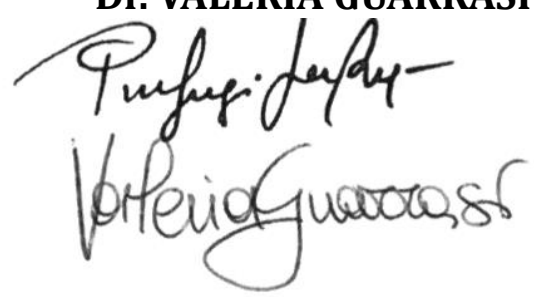




\section{Contents:}

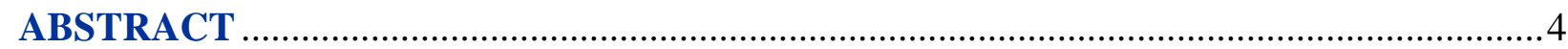

RIASSUNTO

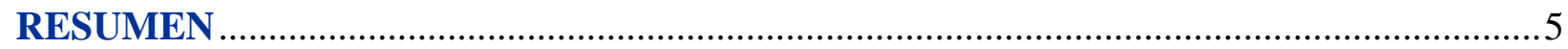

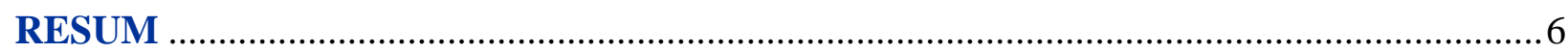

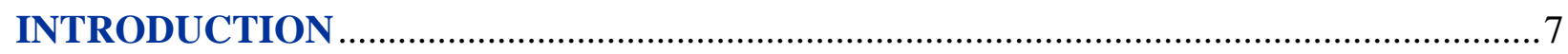

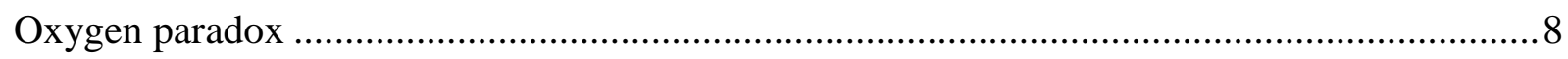

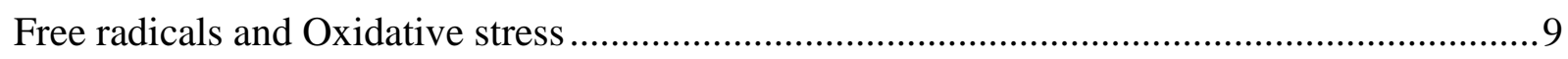

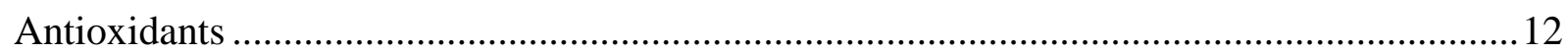

Capparis spinosa L.: nutraceutical value in the Mediterranean diet ..................................... 17

Technical applications for the agro-food characterization ....................................................23

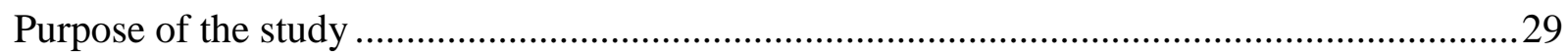

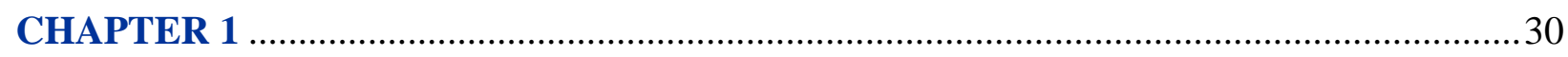

Polyphenols content and antioxidant activity of hydrophilic extracts from Capparis spinosa L.

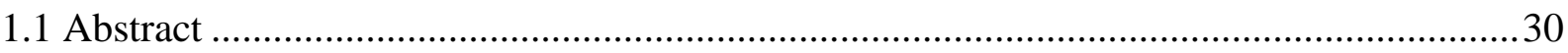

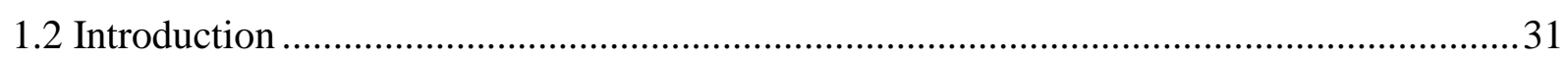

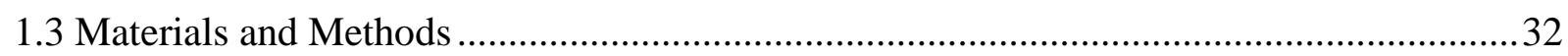

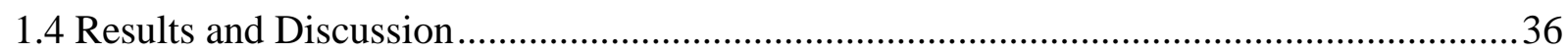

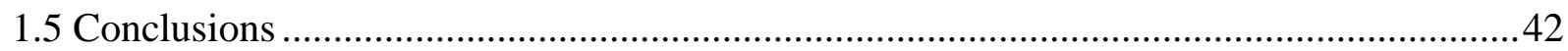

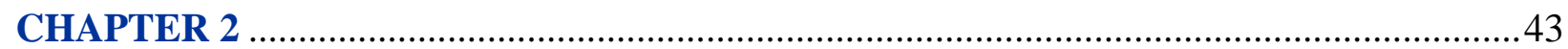

Secondary metabolites characterization of hydrophilic extract from Pantelleria capers (Capparis spinosa L.) by HPLC-PDA-ESI-MSn ................................................................4

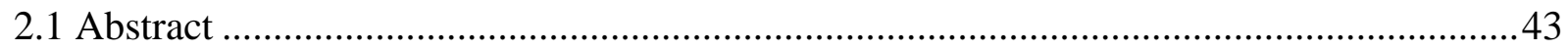

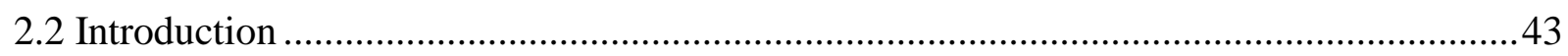

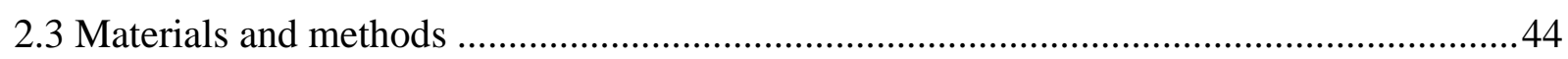

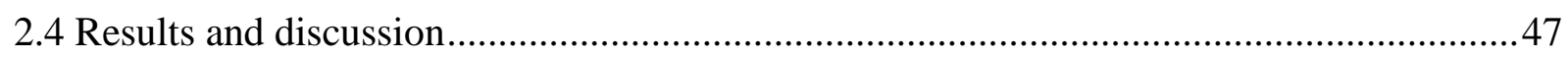

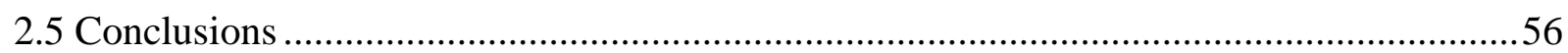

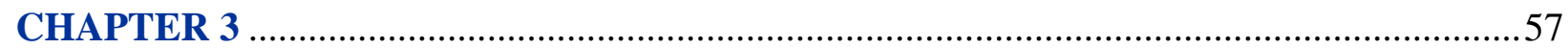

Chemical characteristics and Flavor profile of capers (Capparis spinosa L.) by Electronic Nose, SPME/GC-MS, Electronic Tongue, tecniques .........................................................5

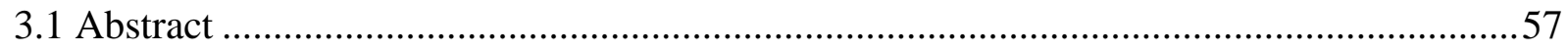

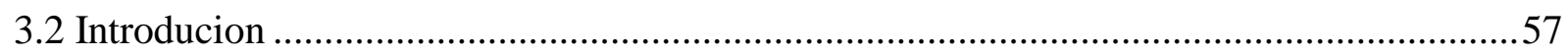

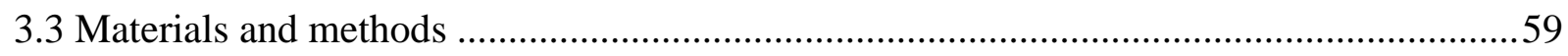

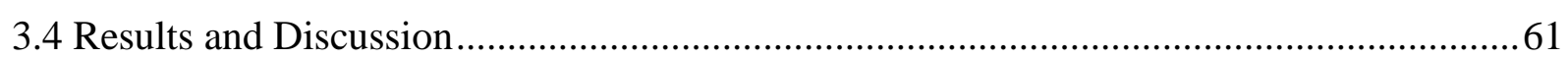


CHAPTER 4

AFLP markers for the assessment of genetic diversity in Capparis spinosa cultivated in Pantelleria Island.

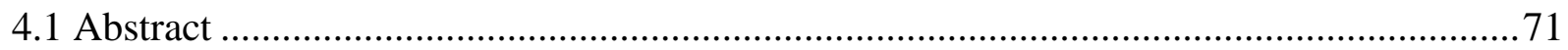

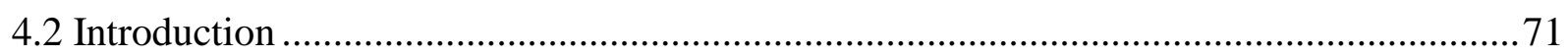

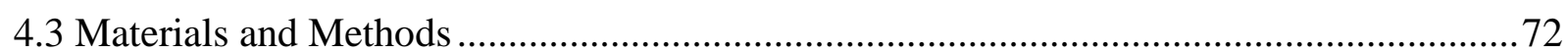

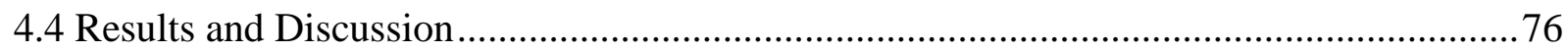

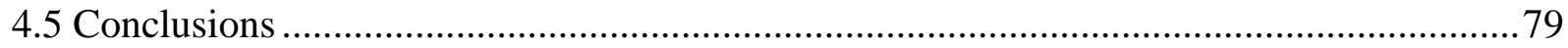

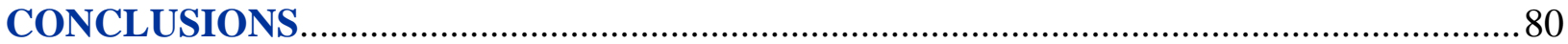

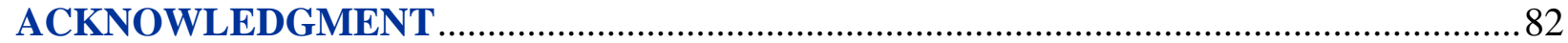

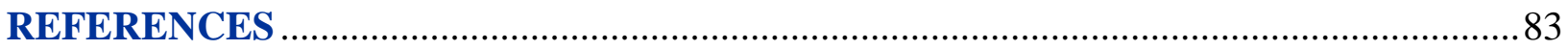




\section{ABSTRACT}

Capparis spinosa is a wild and cultivated bush, which grows mainly in the Mediterranean Basin. Unopened flower buds, called capers are used in the Mediterranean cuisine as flavoring for meat, vegetable and other foods. Several studies evaluated bioactive component and antioxidant activity of Capparis spinosa, increasing the market demand and the economic importance of capers.

The aim of this work was to evaluate the contents of bioactive compounds in floral buds fermented in salt of $C$. spinosa collected from different areas of Pantelleria Island (Italy), testing the effect on healthy function as total antioxidant compounds. Hydrophilic extracts of $C$. spinosa from Pantelleria Island were characterized by high-performance liquid chromatographyelectrospray ionization/mass spectrometry. Among 24 compounds were detected and quantified by HPLC-MS technique: several Kaempherol and Quercetin derivate were characterized, based on UV spectra and $\mathrm{MS}^{\mathrm{n}}$ fragmentation pattern. The antioxidative activity of caper hydrophilic extracts was assessed in a number of chemical assays (ORAC, DPPH and ABTS). In order to determine the genetic diversity within and among populations of Capparis spinosa from Pantelleria Island, AFLPs (Amplified Fragment Length Polymorphism) markers were employed. Moreover, in the present study, a commercial model of an Electronic Nose (EN), EOS ${ }^{835}$ (Sacmi), was preliminarily used to investigate the flavor profile of capers. The EN technique was comparated with a classical techniques gas chromatography-mass spectrometry (GC-MS) analysis, using Head Space Solid-Phase Microextraction (HS-SPME) as a solvent-free sample preparation method.

\section{RIASSUNTO}

Capparis spinosa è un arbusto selvatico e coltivato, che cresce principalmente nel bacino Mediterraneo. I bottoni fiorali non ancora aperti, sono chiamati capperi e sono utilizzati nella cucina Mediterranea come condimento per carne, verdura e altri alimenti. Diversi studi hanno dimostrato la presenza di numerosi componenti bioattivi e l'attività antiossidante di Capparis spinosa, portando ad un aumento della domanda di mercato e dell'importanza economica dei capperi.

Lo scopo di questo lavoro è stato quello di valutare il contenuto di composti bioattivi nei bottoni fiorali di $C$. spinosa dopo fermentazione in salamoia e raccolti in diverse zone dell'Isola di Pantelleria (Italia), evidenziandone gli effetti salutistici come composti antiossidanti totali. Gli 
estratti idrofili di C. spinosa di Pantelleria sono stati caratterizzati mediante cromatografia liquida ad alte prestazioni-ionizzazione elettrospray accoppiata spettrometria massa. Circa 24 composti sono stati individuati e quantificati mediante la tecnica HPLC-MS: sono stati caratterizzati diversi derivati di canferolo e quercetina, sulla base degli spettri UV ed il modello di frammentazione $\mathrm{MS}^{\mathrm{n}}$.

L'attività antiossidante degli estratti idrofili del cappero è stata valutata mediante test chimici (ORAC, DPPH e ABTS). Al fine di determinare la diversità genetica all'interno e tra le popolazioni di Capparis spinosa provenienti dall'Isola di Pantelleria, sono stati impiegati marcatori molecolari di tipo AFLP (Amplified Fragment Length Polymorphism).

Inoltre, nel presente studio è stato utilizzato un modello commerciale di un naso elettronico (EN), $\operatorname{EOS}^{835}$ (Sacmi), per studiare preliminarmente il profilo di dell'aroma dei capperi. La tecnica EN è stata confrontata con una tecnica di analisi classica come la gas cromatografia accoppiata alla spettrometria di massa (GC-MS), utilizzando, come metodo di preparazione del campione, la microestrazione in fase solida dello spazio di testa (HS-SPME) esente da solventi.

\section{RESUMEN}

Capparis spinosa es un arbusto silvestre y cultivado, que crece principalmente en la cuenca mediterránea. Cuando los botones de las flores aún no están abiertas reciben el nombre de alcaparras y se utilizan en la alimentación. Varios estudios han demostrado la presencia de un número de componentes bioactivos in C. spinosa y su actividad antioxidante, lo que ha provocado un aumento de su demanda y ha incrementado la importancia económica de las alcaparras.

El propósito de este trabajo fue evaluar el contenido de compuestos bioactivos en el capullo de la flor de C. spinosa conservado en salmuera, procedente de diferentes zonas de la isla de Pantelleria (Italia). Los resultados se expresan como actividad antioxidante total.

La actividad antioxidante de los extractos hidrófilos de alcaparra se evaluó mediante pruebas químicas (ORAC, DPPH, ABTS). Con el fin de determinar la diversidad genética dentro y entre

poblaciones de C. Spinosa, se utilizaron marcadores moleculares del tipo AFLP (Amplified Fragment Length Polymorphism).

Los extractos hidrófilos de C. spinosa se caracterizaron mediante cromatografía líquida de alta eficacia - ionización electrospray acoplada a espectrometría de masas. Se han identificado y cuantificado aproximadamente 24 compuestos con la técnica de HPLC-MS, y se han 
caracterizado varios derivados de kaempferol y quercetina, sobre la base de los espectros UV y con el modelo de fragmentación $\mathrm{MS}^{\mathrm{n}}$.

En el este estudio también se ha utilizado un modelo de nariz electrónica comercial (ES), EOS ${ }^{835}$ (Sacmi), para un estudio preliminar del perfil de aroma de las alcaparras. La técnica ES se ha comparado con una técnica de análisis clásicos tales como la cromatografía de gases acoplada a espectrometría de masas (GC-MS), utilizando como método de preparación de la muestra el espacio de cabeza de microextracción en fase sólida (HS-SPME) libre de disolventes.

\section{RESUM}

Capparis spinosa és un arbust silvestre i conreat, que creix principalment a la conca mediterrània. Quan els botons de les flors encara no estan obertes reben el nom de tàperes i s'utilitzen en l'alimentació. Diversos estudis han demostrat la presència d'un nombre de components bioactius in $C$. spinosa i la seva activitat antioxidant, el que ha provocat un augment de la seva demanda i ha incrementat la importància econòmica de les tàperes.

El propòsit d'aquest treball va ser avaluar el contingut de compostos bioactius en el capoll de la flor de C. spinosa conservat en salmorra, procedent de diferents zones de l'illa de Pantelleria (Itàlia). Els resultats s'expressen com a activitat antioxidant total.

L'activitat antioxidant dels extractes hidròfils de tàperes es va avaluar mitjançant proves químiques (ORAC, DPPH, ABTS). Per tal de determinar la diversitat genètica dins i entre poblacions de C. Spinosa, es van utilitzar marcadors moleculars del tipus AFLP (Amplified Fragment Length Polymorphism).

Els extractes hidròfils de C. spinosa es van caracteritzar mitjançant cromatografia líquida d'alta eficàcia - ionització electrospray acoblada a espectrometria de masses. S'han identificat i quantificat aproximadament 24 compostos amb la tècnica d'HPLC-MS, i s'han caracteritzat diversos derivats de kaempferol i quercetina, sobre la base dels espectres UV i amb el model de fragmentació MSN.

Al aquest estudi també s'ha utilitzat un model de nas electrònic comercial (ES), $\operatorname{EOS}^{835}$ (Sacmi), per a un estudi preliminar del perfil d'aroma de les tàperes. La tècnica ÉS s'ha acoblat amb una tècnica d'anàlisi clàssics com ara la cromatografia de gasos acoblada a espectrometria de masses (GC-MS), utilitzant com a mètode de preparació de la mostra l'espai de cap de microextracció en fase sòlida (HS-SPME ) lliure de dissolvents. 


\section{INTRODUCTION}

In the last decade, alimentation has lost the typicality and genuineness, because the agro-food products are subjected to industrial processes to address the growing advertising demand. The transformations carried out on foods, indeed, sometime deplete them of important nutritional elements, typical of individual edible products and characteristics of unique region. These nutrients characterize the food as well as the area in which they are produced. Climatic and lithological differences affect the concentration and the presence of different bioactive components that give to the food nutrient and antioxidant properties. However, the interest of the population, today, is focused on a more healthy and conscious diet. The increased occurrence of gastric and intestinal cancers in Western countries has put the health authorities on alert. Conduct diet rich in fat and sugar and low in antioxidants, fiber and vitamins, subjects the body to organ damage such as diabetes, and digestive system disorders such as gastro-esophageal reflux and diverticula, but also to onset of cancers such as stomach cancer and colorectal cancer. The Mediterranean diet is a nutritional model inspired by the culinary traditions of the European countries of the Mediterranean basin; it will scale appropriately with each other all the nutrients and thus reduces the onset and evolution of major organ damage.

In recent years, interest in the nutritional field research has been directed towards the study of individual foods or food groups that are part of the Mediterranean diet (Gardener et al., 2011). Especially the abundant consumption of fruits and vegetables, important sources of bioactive compounds such as antioxidants, fights free radicals present and/or produced by cooking animalderived foods that should therefore be consumed in moderation or less in relation to the first (Kolomvotsou et al., 2013). Antioxidants are substances produced by plants to defend their structures and they contrast oxidation by free radicals produced during the digestive process.

The most well-known antioxidants are for example hydroxytyrosol and oleuropein (Domitrović et al., 2012) content in the olive oil and belonging to the class of phenols (Cicerale et al., 2012); resveratrol (Matos et al., 2012) and the quercetin content in red wine (belonging to the flavonoid class), vitamins E, $\mathrm{C}$ and $\mathrm{A}$.

Characterize foods of a region is important not only to analyze and to safeguard the territories from which they originate, but also to know and apply the positive benefits of the model of the Mediterranean Diet. Already since the early nineties, the European Community has issued regulations to protect local products linked to their geographical origin, to the territory and the specificity of the production process (Regulation 20/03/2006 n.510 - 06/510/CE - G.U.E. 31/03/2006 n. 93). Many studies aimed at defining the "identity card" of foods such as agro- 
food, but the most complete genomic processes proved to be those that combine the nutritional and antioxidant to the territorial area of origin. The PDOs (Protected Designation of Origin) and PGI (protected geographical indication) are trademarks allocated to agricultural and food products prepared at all stages of the production process in a defined geographical area with a production process comply with a product specification (Regulation (CE) n.628/2008).

The caper is a spontaneous Mediterranean plant belonging to the Capparidaceae family, genus Capparis. Of the approximately 250 existing species, the most widespread in the Mediterranean basin, and the object of study of this research is Capparis spinosa. In Sicily, populations typically found are Capparis spinosa subsp. spinosa var. canescens and Capparis spinosa subsp. rupestris.

The flower button of plant, commonly called "caper", after treatments with sea salt or vinegar, is used in the preparation of Mediterranean dishes, given its unique aromatic properties. The fruit, with similar but more delicate flavor, is called "cucuncio" or "capperone" and is traditionally used in the Mediterranean cuisine.

The process of salting, need to make edible capers, involves a change in osmolarity in plant cells which causes the release of the enzyme myrosinase, responsible for the hydrolysis of compounds providing a bitter taste to the caper untreated, and the evaporation of methyl isothiocyanate, toxic molecule that makes inedible fresh capers. Although this process improves the palatability of the caper, it changes the molecular pattern that have healthy and nutraceutical activities.

Many studies have shown that extracts of the caper plant possess anti-oxidant (Tesoriere et al., 2007) and anti-inflammatory properties, making it a rich source of bioactive compounds (Argentieri et al., 2012).

\section{Oxygen paradox}

The paradox of aerobic life, or "oxygen paradox", is based on the idea that the eukaryotic aerobic organisms cannot survive in the absence of oxygen, although this element is dangerous for their same existence (Davies, 1995; Davies \& Ursini, 1995). This dichotomy is explained by the chemical oxygen: each atom has an unpaired electron and is therefore a free radical, as well as the molecular oxygen has two unpaired electrons and is then considered a di-radical. In the mitochondrial electron transport chain, the reduction of molecular oxygen in the water should be a relatively safe process, but the reducing cellular environment causes the formation of reactive intermediates, common products of aerobic life, which, however, are responsible for the oxygen toxicity. 
To survive in an oxygen rich environment, the organisms are able to produce or to absorb a variety of antioxidant compounds soluble in water or in lipids. Moreover, they synthesize a number of enzymes capable of intercepting and inactivating reactive oxygen intermediates. Although they are basic, the compounds and the antioxidant enzymes are not completely efficient in preventing oxidative damage: for this purpose, are synthesized shelter enzymes or removal of the damage, that operate at the level of proteins, lipids and damaged DNA. Since this oxidative insult variable over time, organisms can adapt to these stress fluctuations, inducing the synthesis of both antioxidant enzymes, as well as those in charge of the shelter of the damage.

Despite the protective strategies (cellular senescence and apoptosis), vital components of cells still suffer oxidative damage.

According to Sies "an imbalance in the pro-oxidant/antioxidant system in favor of oxidizing species may cause oxidative stress" (Sies, 1985). Therefore, a situation of oxidative stress may be increasing exposure to oxidants or by a decreased protection against the same oxidants, or from both. In the end, this stress situation can profoundly affect the function and survival of the organism itself.

Substantial aid could come from leading a healthy and regular lifestyle: for example, a diet containing sufficient levels of vitamins, minerals, cofactors and a moderate exercise can minimize the oxidative damage that endogenous antioxidant defenses have to bear. In recent years, attention has increasingly turned towards the health and nutritional aspects: one rich in fruits and vegetables may provide protection against various diseases, such as cardiovascular disease, cancer and other age-related degeneration. The fruits and vegetables, like capers, are considered rich in beneficial effects to health due to their high content of antioxidants that can protect the body from oxidation reactions at cellular level (Wang et al., 1996).

\section{Free radicals and Oxidative stress}

Free radicals are defined as molecules or fragments of these that contain one or more unpaired electrons in their atomic and molecular orbitals, which makes them extremely unstable compounds and fleeting, with great capacity to form more free radicals produced by reactions chemical chain. Among them, the radicals derived from oxygen represent the most important class of radical species generated in living systems (Halliwell, 1991; Dröge, 2002).

The aerobic life requires oxygen to oxidize the nutrients of the diet, and then to obtain energy. Reactive Oxygen Species" and Reactive Nitrogen Species (ROS and RNS, respectively) are the terms in which they were called free radicals derived from oxygen and nitrogen, respectively. 
Reactive Oxygen Species means any radical species and not, resulting from oxidation-reduction reactions of oxygen (Figure 1). The main representatives are the superoxide anion $\left(\mathrm{O}_{2}{ }^{\bullet-}\right)$, hydrogen peroxide $\left(\mathrm{H}_{2} \mathrm{O}_{2}\right)$ and the hydroxyl radical $\left(\mathrm{OH}^{\bullet}\right)$, capable of interacting at different levels and with different effectiveness in biological systems (Dröge 2002).

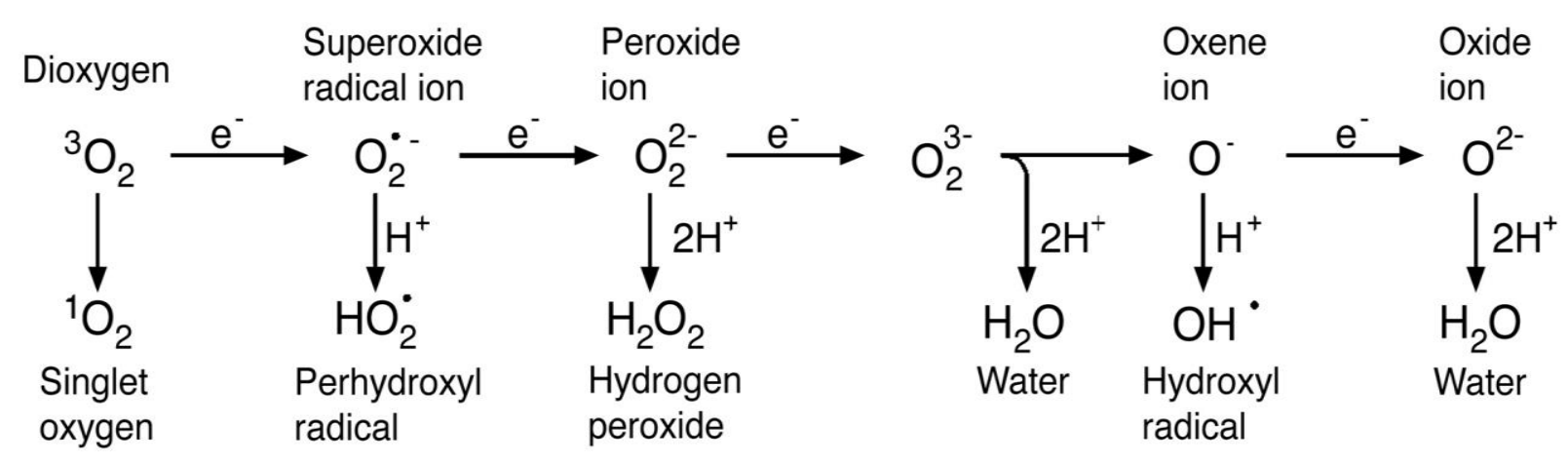

Figure 1. Generation of different ROS by energy transfer or sequential univalent reduction of ground-state triplet oxygen

The superoxide anion is considered the precursor of all the radical species because, in most cases, is the first radical that is produced by the oxidase (Ardanaz \& Pagano, 2006). It is formed from the reduction of oxygen for the transfer of a single electron, and can behave both as a reducing agent, in turn yielding an electron to an oxygen molecule, either as an oxidizing agent, with the formation of hydrogen peroxide.

This reaction is known as dismutation reaction, which can occur spontaneously but extremely slow $(2 \times 105 \mathrm{~m} / \mathrm{sec})$ or it can be catalyzed by the enzyme system of superoxide dismutase, capable of speeding up the process 104 times. The superoxide anion is able to oxidize many biologically important compounds such as catecholamine, polyphenols, leucoflavines, while reduces cytochrome c, tetranitromethane and nitroblue tetrazolium (Fridovich, 1986).

Hydrogen peroxide, thanks to the small size and the lack of charge, is much more stable and has a greater radius of diffusion with respect to the anion superoxide. It is considered toxic within a biological system for its ability to convert to hydroxyl radical, reputedly the most reactive and damaging between the oxygen radicals, through exposure to ultraviolet light or through interaction with metal ions (reaction Fenton) (Ardanaz \& Pagano, 2006).

The superoxide anion can cooperate with hydrogen peroxide in the formation of the hydroxyl radical. This reaction, known as the Haber-Weiss, takes place both in vitro and in vivo (Liochev \& Fridovich, 1994). 
The hydroxyl radical can be produced, as well as through the two just mentioned reactions, also by photochemical reaction water, in which a water molecule is cleaved homiletically with the formation of two radical species.

As mentioned above, the hydroxyl radical is considered the most toxic among the ROS, as it is capable of indiscriminately interact with all biological macromolecules and is so reactive that does not spread more than one or two molecular diameters before reacting with a cellular component (Pryor, 1986).

In its electronic ground state, it is a triplet oxygen $\left({ }^{3} \mathrm{O}_{2}\right)$ and, as it has two unpaired electrons with the same spin, is a diradical (Pryor et al., 2006). The couple the two electrons giving them different spin leads to the formation of so-called singlet oxygen $\left({ }^{1} \mathrm{O}_{2}\right)$, a form of higher energy compared to baseline status. Singlet oxygen is produced by the oxygen triplet through simple thermal processes, but requires the intervention of highly energetic molecules. It is present in various physiological processes, but it is not yet clear its function. However, it plays an important role in the photodynamic therapy of tumors: the tumor cells are irradiated to excite the photosensitive molecules endogenous, such as porphyrins, involved in the formation of singlet oxygen, which can thus trigger cell death.

Alongside the reactive oxygen species, also reactive nitrogen species (RNS) have an important biological relevance.

In particular nitric oxide ( $\left.\mathrm{NO}^{\bullet}\right)$, toxic in moderate concentrations, he held various physiological roles: it is an important vasodilator, inhibits platelet adhesion and aggregation, is produced in the brain as a neurotransmitter, is involved in immune responses and it has a protective effect during the process of ischemia/reperfusion (Wink, 1993; Ignarro, 2000). The NO ${ }^{\bullet}$ is synthesized by oxidation of L-arginine by a family synthase (NOS) of which there are mainly three isoforms (Stuehr, 1999). It is considered toxic because it is capable of reacting with the superoxide anion and generate peroxynitrite, a potent oxidant.

An interesting concept is that nitric oxide, through this reaction, partly neutralizes the toxic superoxide anion transforming it into $\mathrm{ONOO}^{\bullet}$, which partially decomposes into $\mathrm{NO}_{3}{ }^{\bullet}$.

Exist several sources of generation of ROS and RL, could differentiate into endogenous and exogenous.

The endogenous production of ROS follows different metabolic pathways (Sauer, 2001) and the largest training site is represented by the electron transport chain in mitochondria (Beal, 2005).

Currently, there is enough evidence to support the theory of the damage produced by free radicals in vivo nucleic acids, lipids and proteins (Valko et al., 2006). 


\section{Antioxidants}

In aerobic organisms the production of ROS and RNS is inevitable and, within certain concentrations, essential (Feher, 1985). In order to survive, however, these biological systems have had to develop a complex system of antioxidant defenses, thus preventing the generation of more reactive radicals and neutralizing them once formed.

Antioxidant is any substance that, present in concentrations comparable with an oxidizable substrate, retards or prevents the oxidation of the substrate (Halliwell \& Gutteridge, 1989). Subsequently, they were defined from a more general perspective, as "all those compounds, which protect the biological systems against the harmful effect of excessive generation of oxidants" and this definition is currently the most used (Krinsky, 1992).

There is no universal or optimal antioxidant: the defenses against oxidative stress are not able to completely avoid all damage. In a biological system, the antioxidant function depends on various parameters, such as the type of generated ROS, the manner and place in which it was formed, the extent of damage reported.

Each cell is characterized by a particular concentration of electrons (redox state) stored in various cell constituents, which together with their variations determine the cellular function (Schafer \& Buettner, 2001). The balance established between the oxidant and antioxidant systems is essential for the development of living organisms. This redox balance is set at a physiological level, is essential for metabolic regulation, activation and deactivation of biomolecules, signal transduction, obtaining of metabolic energy and cell activations (Cadenas, 1997). The human body is equipped with a large group of antioxidant compounds: some are endogenous synthesized and others obtained through the diet, called exogenous (Ames et al., 1995).

The plants represent the most important source of antioxidants; such compounds have the function of slowing down or counter the spread and propagation of dangerous radical reactions for macromolecules that constitute them (DNA, sugars, proteins, fats).

Why do all plants have antioxidant potential? Chloroplasts and mitochondria are the two main powerhouses and sites of ROS generation within plant cells. These materials are also involved in maintenance of a fine balance between energy linked functions and control of ROS production. Peroxisomes, single membrane-bound subcellular organelles, are a third important site of production of ROS such as hydrogen peroxide $\left(\mathrm{H}_{2} \mathrm{O}_{2}\right)$, superoxide $\left(\mathrm{O}_{2} \bullet\right)$ and nitric oxide $(\mathrm{NO})^{\bullet}$ within plant cells. Peroxisomes contain basic enzymatic constituents such as catalase (CAT), as well as hydrogen peroxide $\left(\mathrm{H}_{2} \mathrm{O}_{2}\right)$ producing flavin oxidases (Del Rio et al., 2006). Plants have an innate ability to synthesize non-enzymatic antioxidants. 
However, under biotic and abiotic stress conditions, the production of reactive oxygen species (ROS) increases in the plants, resulting in induction of oxidative stress. In response to increased oxidative stress, plants augment the production and accumulation of several low molecular weight antioxidants (e.g., vitamin C, vitamin E, phenolic acids, etc.) and high molecular antioxidant secondary metabolites such as tannins, which confer antioxidants to most plants under in vitro studies by functioning as free radical scavengers, reducing agents, and metal chelators.

Plant metabolism is mainly classified as primary or secondary. Compounds produced through primary metabolism, which are generally referred to as primary metabolites; include sugars, fatty acids, amino acids and nucleic acids. Primary metabolites are required for maintenance of plant cells, while secondary metabolites are essential to the normal growth, development and defense of plants (Deepak et al., 2015) (Figure 2).

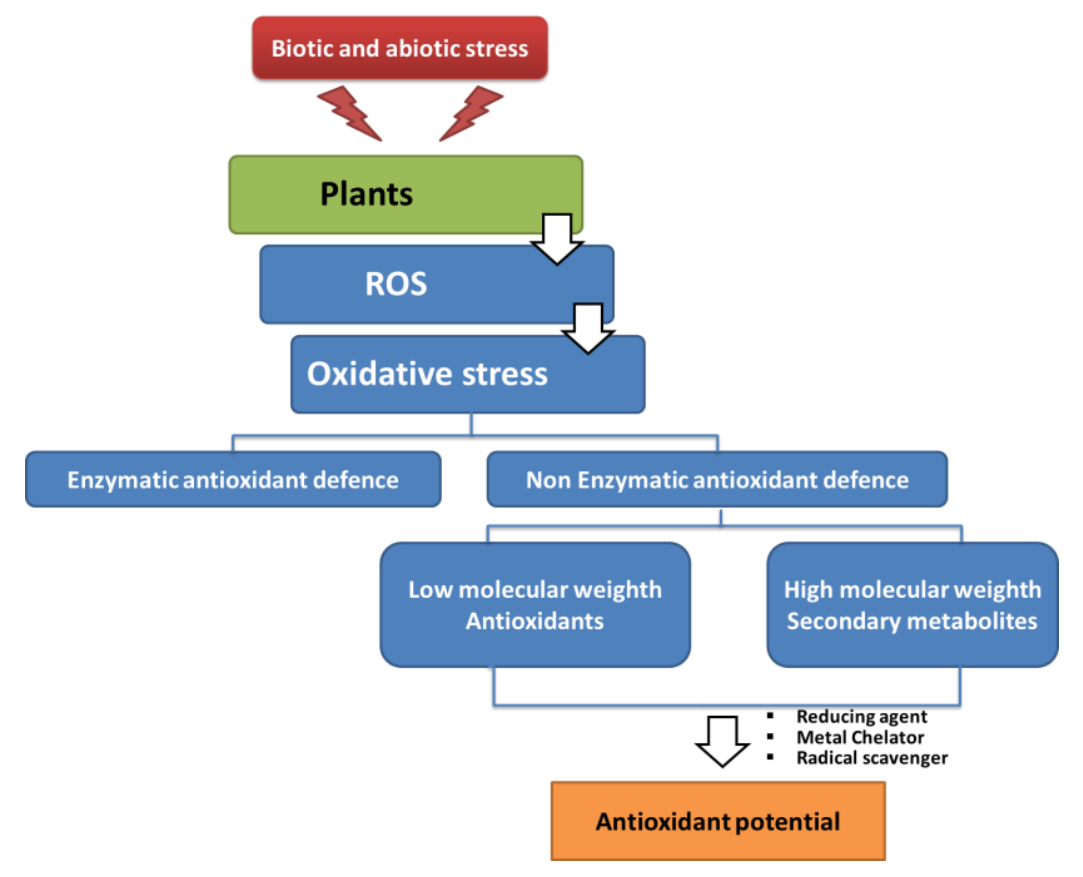

Figure 2. Antioxidant potential of plants.

To date, thousands of different types of secondary metabolites have been identified in plants (Korkina et al., 2007) (Figure 3). Chemically, these compounds are either nitrogen-containing (alkaloids) or nitrogen-deficient (terpenoid and phenolic compounds) (Figure 4). 


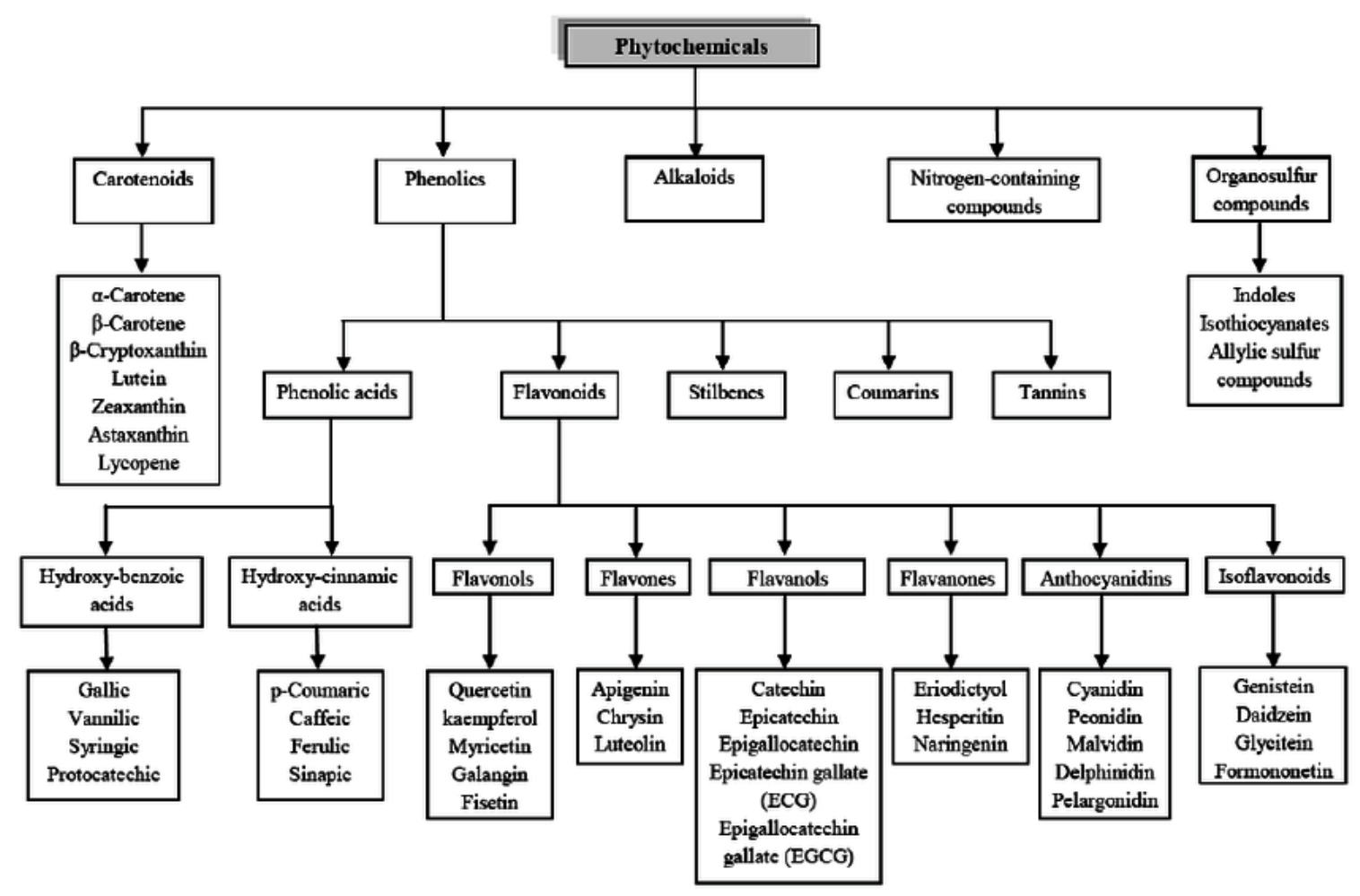

Figure 3. Phytochemicals classification.

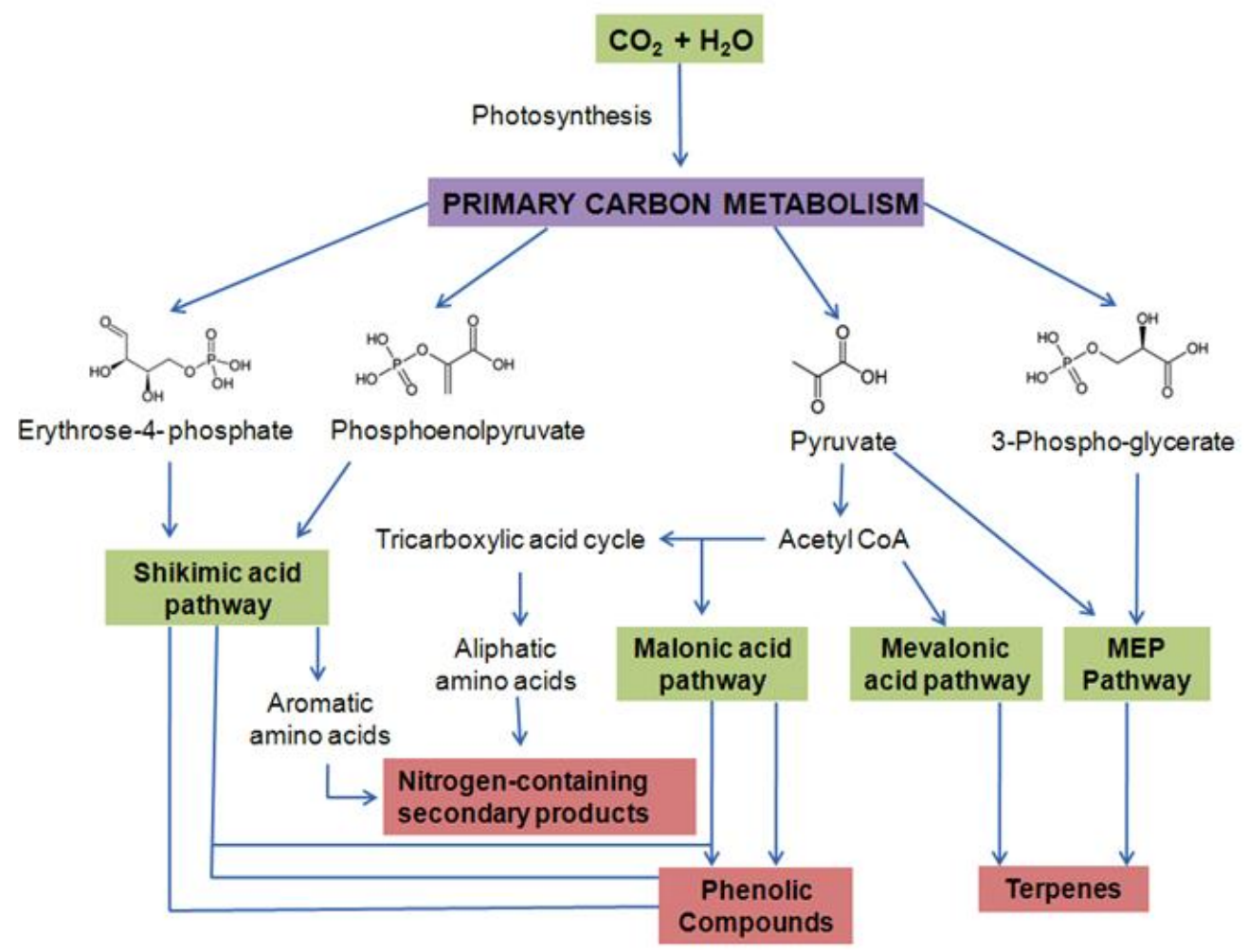

Figure 4. Secondary metabolites of plants and their production. 
Among the secondary metabolites of plants, the most represented are polyphenols.

Polyphenols are the main vegetable antioxidants to scavenger activities and they are present in the plant kingdom in a very large number. This variety depends on the numerous reactions of hydroxylation, glycosylation, methylation and curing process that taking place during the biosynthesis process.

All plant phenolic compounds arise from a common intermediate, phenylalanine, or a close precursor, shikimic acid.

Polyphenols may be classified into different groups as a function of the number of phenol rings that they contain and based on structural elements that bind these rings to one another. The main classes include phenolic acids, flavonoids, stilbenes and lignans (Pandey and Rizvi, 2009) (Figure 5).<smiles>[R3]c1cc([R3])cc(C(=O)O)c1</smiles>

Phenolic acids (hydroxy-benzioc \& cinnamic acids)<smiles>[R19]c1ccc(/C=C/C(=O)O)cc1Br</smiles>
$R_{2}$

(1)

$$
\text { . }
$$


Flavonoids comprise the most studied group of polyphenols. This group has a common basic structure consisting of two aromatic rings bound together by three carbon atoms that form an oxygenated heterocyclic (Figure 6). More than 4,000 varieties of flavonoids have been identified, many of which are responsible for the attractive colors of the flowers, fruits and leaves. Based on the variation in the type of heterocyclic involved, flavonoids may be divided into six subclasses: flavonols, flavones, flavanones, flavanols, anthocyanins and isoflavones. Individual differences within each group arise from the variation in number and arrangement of the hydroxyl groups and their extent of alkylation and/or glycosylation. Quercetin, myricetin, catechins etc., are some most common flavonoids.

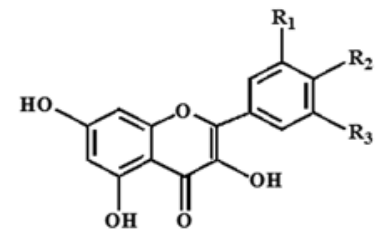

Flavonols<smiles>Nc1cc(C2CC(=O)c3c(O)cc(O)cc3O2)cc(Br)c1Br</smiles>

Flavanones

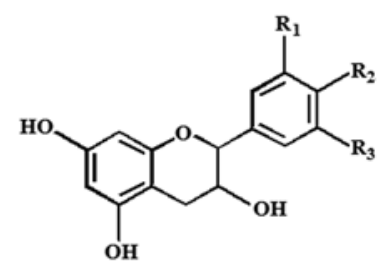

Flavanols

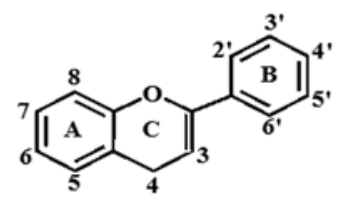

Basic Favonoid Structure<smiles>[R19]c1c(Br)cc(-c2cc(=O)c3c(O)cc(O)cc3o2)cc1[13I]</smiles>

Flavones<smiles>[R2]c1cc(-c2[o+]c3cc(O)cc(O)c3cc2O)cc(Br)c1O</smiles>

Anthocyanins<smiles>[R3]c1cc(O)cc2occ(-c3ccc(O)cc3)c(=O)c12</smiles>

Isoflavones

Figure 6. Chemical structures of sub-classes of flavonoids.

Stilbenes contain two phenyl moieties connected by a two-carbon methylene bridge. Occurrence of stilbenes in the human diet is quite low. Most stilbenes in plants act as antifungal phytoalexins, compounds that are synthesized only in response to infection or injury. One of the best studied, naturally occurring polyphenol stilbene is resveratrol (3, 4', 5-tri-hydroxystilbene), could be found in grapes. A product of grapes, red wine also contains significant amount of resveratrol (Pezet and Cuenat 1996). 
Lignans are diphenolic compounds that contain a 2,3-dibenzylbutane structure that is formed by the dimerization of two cinnamic acid residues. Several lignans, such as secoisolariciresinol, are considered phytoestrogens.

Numerous factors affect the polyphenol content of plants; these include degree of ripeness at the time of harvest, environmental factors, processing and storage. Polyphenolic content of the foods is affected by environmental factors as well as edaphic factors like soil type, sun exposure, rainfall, etc.

Bioavailability is the proportion of the nutrient that is digested, absorbed and metabolized through normal pathways. However, bioavailability of each polyphenol differs; there is no relation between the quantity of polyphenols in food and their bioavailability in human body.

\section{Capparis spinosa L.: nutraceutical value in the Mediterranean diet}

Caper is a perennial shrub and is the common name of the genus Capparis, family Capparidaceae o Capparaceae (Fici, 2014). This genus is represented by several species (about 250). It is known by various names, e.g. Caper (English), Kabbar (Arab), Alcaparro (Spain), and Gollaro (Pakistan).

Two species in particular are growing in the Mediterranean basin: Capparis ovata and Capparis spinosa (Mediterranean Europe). The latter is the most widely planted variety in Italy and Spain. It is a woody shrub, less than a meter tall, with branches partially hanging and crawling on the ground, with deciduous and oval blade. The flowers possess four sepals rosy purplish, four white petals and numerous stamens with violet tips (Figure 7).

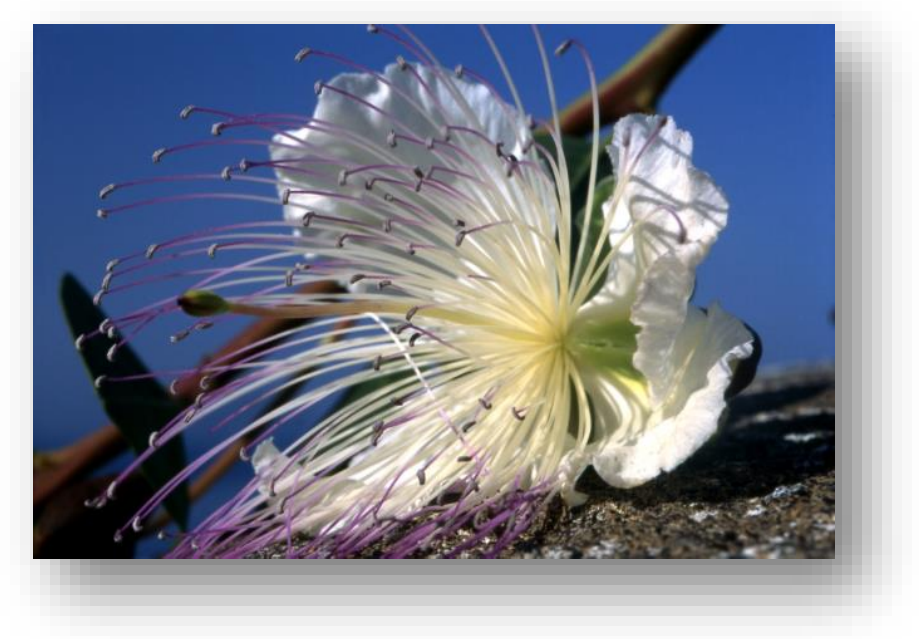

Figure 7. Opened caper flower 
The fruit is a green berry oval and reddish after maturation, containing numerous seeds reniform (Figure 8).

The flower buds (Figure 9), generally known as "cappers," are the product mainly marketed: are deep green, hairless and round, with bracts whose compactness is an important quality index
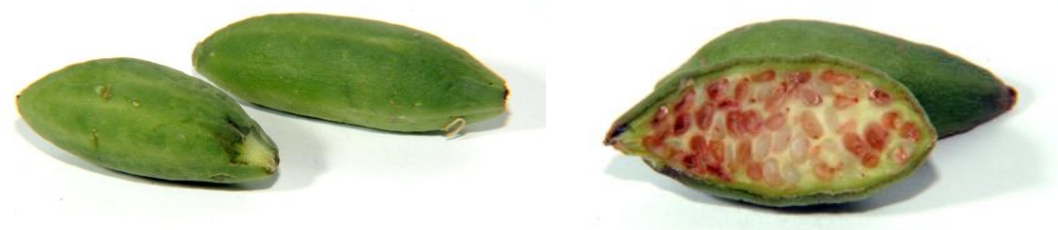

Figure 8. Caper fruits
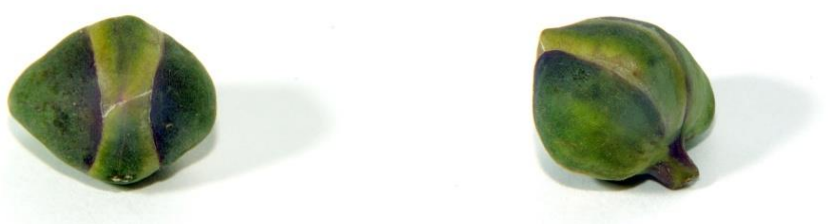

Figure 9. Flower buds of Capparis spinosa

According to Higton \& Akeroyd (1991), Sicilian populations are both represented by Capparis spinosa subsp. spinosa var. canescens that C. spinosa subsp. rupestris. The first is found in xerophilous areas of central and southern Sicily, were soils are clay and saline. The second sub species, rupestris is frequent along the coasts; it is often, in fact, seen growing spontaneously on cliffs and rocky slopes. The latter species is strongly xerophile since it is located on Mesozoic compact limestone and ologenetics, chalk, lava and volcanic tuff. In fact, despite being a rupicola plant, in nature where it grows in the crevices of walls and rocks, it also grows very well if planted in the ground, on poor soils, dry and well drained, especially of volcanic origin such as volcanic lapilli. As the prickly pear, caper is an icon of the Mediterranean nature for his property to grow lush in the most arid and inhospitable sites. They were selected for the cultivation of "biotypes" suitable and profitable cropping purposes, thanks to their characters considered optimal for producing, stabilizing and marketing (e.g. Nocellara di Pantelleria, Ciavulara, Spinosa di Pantelleria, Nocella di Salina, Salina Spinosa). The only top quality recognized 
biotype is the Caper of Pantelleria (biotype Nocellara) from which PGI recognition from the Italian Ministry of Food Resources in 1993 (Geographical Indication Production Regulations Protected "Cappero di Pantelleria"; DM 2 December 1993 - GURI n. 302 of 27 December 1993 Entry in the "Register of protected designations of origin and protected geographical indications" under EC Reg. No. 1107/96). The buttons of the Italian floral crops, and in particular of Pantelleria, belong to biotype Nocellara and are of nearly spherical shape.

The plants show strong resistance to harsh environmental conditions. Despite adverse conditions, plants of Capparis do not seem to show any water stresses or any symptoms of photo-inhibition, and the plant efficiently utilizes the high irradiance throughout the growth season (Levizon et al., 2004).

Caper is adapted to poor soils, and is widespread on rocky areas, mountains and it grows on numerous soil types, including alfisols, regosols and lithosols. It shows a good response to volcanic or alkaline soils. Soil pH from 6.1 to 8.5 is tolerated (Pugnaire et al., 1991; Janick et al., 2006). Every farmer from Pantelleria always chooses carefully the seedlings to be planted and identifies the most suitable land. In this way it was found, with a long experience from generation to generation, that the best land is terraced and those most exposed to the sun. In fact, all over the island, but especially in the southern part you can see the immense wealth built up through a huge work, from construction over several centuries the system of terraces, made with the dry stonewalls that characterize so unmistakable pantellerian environment. The soil is handiling worked and fertilized in the winter. The plants reach full production after about three years after implantation.

Caper plants grow widely immediately after rain (April-May) and start disappearing in the beginning of the cold weather (September-October). The picking (Figure 10) usually starts between May and June and ends in late August. At dawn, before the sun cues, every farmer start, in his own field and usually with his family, to collect the precious budsbefore their blooming. At the end of the day, capers are placed, carefully, in special vats to mature slowly, in brine, with jealously transmit from father to son proceedings. This phase of slow maturation gives to capers the most valuable qualities: aroma, flavor, fragrance, and meaty texture. 


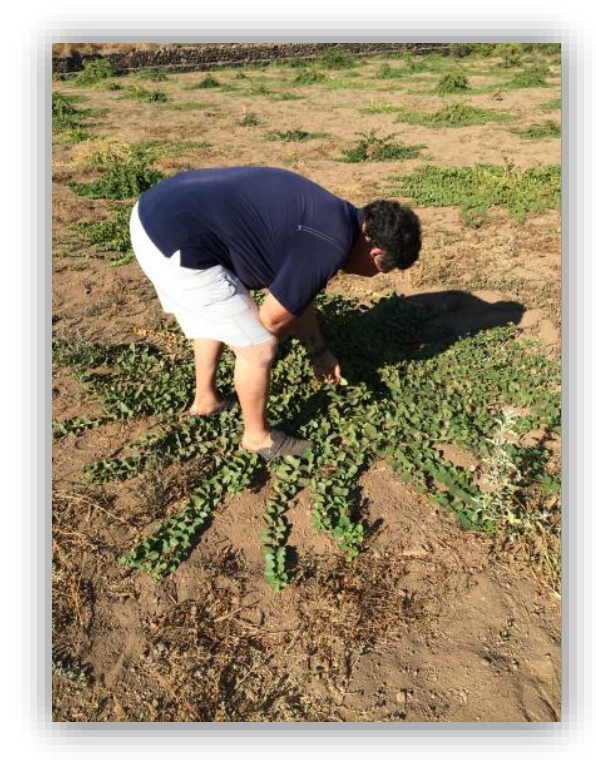

Figure 10. Harvesting of capers

In Italy (Pantelleria and Salina islands), harvested Capers are placed in cement containers. Salting is carried out with sea salt. In a first phase (8-10 days), is added the $40 \%$ of salt compared to the weight of the product, which is daily stirred to ensure a homogenous lactic fermentation process. At the end, the vegetation water (brine) is removed and partly reabsorbed from the buttons themselves. In the next step is added sea salt to $25 \%$ of the total weight with continuous mixing and draining. After ten days the process is completed (Figure 11), and capers are qualitatively suitable for the trade (Figure 12). Alternatively, in Ustica and Salina Islands, capers proceed to the pickling by mixing $25 \mathrm{~kg}$ of sea salt in 100 liters of water.

The salting process is important, not only to stabilize and give the typical flavor and aroma of the product, but it has also a secondary role in defining the final antioxidant profile.

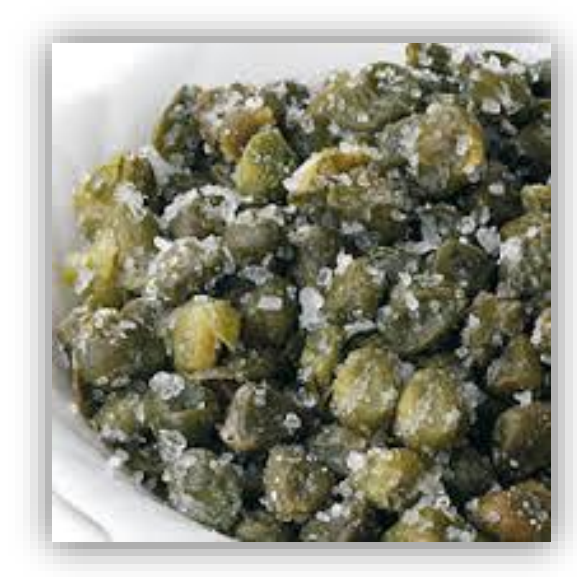

Figure 11. Capers fermented with salt 


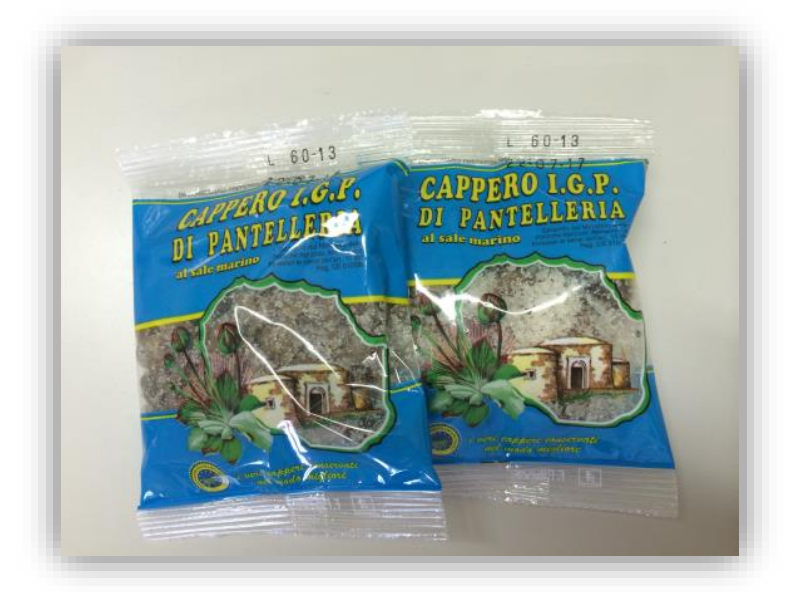

Figure 12. Commercial capers from the Soc. Coop. Agr. Produttori Capperi a r.l., Pantelleria (Trapani-Sicily, Italy).

The quality of the IGP caper of Pantelleria lies precisely in the type of storage and in particular in dry salting. It ensures to the final product a marked flavor and a stable green color.

The caper is used in herbal medicine for its properties: the aqueous extract is obtained from the aerial parts of the plant and it is used as anti-inflammatory (Al-Said et al., 1988), anti-fungal (Ali-Shtayeh et al., 1999), anti-diabetic (Yaniv et al., 1987) and anti-oxidant (Bonina et al., 2002; Germanò et al., 2002). It is used also as constituent of herbal pharmaceutical preparations for the treatment of morbid states of the liver (Handa et al., 1986). The roots, harvested in late summer, are used in powder form or as infusion for their astringent functions, diuretic and stimulant Capers, however, have diuretic and digestive properties. They also can be used in the dermatological sector, to heal wounds and to make the skin velvety. Numerous studies have investigated the constituents of fresh flower buds (Gull et al., 2015). In addition to lipids and alkaloids, they contain glucocapparin, which is the main glucosinolate. Furthermore, capers contain a number of phytochemical antioxidants such as flavonoids and other polyphenols. Among these, rutin (Figure 13) (quercetin-3-rutinoside) seems to be the most abundant in Capparis spinosa L. (Germanò et al., 2002).

Phenolic compounds are present in a high level in commercial caper (Tlili et al., 2011). Content of rutin, quercetin, 3-rutinoside, keampferol 3-rutinoside; and kaempferol 3-rhamnosylrutinoside was reported in commercial caper (Innocencio et al., 2000; Tlili et al., 2011). The absence of free aglycones in the original buds indicates that they were produced during the brining process (Innocencio et al., 2000). 


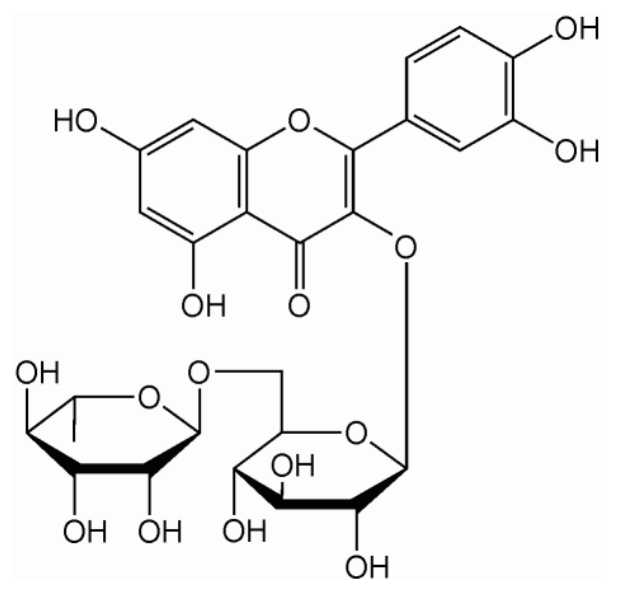

Figure 13. Quercetin-3-rutinoside (Rutin)

Caper is appreciated for the pungent taste and strong aroma and is eaten as an appetizer along with olives, cheese and dried fruit, or served as a sauce with meat, salad, pasta and other dishes. The capers cannot be eaten fresh for the bitter taste conferred by glucosinolates components, glucocapparin and glucocleomin (Figure 14). The flower bud is collected just before the blossoming and then is subjected to the treatment in brine or salt, in order to decrease the content of these compounds.

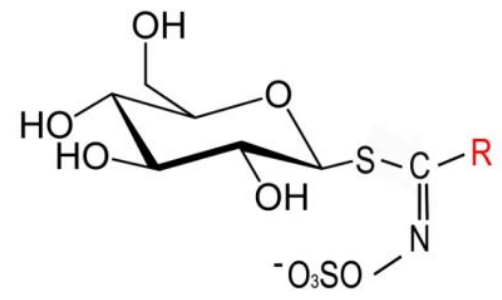

Figure 14. Structure of a generic glucosinolate; $\mathrm{R}$ is an alkyl group, $\mathrm{R}=\mathrm{CH}_{3}$ in glucocapparin, $\mathrm{R}=\mathrm{CH}_{2} \mathrm{C}(\mathrm{OH})\left(\mathrm{CH}_{3}\right)\left(\mathrm{CH}_{2} \mathrm{CH}_{3}\right)$ in glucocleomin.

The stabilization process, by changing the osmolarity of the plant cell, causes the release of the enzyme myrosinase (thioglucoside-glucohydrolase) contained in the lysosomes. Myrosinase makes an enzymatic hydrolysis of glucosinolates, and produces, with a fermentation process, a number of products (Figure 15). Methyl isothiocyanate is the most abundant product, from hydrolysis of glucocapparin; particularly volatile, it is responsible of the typical aroma and flavor of the caper. 


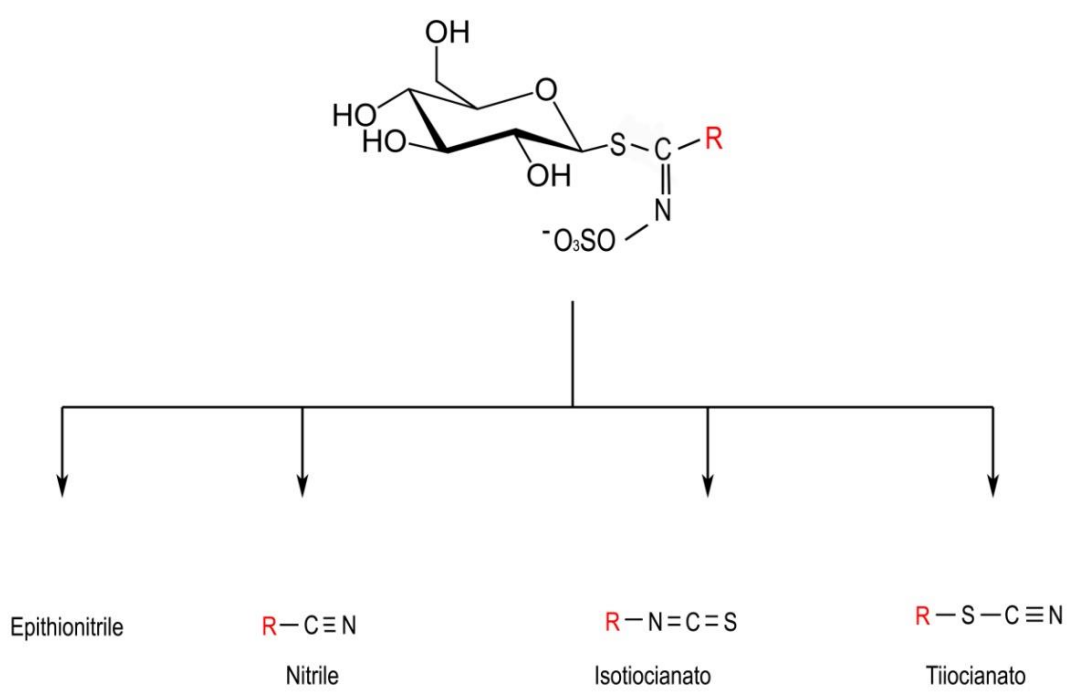

Figure 15. Products derived from the enzymatic hydrolysis of glucosinolates

Volatile compounds were identified and quantified in salted capers; aldehydes and esters are the most abundant chemical classes; methyl-isothiocyanate is the major one, followed by benzylisothiocyanate (Romeo et al., 2007).

\section{Technical applications for the agro-food characterization}

\section{HPLC-DAD-ESI-MS/MS}

Most polyphenols, such as flavonoids, are commercially available and are usually obtained in pure forms by extraction/purification from their natural sources. To identify and quantify secondary metabolites from plant the most efficient technique is the high-performance liquid chromatography/electrospray ionization source/mass spectrometry (HPLC-ESI- MS), coupled with a photodiode array detector (PDA).

HPLC-ESI-MS/MS has been proved a modern powerful tool for the identification of substances in herb extracts with the advantage of rich structural information of analytes acquired by MS $^{\mathrm{n}}$ technique (Zhu et al., 2011).

Electrospray ionization mass spectrometry (ESI-MS) combined with high performance liquid chromatography with photodiode array detector (PDA) (Figure 16), provides a simple and versatile approach to identify the constituents in crude plant extracts. HPLC-PDA-ESI-MS/MS simultaneously provides UV, retention time (RT), mass spectra which are important for analysis 
and structural characterization of known compounds by comparing chromatograms and mass spectra with authentic markers.

The high performance liquid chromatography technique is characterized by the use of columns of variable internal diameter and length of less than $30 \mathrm{~cm}$, packed with solid microparticles stationary phase of extremely small diameter $(5-10 \mu \mathrm{m})$ such as to require the application of high pressures upstream to allow the flow of the mobile phase; a packing of this type ensures a high extension of the surface of the stationary phase, resulting in higher resolution and accuracy than chromatographic techniques at low pressures. Over the last decade, electrospray ionization mass spectrometry (ESI-MS) has emerged as an important technique in clinical laboratories. It provides a sensitive, robust, and reliable tool for studying, at femto-mole quantities in micro-liter sample volumes, non-volatile and thermally labile bio-molecules that are not amenable to analysis by other conventional techniques. Coupled with a high performance liquid chromatograph (HPLC) for molecular fractionation prior to mass spectrometric analysis, HPLC/ESI-MS has become a very powerful technique capable of analyzing both small and large molecules of various polarities in a complex biological sample. Together with automated sample introduction, HPLC/ESI-MS/MS is a flow analysis technique for rapid analysis and high sample throughput (Ho et al., 2003).

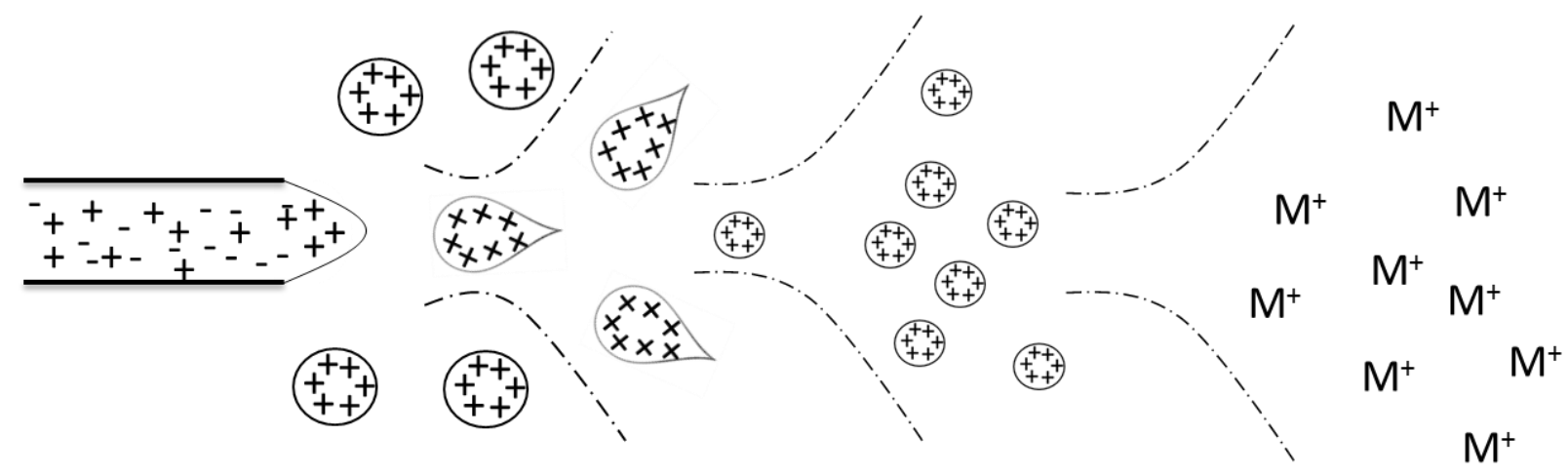

Figure 16. Mechanism of electrospray ionization

Photodiode array detector HPLC Detectors (Figure 17) is most commonly used to record the ultraviolet and visible (UV-VIS) absorption spectra of samples that are passing through a highpressure liquid chromatograph. This enables qualitative information to be gathered about the samples. 


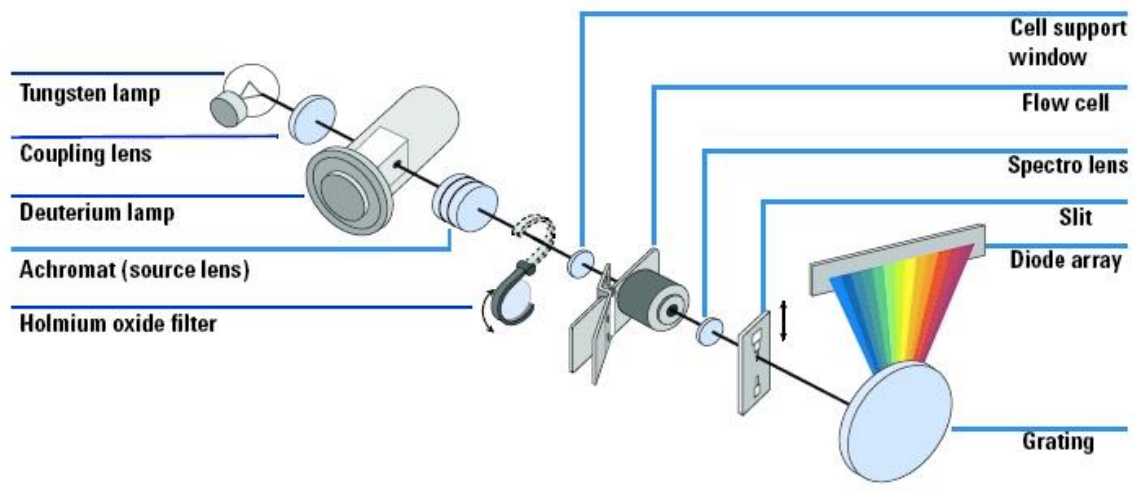

Figure 17. Schematic diagram of the major components of a Photodiode Array Detector

\section{GC-MS and ELECTRONIC NOSE}

Human senses are very important to our link between the external world and our consciousness. The perception of volatile compounds by the human nose is of great importance in evaluating the quality of foods, cosmetics and numerous other items of everyday life.

From the evolutionary point of view, smell is one of the oldest senses, allowing identifying food, recognizing danger and so on. Consequently, the olfactory sense has become a key element in the development of many commercial industries that manipulate the aroma properties in order to improve product appeal and quality, thus consumers identify the individual commodities that have unique scents. As already reported many factors can influence the quality and quantity of volatile compounds in fruit including cultivar, cultural practices, ripeness and postharvest handling.

Extracted volatiles are typically analyzed using Gas Chromatography $(G C)$ techniques (Figure 18). Upon the separation step (chromatographic phase), molecules can be identify with a Mass Spectrometer (MS) detector. It is used to identify the structure of each one molecule.

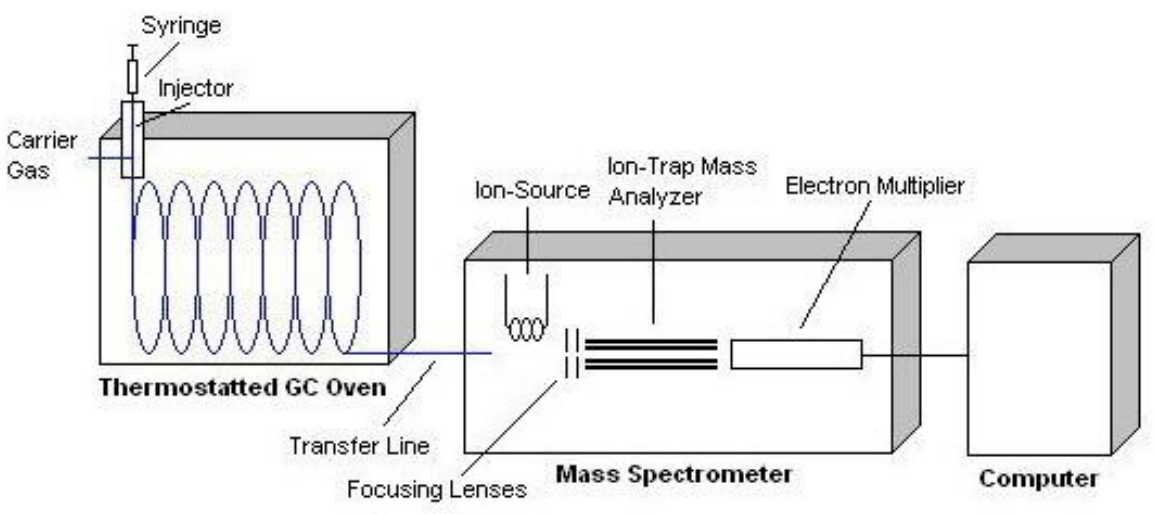

Figure 18. Schematic diagram of the components of a GC-MS. 
This technique (GC/MS) offers good sensitivity and a wide dynamic range for almost all volatiles. Depending on the method of sample collection, a variety of methods of sample introduction can be used.

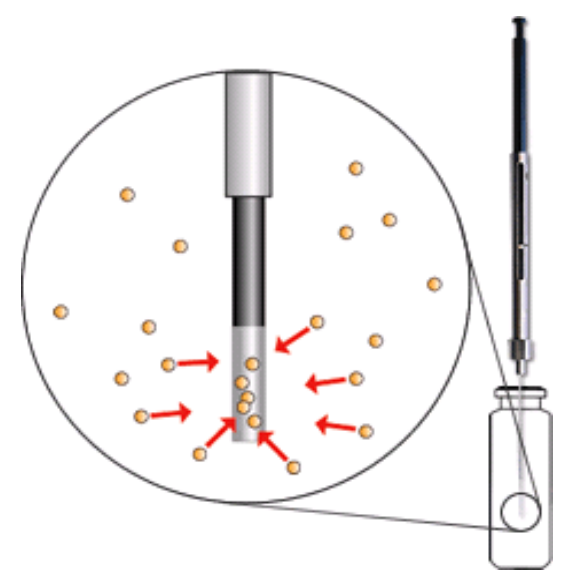

Figure 19. Thermal absorption of volatile compounds to the SPME fiber.

These include liquid injection, cold on-column injection of headspace samples, thermal desorption of Solid Phase Micro Extraction (SPME) fibers (Figure 19) in temperature programmable injection ports, and thermal desorption of collection tubes. The latter requires specialized equipment, but the use of collection tubes provides many advantages, flexibility in collection volumes and storage of collected samples.

Sensor arrays have been applied in the past as tools for the odors characterization of particular classes of foods and beverages.

The electronic nose (E-nose) is a new technology that can be employed to analyze flavor and aroma. This technology may offer alternatives to the classical approach of food volatile measurement by means of GC/MS.

Persaud and Dodd (1982) proposed the concept of an artificial nose system in 1982 at the University of Warwick.

The principal limit of the electronic nose is that, even if it offers the possibility of detecting some important non-odorant gases, at the same time it has a relative small number of sensors. One of the main reasons why it has not been possible to make a one to one copy of the human nose is the high specificity of the human receptors.

The Electronic Olfactory System $\operatorname{EOS}^{835}$ (SACMI IMOLA scarl, Imola, Italy), (Figure 20), has been extensively used in the past in various application fields (Pardo and Sberveglieri, 2004) including the case studies that will be illustrated in this thesis. 


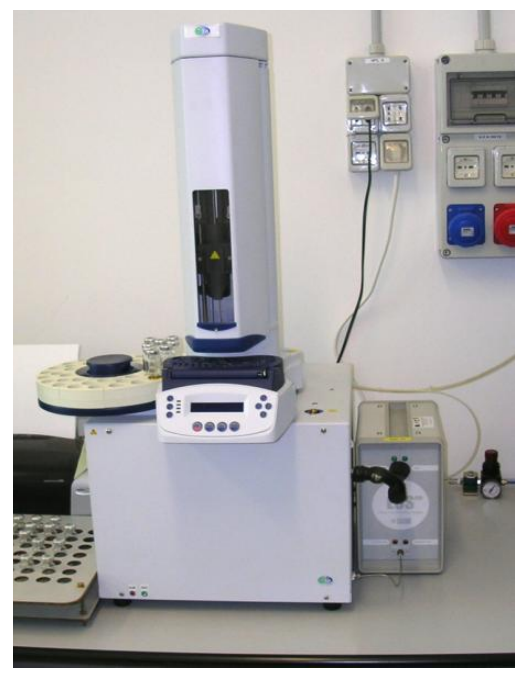

Figure 20. $\operatorname{EOS}^{835}$ (Sacmi, Imola, Italy) at Biophysics Institute (IBF) - National Research Council (CNR) of Palermo (Italy).

It consists of a pneumatic assembly for dynamic sampling (pump, electrovalve, and electronic flow meter), a thermally controlled sensor chamber of $20 \mathrm{~mL}$ internal volume, an electronic board for controlling the sensor heaters and measuring the sensing layers, and software for data acquisition and signal processing. The instrument remote control and the data acquisition can be performed by an external laptop through standard communication port.

$\operatorname{EOS}^{835}$ array is equipped with six Metal Oxide Semiconductor (MOS) sensors (Figure 21Simon et al. 2001) that consist of three layers: a silicon semiconductor, a silicon oxide insulator and a catalytic metal through which the applied voltage creates an electric field.

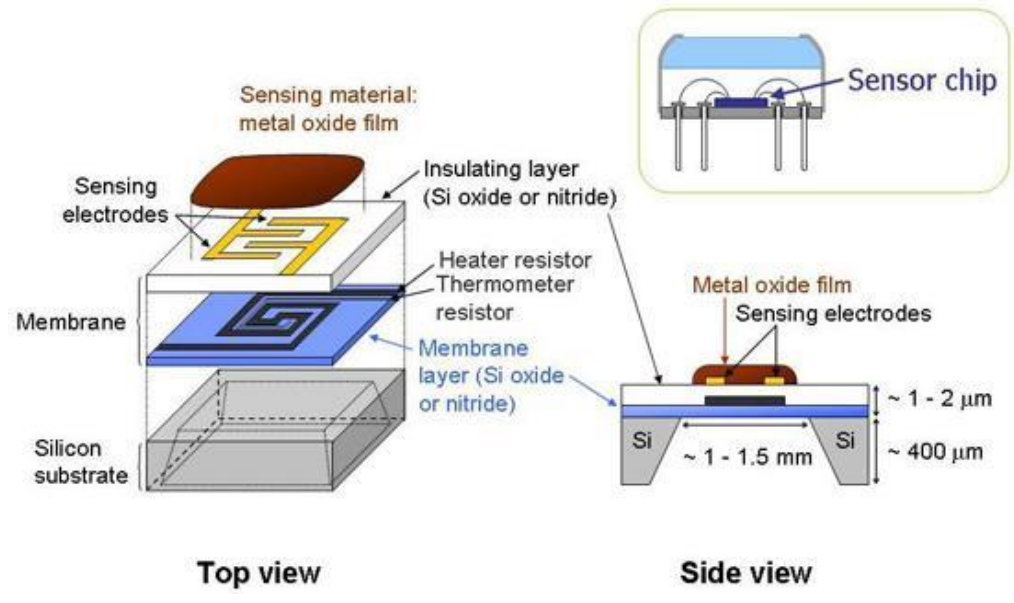

Figure 21. Example of an MOS technology sensor. 
The EOS supports dynamic or static headspace sampling unit (optionally with an autosampler HT200H, HTA s.r.l., Italy). Static headspace has clear advantages in terms of reproducibility and repeatability. The HS (Head Space) generation parameters (incubation temperature, time, and so on) can be fully and accurately controlled. Besides, the HS analysis is carried out without perturbing the equilibrium conditions this ensures there are no artefacts in the sensor response due to changes of HS concentration during the measurement.

Finally, static headspace may be used to perform long runs of measurements, thus improving the training set collection and the device calibration. Nevertheless, the use of static headspace sampling strongly limits the EN sensitivity due to the small amount of available headspace (about $5 \mathrm{~mL}$ ) and consequently low carrier flow rate values $(10 \mathrm{~mL} / \mathrm{min})$. Therefore, in some applications, dynamic headspace is to be preferred; it consists of a pump and a flow controller that conveys the odor sample under investigation from a vessel (typically $100 \mathrm{~mL}$ in volume) into the sensor array chamber. As shown in previous works (Cagnasso et al., 2010), sensitivity can be enhanced by one order of magnitude and sensor recovery time can be correspondently halved by using dynamic headspace.

Independently on the character of the product, it is important to ensure that it has always the same characteristics. The introduction of electronic noses into the area of food is envisaged for quality control, process monitoring, freshness evaluation, shelf-life investigation and authenticity assessment. An 'electronic nose' is a system originally created to mimic the function of an animal nose. However, this analytical instrument is more a 'multi-sensor array technology' than a real 'nose'. Whatever the sensor technology, it is still far from the sensitivity and selectivity of a mammalian nose. Traditional analytical methods, such as GC-analysis, will always be needed to determine qualitatively or/and quantitatively why one food sample differs from others. The 'electronic nose' can only perform quick 'yes or no' tests in comparison to other products. Therefore, an "electronic nose" can be viewed as an interesting tool for a quick quality test in various food applications. 


\section{Purpose of the study}

Considering the healthy function of anti-oxidants principles, the purpose of this research is to identify, characterize, and evaluate different genotypes of Capparis spinosa from Pantelleria Island (Sicily, Italy), in particular from five different areas named: Scauri $\left(36^{\circ} 46^{\prime} \mathrm{N}, 11^{\circ} 58^{\prime} \mathrm{E}\right)$, Rekhale $\left(36^{\circ} 75^{\prime} \mathrm{N}, 11^{\circ} 99^{\prime} \mathrm{E}\right)$, Tracino $\left(36^{\circ} 79^{\prime} \mathrm{N}, 1^{\circ} 04^{\prime} \mathrm{E}\right)$, Barone $\left(36^{\circ} 77^{\prime} \mathrm{N}, 1^{\circ} 03^{\prime} \mathrm{E}\right)$ and Bugeber $\left(36^{\circ} 80^{\prime} \mathrm{N}, 11^{\circ} 99^{\prime} \mathrm{E}\right)$ (Figure 22). Capers were collected from the Cooperativa Agricola Produttori Capperi, a r.l., Pantelleria (Trapani-Sicily, Italy).

In particular, the subject of study and purpose of this thesis have been:

- The evaluation of polyphenols content (TPC) and antioxidant activity of hydrophilic extracts by ABTS, DPPH and ORAC assays;

- The secondary metabolite characterization of hydrophilic extract by HPLC-PDA-ESI$\mathrm{MS}^{\mathrm{n}}$

- The evaluation of chemical and flavor profile by Liquid sensors, Electronic Nose and SPME/GC-MS;

- The study of the genetic diversity by AFLP markers.

This research project is part of a scientific context that aims to enhance the Mediterranean diet, considered important in the primary prevention of diseases such as cancer and cardiovascular diseases caused by oxidative stress, as demonstrated by several epidemiological studies (Esposito et al., 2004; Hashem et al., 2011).

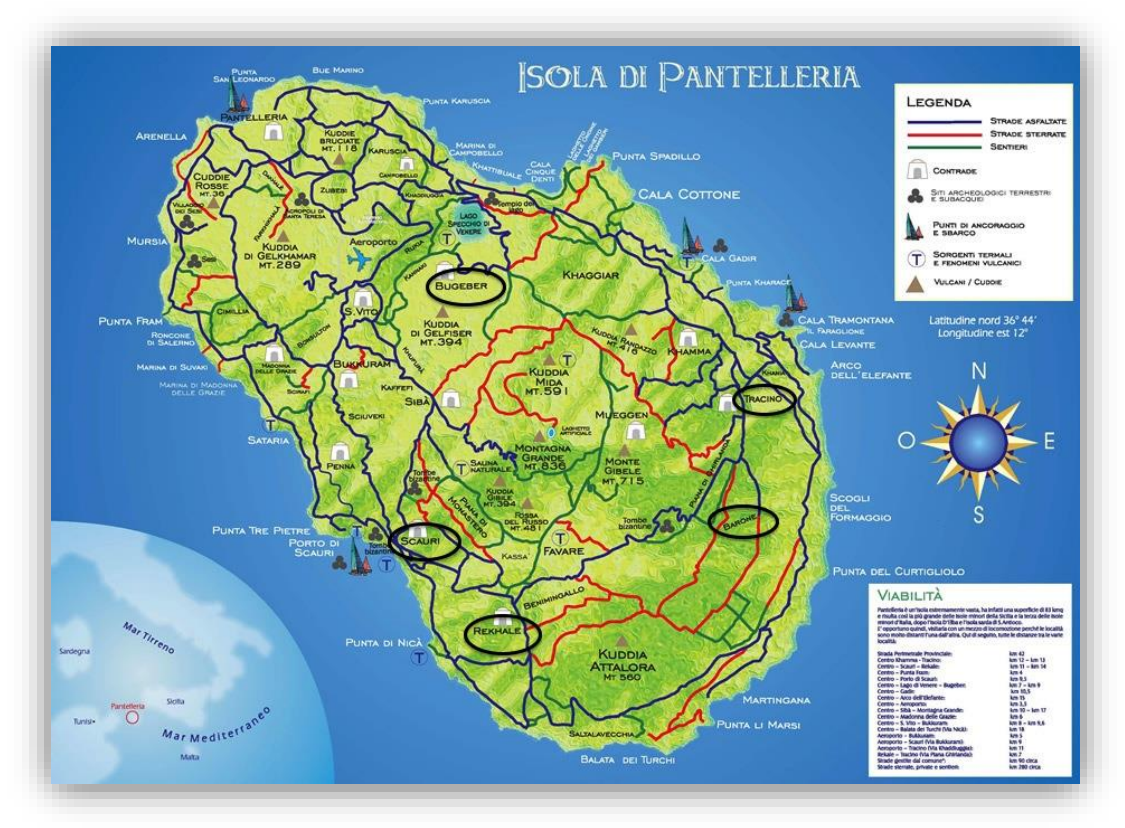

Figure 22. Pantelleria Island with collection's areas marked. 


\section{CHAPTER 1}

\section{Polyphenols content and antioxidant activity of hydrophilic extracts from Capparis spinosa $\mathrm{L}$.}

\subsection{Abstract}

Capparis spinosa is a wild and cultivated bush, grows in the Mediterranean area. Unopened flower buds, called capers, are used, after fermentation, in the Mediterranean cuisine as flavoring for foods. The caper culture shows an important territorial concentration in Sicily. In the present study, polyphenols contents and antioxidant activity of hydrophilic extract of capers were assessed. Samples were collected from different areas of the Pantelleria Island (Italy). FolinCiocalteu and Total Flavonoids assays were carried out to determine phenolic content. ORAC, DPPH and ABTS assays were used to determine antioxidant capacity and radical scavenger activity.

Person's coefficient indicated a high correlation between total phenolic content and antioxidant capacity (by DPPH assay) $\left(R^{2}=0.789\right)$, as well as between total flavonoid content and antioxidant capacity (by ORAC assay) $\left(R^{2}=0.918\right)$.

The overall phytochemical data indicate that $C$. spinosa flower buds (capers) from Pantelleria Island represents a rich source of bioactive compounds with potential nutraceutical relevance.

\footnotetext{
Abbreviations: AAPH, 2,20 -azo bis(2-amidinopropane)dihydrochloride; ABTS, 2,20 -azinobis-(3-ethylbenzothiazoline-6-sulfonic acid)diammonium salt); AUC, area under the curve; DPPH, 2,2-diphenyl-1-picryl-hydrazyl; DW, dry weight; EC50, half maximal effective concentration; GAE, gallic acid equivalent; GIP, Geographical Indications Protected; ORAC, oxygen radical absorbance capacity; PBS, saline phosphate buffer; RE, rutine equivalent; TAA, total antioxidant activity; TE, trolox equivalent; TEAC, trolox equivalent antioxidant capacity; TF, total flavanols; TPC, total phenolic content; Trolox, 6-hydroxy-2,5,7,8-tetramethylchroman2-carboxylic acid;
} 


\subsection{Introduction}

Capparis spinosa $\mathrm{L}$. is a plant native to the Mediterranean basin, even if it grows widely in various regions worldwide. Nowadays, Morocco and Turkey are the main producer countries (Haciseferoğullari et al., 2011; Tlili et al., 2011; Özcan \& Akgul, 1998). Unopened flower buds, called capers, are used, after fermentation, in the Mediterranean cuisine as flavoring for foods. The caper pharmacology and cosmetic properties as well as its use as spice and flavoring are known and appreciated in many European, Mediterranean and overseas countries. In Italy, Capparis spinosa L. cultivations are developed mainly in several minor Sicilian islands (Aeolian Archipelago, Pantelleria, Ustica and Linosa). In particular, C. spinosa subsp spinosa var canescens and C. spinosa subsp. rupestris are endemic species in Sicily (Fici \& Gianguzzi, 1997). The Sicilian production of flower buds and caper berries are prevalent for cooking uses.

In Pantelleria Island, the caper (flower buds) production has obtained the quality marked, Geographical Indications Protected (GIP), for its particular property and characteristics due to the geographical origin. In a dedicated disciplinary board for production, the process to obtain the commercial product "Cappero di Pantelleria IGP (Indicazione Geografica Protetta)" (European Union (EU) Regulation (EC) No. 1107/96) is described. These capers are organically grown and are handpicked one by one. They are cured and conserved in sea salt by the local farmers.

The Mediterranean diet is characterized by an abundance of fruits and vegetables considered nutraceutical foods. Indeed, due to a high content of polyphenols, fruits and vegetables play an excellent role in maintaining human well being, enhancing health and preventing or even treating specific diseases (Germanò et al., 2002). Polyphenols are a unique group of phytochemicals with substantial healthy potential in many medical areas. Their activity is based on functional groups capable of accepting a free radical negative charge.

Phenolic compounds, or so-called polyphenols, are secondary metabolites that can be commonly found in many plants (Pandey et al., 2009; Quideau et al., 2011; Francesca et al., 2016). They are the principals responsible of the nutritional and healthy value of food, because they help through physiological mechanisms to maintain the correct oxidative cells state. An excess of production of Reactive Oxygen Specie ROS, not offset by the activity of antioxidant biological system, causes oxidative stress (Zima et al., 2001). Free radical oxidative stress is involved in the pathogenesis of a range of human diseases.

With the aim to focus natural sources of antioxidants, the present study was carried out to evaluate the antioxidant radical scavenger activities from fermented unopened flower buds (capers) of Capparis spinosa L., grown in five different areas of Pantelleria Island, Sicily, Italy. 
Multiple assays have been used to screen the antioxidant capacity of hydrophilic extracts of caper. Particularly, diphenyl-picryl-hydrazyl (DPPH), 2,2-azo bis-(3-ethyl-benzothiazoline-6sulfonate (ABTS) and oxygen radical absorbance capacity (ORAC) assays were performed. These assays are extensively used as in vitro tests for estimating antioxidant potential (Huang et al., 2005; Cíž et al., 2010). Therefore, Total Flavonoids and Folin-Ciocalteu assays were used to quantify polyphenolic compounds. Natural sources of antioxidants, expressed as polyphenolic content and antioxidant capacities, were related using Person correlation.

\subsection{Material and Method}

\subsubsection{Plant material}

Capers (C. spinosa L.) used in this study were obtained from cultivated plants. The unopened flower buds were collected from Pantelleria Island (Sicily, Italy), in particular from five different areas named: Scauri $\left(36^{\circ} 46^{\prime} \mathrm{N}, 11^{\circ} 58^{\prime} \mathrm{E}\right)$, Rekhale $\left(36^{\circ} 75^{\prime} \mathrm{N}, 11^{\circ} 99^{\prime} \mathrm{E}\right)$, Tracino $\left(36^{\circ} 79^{\prime} \mathrm{N}\right.$, $\left.12^{\circ} 04^{\prime} \mathrm{E}\right)$, Barone $\left(36^{\circ} 77^{\prime} \mathrm{N}, 1^{\circ} 03^{\prime} \mathrm{E}\right)$ and Bugeber $\left(36^{\circ} 80^{\prime} \mathrm{N}, 11^{\circ} 99^{\prime} \mathrm{E}\right)$. The capers were obtained, already fermented in salt, from farmers of the local "Cooperativa Agricola Produttori Capperi” (Figure 23). Unopened flower buds were harvested manually from June to September 2014 and the subsequent salting took place using the official disciplinary for production.

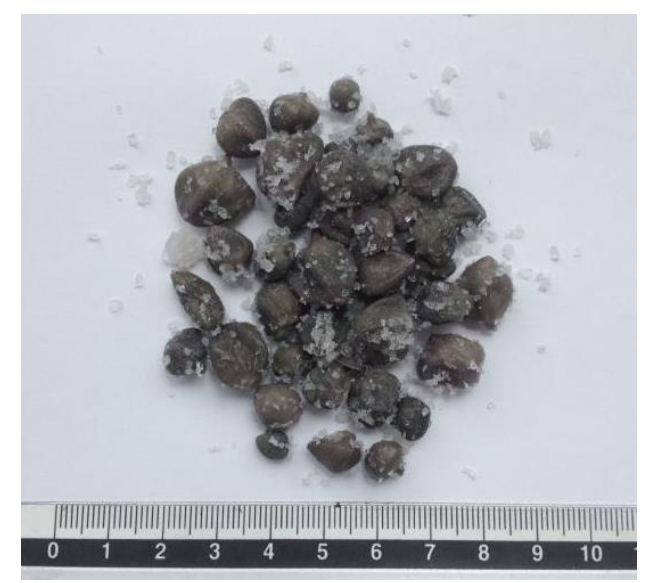

Figure 23. Pantelleria capers fermented in salt

The processing procedure consisted in a pre-treatment after harvesting in which fresh capers are mixed with marine salt (30-40\% by weight) and shuffled for about 8 to 10 days. During this time, brine was formed and fermentation occurred. At the end of this step the brine was 
discarded and the capers were treated with marine salt (20-25\% w/w) for another 20 to 30 days obtaining the commercial product (European Union (EU) Regulation (EC) No. 1107/96).

\subsubsection{Chemicals, reagents, and equipment}

Potassium persulfate $\left(\mathrm{K}_{2} \mathrm{~S}_{2} \mathrm{O}_{8}\right)$, Fluorescein, 2.2'-azobis(2-methylpropionamidine) dihydrochloride (AAPH), [2.2-Azino bis (3-ethylben- zothiazoline-6-sulfonic acid)] diammonium salt (ABTS), Folin-Ciocalteu's reagent, 2.20-Diphenyl-1-picryl hydrazyl (DPPH), gallic acid, rutine and Trolox (6-hydroxy-2.5.7.8-tetramethylchroman-2-carboxylic acid) were from Sigma-Aldrich (Italy).

Spectrophotometric measurements were performed using a UV-VIS Spectrophotometer (UV2401PC) (Shimadzu, Italy). Centrifugation was performed using an Avanti ${ }^{\mathrm{TM}} 30$ Centrifuge (Beckman, USA). Spectrofluorimetric measurements were performed using a Fluoroskan Ascent $^{\mathrm{TM}}$ Microplate Fluorimeter (Thermo Scientific, USA). Rotary evaporator used was IKA RV 10 (IKA Laboratory Equipment, Germany) and freeze dryer was Christ ALPHA 1-2 LD Plus from Martin Christ, Germany.

\subsubsection{Hydrophilic Extracts Preparation}

Hydrophilic extracts were prepared following the protocol by Tesoriere et al., (2007), with minor modifications. Immediately before the use, capers were washed three times with large amounts of $5 \mathrm{mM}$ saline phosphate buffer (PBS), pH 7.4, dried on blotting paper and finely chopped. Samples $(30 \mathrm{~g})$ were then extracted with $150 \mathrm{~mL}$ of solutions methanol/water $(2: 1, \mathrm{v} / \mathrm{v})$. After a cleanup step via centrifugation (3000 rpm, $4{ }^{\circ} \mathrm{C}, 15 \mathrm{~min}$ ) and filtration through a Millex HV 0.45 $\mu \mathrm{m}$ filter (Millipore, Billerica, MA). The extracts were subjected to rotary evaporation to remove the organic solvents. Finally, the hydrophilic extract was freeze dried. All extracts were stored at $-80{ }^{\circ} \mathrm{C}$. Before the use, the dried extracts were suspended in water and diluted at the required concentration.

\subsubsection{Total Phenolic Content (TPC) determination}

Total polyphenols were determined according to a modified method by Singleton et al., (1999). Folin-Ciocalteu's (FC) reagent, to blue reaction products in alkaline solution, was used to determine TPC in hydrophilic extracts. Briefly, lyophilized of hydrophilic extract was suspended in $1 \mathrm{~mL}$ of water and, than, diluted 1:15 (v/v). An aliquot of $50 \mu \mathrm{L}$ was added to $150 \mu \mathrm{L}$ of water. $1 \mathrm{~mL}$ of diluted FC's reagent $(1: 30 \mathrm{v} / \mathrm{v})$ was added. After $3 \mathrm{~min}$ incubation at room temperature, $800 \mu \mathrm{L}$ of sodium carbonate $(75 \mathrm{~g} / \mathrm{L})$ was added, mixed, and the reaction mixture 
was incubated at room temperature for two hours, protected from the light. Absorbance was measured at $765 \mathrm{~nm}$. Gallic acid, in the concentration range between 50 and $500 \mathrm{mg} / \mathrm{L}$, was used to generate the calibration curve $\left(R^{2}=0.8140\right)$, and total phenolic content was expressed as $\mathrm{mg}$ gallic acid equivalent (GAE) in $100 \mathrm{~g}$ of dry weight (DW). Tests were carried out in triplicate.

\subsubsection{Total Flavonoids (TF) determination}

Quantification of flavonoids was carried out by the aluminum chloride colorimetric method as described by Zhishen et al., (1999) and Allaith (2014). Lyophilized of hydrophilic extract was suspended in $1 \mathrm{~mL}$ of water and, than, diluted 1:20 (v/v). An aliquot of $100 \mu \mathrm{L}$ was added with a $60 \mu \mathrm{L}$ of $5 \% \mathrm{NaNO}_{2}$ solution. Following 5 min incubation at room temperature, $60 \mu \mathrm{L}$ of $\mathrm{AlCl}_{3}$ solution (10\%) was added. After $6 \mathrm{~min}, 400 \mu \mathrm{L}$ of $1 \mathrm{M} \mathrm{NaOH}$ was added and the volume was brought to $2 \mathrm{~mL}$ with water. Absorbance was measured at $510 \mathrm{~nm}$. Rutin was used in the concentration range of 20 and $200 \mu \mathrm{g} / \mathrm{mL}$ to obtain the calibration curve $\left(R^{2}=0.8445\right)$, and total flavonoid (TF) content was expressed as mg rutin equivalent (RE) in $100 \mathrm{~g}$ of dry weight (DW). Determinations were carried out in triplicate.

\subsubsection{ABTS radical scavenging activity}

The antioxidant activity of the hydrophilic extract was evaluated using the ABTS radical cation decolorization assay, as described by Miller and Rice-Evans (1996). 2.2-azino-bis (3ethylenebenzothiazoline-6-sulfonic acid) radical cation $\left(\mathrm{ABTS}^{\cdot+}\right)$ was prepared before to use by reacting ABTS with $\mathrm{K}_{2} \mathrm{~S}_{2} \mathrm{O}_{4}$, incubated for 18 hours. Samples, lyophilized of hydrophilic extract suspended in $1 \mathrm{~mL}$ of water, were analyzed in triplicate, using a kinetic spectrophotometric program at $734 \mathrm{~nm}$. The $\mathrm{ABTS}^{\circ+}$ scavenging capacity of the extract was compared with that of synthetic antioxidant Trolox, and results were expressed as $\mu \mathrm{mol}$ of Trolox equivalent per gram of dried weight, TEAC (Trolox Equivalent Antioxidant Capacity).

\subsubsection{DPPH radical scavenging activity}

The method described by Molyneux (2004) was used to measure the free DPPH radical scavenging activity with some modifications as described by Allaith (2014). An aliquot (100 $\mu$, $50 \mu \mathrm{L}$ or $5 \mu \mathrm{L}$ ) of sample (lyophilized of hydrophilic extract suspended in $1 \mathrm{~mL}$ of water) was added to $2 \mathrm{~mL}$ of $100 \mu \mathrm{mol}$ methanolic solution. Absorbance was measured at $517 \mathrm{~nm}$, after 15 min of incubation at room temperature. Gallic acid, in the range of 125 to $500 \mathrm{mg} / \mathrm{L}$ was used to generate the standard curve $\left(R^{2}=0.9568\right)$. 
Inhibition was calculated as reported:

$$
\% \text { Inhibition }=\left(\left(A_{D P P H}-A_{\text {sample }}\right) / A_{D P P H}\right) * 100
$$

where $A_{D P P H}$ is absorbance of DPPH solution in the absence of sample or standard, and $A_{\text {sample }}$ is absorbance of a DPPH solution with a tested sample or positive control (Rapisarda et al., 2008). The antiradical activity $\left(\mathrm{EC}_{50}\right)$, defined as the concentration of the sample resulting in $50 \%$ inhibition, was calculated from a dose-response plot, in which \% inhibition versus sample volumes $(100 \mu \mathrm{L}-5 \mu \mathrm{L})$ was plotted. Tests were carried out in triplicate.

\subsubsection{Oxygen Radical Absorbance Capacity (ORAC)}

Analyses were conducted applying the method used by Giomaro et al. (2014) with some minor modifications. Fluorescein (3'-6'-dihydroxy-spiro (isobenzofuran-1 (3H), 9'(9H)-xanthen)-3one) was chosen as the fluorescent probe (Ou et al., 2001; Prior et al., 2003). Fluorescein was prepared at $0.49 \mathrm{nM}$ in sodium phosphate buffer (PBS) $75 \mathrm{mM}, \mathrm{pH}$ 7.0. Peroxyl radical was generated using 2.2'-azobis (2-amidino-propane) dihydrochloride (AAPH). It was prepared for each run with a concentration of $150 \mathrm{mM}$ in PBS $75 \mathrm{mM}$. The standard reference was performed with Trolox at $250 \mathrm{mM}$.

The final reaction mixture for the assay $(200 \mu \mathrm{L})$ was prepared as follows: $165 \mu \mathrm{L}$ of $0.49 \mathrm{nM}$ fluorescein (as above reported), $20 \mu \mathrm{L}$ of samples (lyophilized of hydrophilic extract suspended in $1 \mathrm{~mL}$ of water and diluted 1:300 v/v in $75 \mathrm{mM}$ PBS) or $250 \mathrm{mM}$ Trolox. The control (as blank) was $75 \mathrm{mM}$ sodium phosphate buffer, $\mathrm{pH}$ 7.0. When stability was reached, the reaction was started with $15 \mu \mathrm{L}$ of $150 \mathrm{mM}$ AAPH and fluorescence was measured every 10 seconds. The fluorescence was read using follows conditions: excitation at $485 \mathrm{~nm}$ and emission at $535 \mathrm{~nm}$. The ORAC value is calculated according to the formula reported by Giomaro et al. (2014):

$$
\text { ORAC (umol Trolox equivalent } / g D W)=\left[\left(A b s_{S}-A b s_{B}\right) /\left(A b s_{T}-A b s_{B}\right)\right] k a h
$$

where $A b s_{S}$ is the area under the curve (AUC) of fluorescein in the presence of the sample, $A b s_{T}$ is the AUC of the Trolox, $A b s_{B}$ is the AUC of the control, $k$ is the dilution factor, $a$ is the concentration of Trolox in $\mu \mathrm{mol} / \mathrm{L}$ and $h$ is the ratio between the liters of extract and the grams of sample used for the extraction. Results are expressed as Trolox Equivalent Antioxidant Capacity (TEAC) then $\mu$ mol Trolox equivalent per gram of dried weight (DW). 


\subsubsection{Statistical analysis}

Statistical analysis of the data was performed using the STATSOFT 6.0 program (Vigonza, Padova, Italy). The significant differences $(p \leq 0.05)$ were evaluated by variance analysis (ANOVA), and the means separation was conducted using the Tukey post-hoc test.

To study the correlation between the polyphenol compounds (TPC and TF) and the antioxidant activity evaluated by DPPH, ABTS and ORAC assays. Pearson's correlation coefficient was applied carried out using the SIGMAPLOT 10 software (Systat software Inc., San Jose, USA).

\subsection{Results and Discussions}

The total polyphenols content and total flavonoids value of hydrophilic extract of capers from the five above-mentioned areas of Pantelleria Island are reported in Table 1. Table 1 shows the results for TPC, expressed as mg of gallic acid equivalent for 100 grams of dried weight, and for $\mathrm{TF}$, expressed as mg of rutine equivalent in 100 grams of dried weight.

Table 1. Total concentration of bioactive compounds and antioxidant activities of hydrophilic extract of caper (Capparis spinosa L.) collected from Pantelleria Island (Sicily, Italy).

\begin{tabular}{cccccc}
\hline $\begin{array}{c}\text { Area of } \\
\text { collection }\end{array}$ & $\begin{array}{c}\text { Total Phenolic } \\
\text { Content } \\
(\mathrm{mg} \text { GAE/100g } \\
\mathrm{DW})\end{array}$ & $\begin{array}{c}\text { Total } \\
\text { Flavonoids } \\
(\mathrm{mg} \mathrm{RE} / 100 \mathrm{~g}\end{array}$ & $\begin{array}{c}\text { DPPH } \\
\left(\mathrm{EC}_{50}-\mathrm{mg}\right. \\
\mathrm{DW})\end{array}$ & $\begin{array}{c}\text { ABTS }) \\
(\mu \mathrm{mol} \text { TE/g } \\
\mathrm{DW})\end{array}$ & $\begin{array}{c}\begin{array}{c}\text { ORAC } \\
\text { ORol TE/g }\end{array} \\
\mathrm{DW})\end{array}$ \\
\hline Scauri & $815.76 \pm 81.16$ & $90.31 \pm 0.01$ & $2.19 \pm 0.16$ & $5.06 \pm 0.05$ & $655.98 \pm 58.34$ \\
Rekhale & $843.92 \pm 44.83$ & $49.11 \pm 0.72$ & $1.93 \pm 0.13$ & $4.50 \pm 0.04$ & $501.50 \pm 14.12$ \\
Tracino & $661.99 \pm 59.84$ & $53.52 \pm 0.71$ & $2.67 \pm 0.16$ & $5.15 \pm 0.01$ & $483.34 \pm 18.01$ \\
Barone & $797.41 \pm 31.97$ & $52.61 \pm 0.62$ & $2.08 \pm 0.12$ & $6.39 \pm 0.02$ & $503.53 \pm 31.37$ \\
Bugeber & $596.92 \pm 53.15$ & $20.65 \pm 0.01$ & $2.50 \pm 0.02$ & $4.69 \pm 0.02$ & $231.70 \pm 12.19$ \\
\hline
\end{tabular}

Abbreviations: $\mathrm{GAE}=$ gallic acid equivalent; $\mathrm{RE}=$ rutin equivalent; $\mathrm{DW}=$ dried weight; $\mathrm{DPPH}=\mathrm{DPPH}$ assay; $\mathrm{ABTS}=\mathrm{ABTS}$ assay; $\mathrm{ORAC}=\mathrm{ORAC}$ assay.

Values of total phenolic compounds ranged from $843.92 \pm 44.83$ (for Rekhale) to $596.92 \pm 53.15$ (for Bugeber) of mg GAE/100g DW. Values of total flavonoids ranged from $90.31 \pm 0.01$ (for Scauri) to $20.65 \pm 0.01$ (for Bugeber) of $\mathrm{mg}$ RE/100 g DW. The total phenols and flavonoids content were considered according the geographic area of caper collection, data were analyzed 
by variance analysis (ANOVA) and mean separation was determined by Tukey's test with STATSOFT 6.0. (Figure 24).

Regarding the TPC, there are significant differences among the capers collected from different areas in the Pantelleria Island. Particularly, the content of TPC, expressed as mg GAE/100g DW was statistically higher in Scauri and Rekhale, lower in Bugeber. TPC detected in this study makes C. spinosa capers from around Pantelleria Island a good natural source of bioactive compounds when compared with other natural sources, such as, for example, spices and herbs (Embuscado, 2015), plants of industrial interest (as oak, pine, cinnamon, mate, and clove extracts) (Dudonné et at., 2009), and Aloe as Aloe greatheadii var. davyana (Botes et al., 2008).
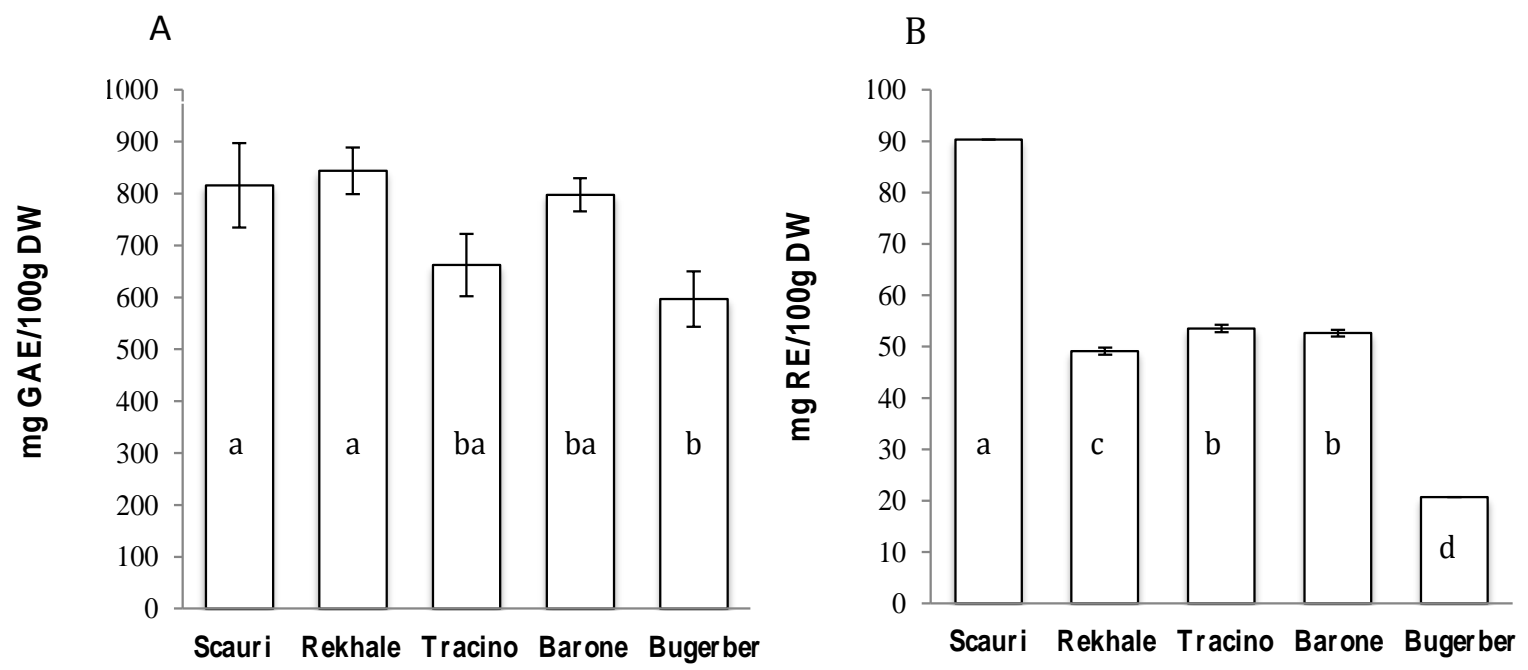

Figure 24. Total Phenolic (A) and flavonoids (B) contents according the geographic area of caper collection. Different letters indicate significant differences at $p \leq 0.05$.

Comparatively, phenolic content, in capers from several locations in the main island of the Kingdom of Bahrain, ranged from 90.0 to $210.0 \mathrm{mg}$ GAE/100 g DW with an overall average of $120.0 \pm 42.5 \mathrm{mg}$ GAE/100 g DW (Allaith, 2014). Lower total phenolic content, $37 \mathrm{mg}$ GAE/100 g DW, was reported in Turkish C. spinosa by Aliyazicioglu et al., (2013).

Data regarding TF show how the diverse geographic areas, together with the different genotypes, affect the relative amount. Actually, capers from Scauri had a higher significant content in flavonoids than other areas. These results indicate that the harvesting location, together with the different genetic material, are important factors influencing the content of some bioactive 
compounds. Really, flavonoid compounds are a group of polyphenols and represent the $7 \%$ of the total phenolic compounds, as reported by Tlili et al., (2009).

To understand how polyphenols displays their antioxidant activity, DPPH, ABTS and ORAC assays were performed. Results of antioxidant assay are shown also in Table 1.

ABTS and DPPH are the commonly analyses used to measure antioxidant capacity (Antolovich, et al., 2001). Both of them are characterized by excellent reproducibility under certain assay conditions (Shalaby \& Shanab, 2013), showing significant differences in their response to antioxidants (Thaipong et al., 2006).

The DPPH assay provides information about the activity of samples with stable free radicals (DPPH) and its effect is thought to be due to their hydrogen donating ability: stronger radical quenching results in a lower $\mathrm{EC}_{50}$ value and vice-versa. The ABTS assay, indeed, provides information about the activity of samples based on inhibition of the production of the ABTS radical cation; the accumulation of $\mathrm{ABTS}^{\circ+}$ can be inhibited by the presence of an antioxidant in the reaction medium.

For the DPPH, radical capers from Rekhale showed lowest DPPH assay value based EC 50 (1.93 $\pm 0.13 \mathrm{mg}$ DW), while Tracino displayed the highest (2.67 $\pm 0.16 \mathrm{mg} \mathrm{DW})$ (Figure 25, A).

For the ABTS, radical capers from Rekhale and Barone showed respectively minimum and maximum value of TEAC $(4.50 \pm 0.04$ and $6.39 \pm 0.02 \mu \mathrm{mol}$ TE/g DW respectively) (Figure 25, B).

The antioxidant capacity of hydrophilic extracts of capers was measured also by ORAC assay. Sample from Bugeber shown the minimum ORAC value: $231.70 \pm 12.19 \mu \mathrm{mol}$ TE/100 g DW; sample from Scauri shown the maximum ORAC value: $655.98 \pm 58.34 \mu \mathrm{mol} \mathrm{TE} / 100 \mathrm{~g} \mathrm{DW}$. No significant difference of ORAC value was registered for samples from Rekhale, Tracino and Barone (Figure 25, C). The mean value of ORAC for caper from Pantelleria Island is comparable to same spices and herbs as reported by Embuscado (2015), but it is lower than fruits, as for example, lemon according to Amenta et al. (2015).

In order to evaluate the correlation between the polyphenols content and antioxidant activity, the Person's coefficients were used. 

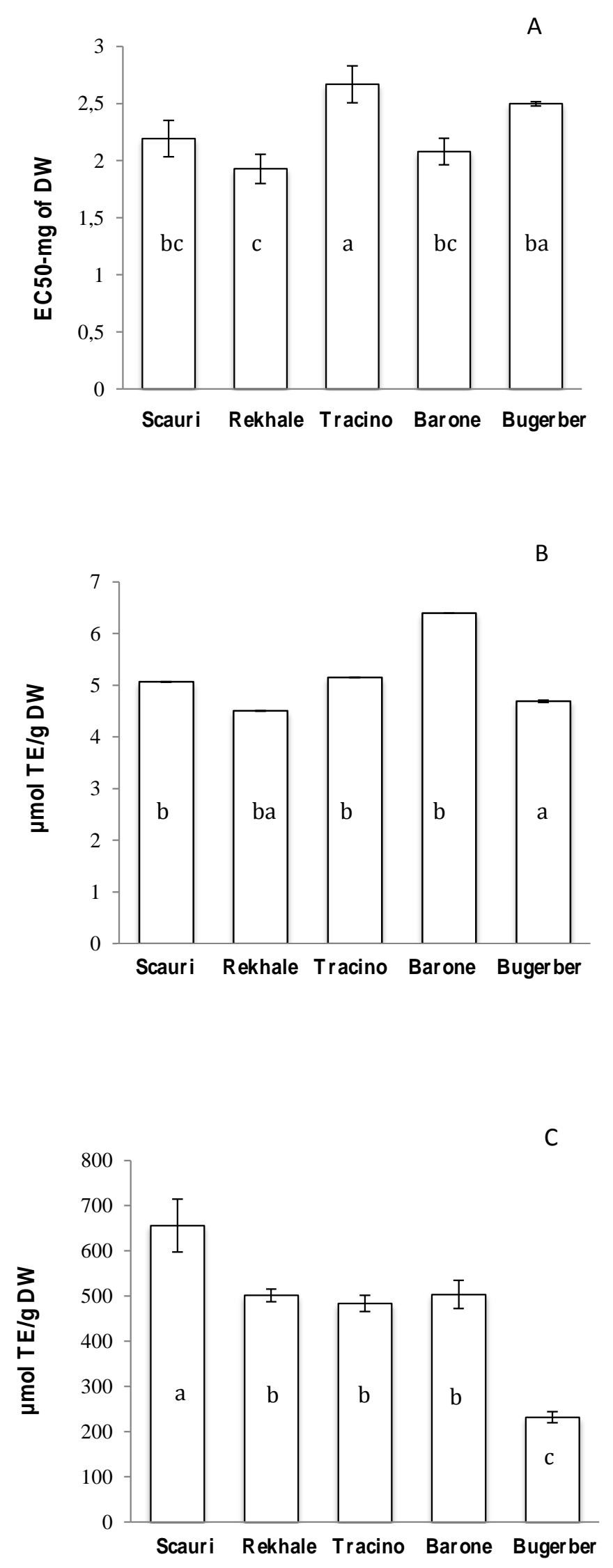

Figure 25. Polyphenols antioxidant activity tested by DPPH (A), ABTS (B) and ORAC (C) assays. Different letters indicate significant differences at $p \leq 0.05$. 
The correlation between TPC and TF versus antioxidant activity, expressed by DPPH, ABTS and ORAC assay, has been widely studied. It is interesting to examine the relation between the main antioxidant compounds of the caper (as polyphenols) and the antioxidant capacity measured by the three different methods tested (Table 2).

Table 2. Pearson's correlation coefficients $\left(R^{2}\right)$ of total phenols, total flavonoids content and antioxidant activities expressed by ORAC, ABTS, DPPH assay, of caper (Capparis spinosa L.) from Pantelleria Island (Sicily, Italy) (p-values <0.01).

\begin{tabular}{ccc}
\hline Assay* $^{*}$ & TPC & TF \\
\hline TPC & - & \\
TF & 0.350 & - \\
ORAC & 0.536 & 0.888 \\
ABTS & 0.156 & 0.594 \\
DPPH & 0.665 & 0.074 \\
\hline
\end{tabular}

*Abbreviations: TPC $=$ Total Phenolic Content (mg GAE/100 g DW); TF= Total Flavonoids (mg RE/100 g DW); DPPH= DPPH Assay (EC50-mg DW); ABTS= ABTS Assay $(\mu \mathrm{mol}$ TE/g DW $) ;$ ORAC $=$ ORAC value $(\mu \mathrm{mol}$ TE $/ \mathrm{g}$ DW).

Dancey and Reidy (2004) report that the correlation coefficient values from 0.1 to 0.3 are considered low; from 0.4 to 0.6 are moderate, and from 0.7 to 1.0 are high. The closer to 1.0 , regardless the signal, the higher is the degree of statistical linear dependence between the two variables analyzed.

According to Pearson's correlation coefficient (R2), there is a low correlation between TPC and $\mathrm{TF}$, highly significant $(\mathrm{p}<0.01)$, probably because antioxidant activity is not originate from the number of flavonoid present in capers but from the interaction of flavonoids with themselves and other bioactive compounds.

According to Pearson's correlation coefficients (R2), the correlation between total polyphenols and antioxidant activity was higher for the DPPH assay (R2=0.665) (Figure 26, A) and lower for the ABTS assay $(\mathrm{R} 2=0.156)$, highly significant $(\mathrm{p}<0.01)$. Moreover, the correlation between total flavonoids and the antioxidant activity was a higher for the ORAC assay $\left(R^{2}=0.888\right)$ (Figure $26, \mathrm{~B})$, lower for the DPPH assay $\left(R^{2}=0.074\right)$ and moderate for the ABTS assay $\left(R^{2}=0.594\right)$. Thus, it can be deduced that: i) the antioxidant capacity of bioactive compounds from caper can be suitably determined by ORAC assay, and ii) flavonoids are polyphenols with very high antioxidant activity. 
Several studies have reported the correlation between the phenolic content and the antioxidant activity, considering phenolic compounds as the most representative among the bioactive substances with antioxidant capacity (Dudonné et al., 2009; Kalita \& Jayanty, 2014; Embuscado, 2015). However, the understanding about the contribution of each phenolic compounds to the antioxidant activity of different species of fruits and vegetables is still under study. Some authors suggested that the antioxidant activity expressed is a consequence of the synergism between different phenolic compounds and it cannot be attributed specifically to one constituent (Arnous et al., 2002; Lee et al., 2003).

In our study, flavonoid content found in hydrophilic extract from caper presented high antioxidant capacity. However, further investigations are necessary to identify the molecules that are involved in this activity.

A

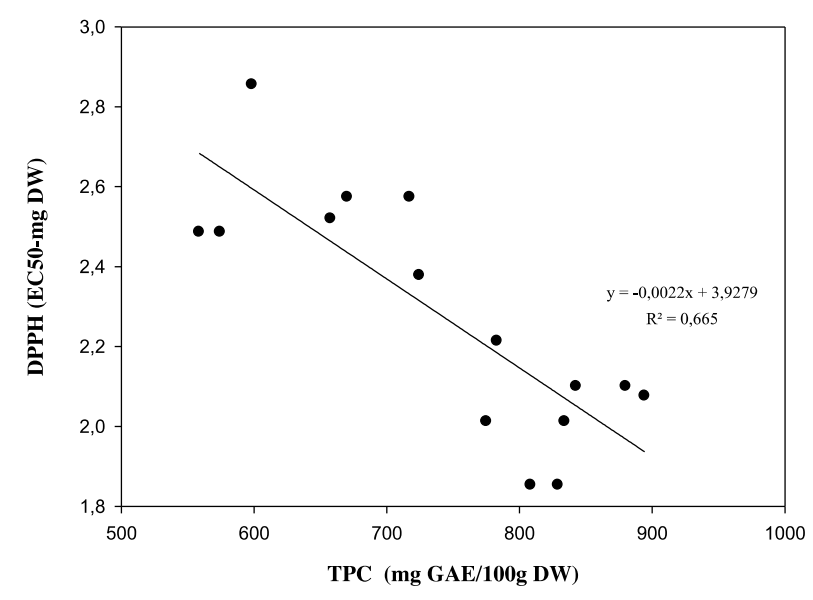

B

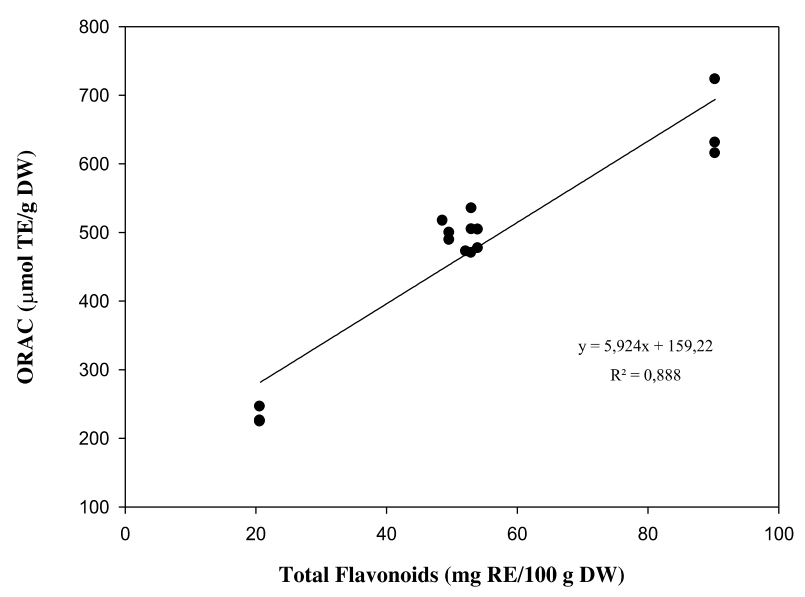

Figure 26. Correlation between total polyphenols and antioxidant activity (A) and between total flavonoids and the antioxidant activity (B). 


\subsection{Conclusion}

Caper is a good source of phenolic compounds, which are known to provide health-improving benefits, due to their various biological activities (antioxidant, anticarcinogenic, antimicrobial, antimutagenic) (Siracusa et al., 2011; Matthaus \& Özcan, 2002). The present study reports that capers, unopened flower buds of Capparis spinosa L., collected and processed in Pantelleria Island (Sicily, Italy) represent a good source of antioxidant compounds. This typical Mediterranean food product contains a high level of phenolic compounds, especially in flavonoids content, which explains its high antioxidant activity. Actually, ORAC assay were the best determination for antioxidant activity in capers. The results obtained from this study point up the nutritional value of the unopened flower buds or capers and promote them as food for wellness. 


\section{CHAPTER 2}

\section{Secondary metabolites characterization of hydrophilic extract from Pantelleria capers (Capparis spinosa L) by HPLC-PDA-ESI-MS ${ }^{n}$}

\subsection{Abstract}

Hydrophilic extracts of Capparis spinosa from Pantelleria Island (Trapani, Italy) were characterized by high-performance liquid chromatography-electrospray ionization/mass spectrometry. Among the 24 detected compounds, several kaempferol and quercetin derivatives were identified including kaempferol-7-O-rhamnoside, kaempferol-3-O-rhamnosyl-7-Oglucosyl-glucoside, kaempferol-3-O-neohesperidoside-7-O-rhamnoside, kaempferol-3-Oneohesperidoside, kaempferol-3-O-glucoside, kaempferol-7-O-neohesperidoside, quercetin-7-Oneohesperidoside, quercetin-7-O-glucoside, and quercetin-3-O-neohesperidoside. Ten different glucosinolates were also detected. The identification was based on UV and MS spectra, and MS ${ }^{\mathrm{n}}$ fragmentation pattern. Kaempferol and quercetin derivates were quantified as mg of kaempferol and quercetin equivalents in $100 \mathrm{~g}$ dry weight caper, respectively.

Keywords: Caper; HPLC-PDA-ESI-MS ${ }^{\text {; }}$ kaempherol; quercetin; secondary metabolites.

\subsection{Introduction}

Capparis spinosa L. species is a common small shrub belonging to Capparidaceae family, which is closely related to the mustard family (Cruciferae) (Inocencio et al., 2000). It is an aromatic plant native to dry Mediterranean and west and central Asia regions, growing both wild around rocky areas and also cultivated. Flower buds, gathered before blossoming, and fruits are commercialized, after salt fermentation, in the Mediterranean countries, where they are used as food ingredient for several recipes, highly appreciated for their pungent and strong flavor (Argentieri et al., 2012). Caper has been used for medicinal purposes since Sumerians time (2000 B.C.) (Bottema \& Hansen, 1992) and it has been found to exhibit different bioactivities including diuretic, antihypertensive, antihepatotoxic, antidiabetic, anti-inflammatory, anticarcinogenic, antifungal, and antioxidant effects (Ao et al., 2007; Eddouks et al., 2005; Kulisic-Bilusic et al., 2012; Tlili et al., 2011; Zhou et al., 2011; Zhou, et al., 2010).

Several types of bioactive components occurring in capers, including alkaloids, lipids, flavonoids, indoles, and aliphatic glucosinolates, have been identified (Matthäus \& Özcan, 2002; 
Siracusa et al., 2011). Among these, pholyphenols, (plant secondary metabolites derived exclusively from the phenylpropanoid and/or the polyketide pathway(s)) are known to provide health-improving benefits strongly related to anti-oxidative action ( $\mathrm{Li}$ et al., 2014). Reactive oxygen species (ROS) generation is common in a biological system, but when ROS production exceeds the endogenous antioxidant capacity results in free radical oxidative stress, involved in the pathogenesis of a large range of human diseases. Epidemiological studies have repeatedly shown an inverse association between the risk of chronic human diseases and the adoption of a polyphenolic rich diet (Scalbert et al., 2005). In fact, the phenolic groups in polyphenols can accept an electron to form relatively stable phenol radicals, thereby disrupting chain oxidation reactions in cellular components (Pandey \& Rizvi, 2009).

Previous works demonstrated the in vitro antioxidant activity of Capparis spinosa L. bud extracts (Bonina et al., 2002; Germanò et al., 2002), and in particular the unopened flowers of Capparis spinosa L. from Pantelleria Island had a strong antioxidant and free-radical scavenger effectiveness due to its high level of phenolic compounds (Tesoriere et al., 2007).

Many analytical procedures have been developed to detect secondary metabolites in different plants, and high-performance liquid chromatography (HPLC) using a photodiode-array detector (PDA) coupled with electrospray ionization/mass spectrometry $\left(\mathrm{ESI}^{-M S^{\mathrm{n}}}\right)$ is the method of choice for such studies. HPLC-ESI-MS ${ }^{\mathrm{n}}$ provides information on the aglycone part, the types of carbohydrates present, the stereochemistry of terminal monosaccharide units, the sequence of the glycan part, and interglycosidic linkages (Ferreres et al., 2004).

As the cultivation location and the genotype are very important factors influencing the bioactive compounds composition (Conforti et al., 2011; Tlili et al., 2009), the aim of the present work was the identification and quantification of secondary metabolites, in particular polyphenols, present in fermented flower bud methanolic extracts of five different Capparis spinosa L. accessions collected from five different areas of Pantelleria Island (Sicily, Italy), namely Scauri, Barone, Rekale, Bugeber and Tracino. All these accessions produce capers that have earned the Protected Geographical Indication (PGI) status.

\subsection{Materials and methods}

\subsubsection{Materials and chemicals}

All reagent and solvents of HPLC-grade and HPLC-MS grade, and vanillic acid were purchased from Sigma-Aldrich (Saint Louis, MO). HPLC-grade water, used for sample preparation, was obtained with a Milli-Q water purification system (Millipore, Billerica, MA). Quinic acid was 
purchased from Acros Organics (Geel, Belgium), while kaempferol-3-O-glucoside and kaempferol-7-O-neohesperidoside were purchased from Extrasynthese (Genay Cedex, France). Filtration membranes $(0.45-\mu \mathrm{m}$ cellulose acetate/cellulose nitrate mixed esters) were purchased from Phenomenex (Torrance, CA).

\subsubsection{Plant material and extraction procedure}

Fermented capers (Capparis spinosa L.) used for analysis were collected in five different areas of the Pantelleria Island (Sicily, Italy), namely Scauri $\left(36^{\circ} 46^{\prime} \mathrm{N}, 11^{\circ} 58^{\prime} \mathrm{E}\right)$, Rekhale $\left(36^{\circ} 75^{\prime} \mathrm{N}\right.$, $\left.11^{\circ} 99^{\prime} \mathrm{E}\right)$, Tracino $\left(36^{\circ} 79^{\prime} \mathrm{N}, 12^{\circ} 04^{\prime} \mathrm{E}\right)$, Barone $\left(36^{\circ} 77^{\prime} \mathrm{N}, 12^{\circ} 03^{\prime} \mathrm{E}\right)$ and Bugeber $\left(36^{\circ} 80^{\prime} \mathrm{N}\right.$, $\left.11^{\circ} 99^{\prime} \mathrm{E}\right)$. All these accessions have earned Protected Geographical Indication (PGI) status. The "Cooperativa Agricola Produttori Capperi" collects capers from different local farmers who transform the product using the official disciplinary for production. The fresh floral buds were treated with $40 \%$ sea salt (w/w) for 8 - 10 days and then with $25 \%$ sea salt (w/w) for 20 - 30 days stirring them several times during the fermentation period and obtaining the commercial product (European Union (EU) Regulation (EC) No. 1107/96). After fermentation, capers ready to be used, are given to the "Cooperativa Agricola Produttori Capperi" for storing or packaging.

The extraction of polyphenols was performed using the method described in Tesoriere et al. (Tesoriere et al., 2007), with some minor modifications. Immediately before the analysis, capers were washed three times with large amounts of $5 \mathrm{mM}$ saline phosphate buffer, $\mathrm{pH} 7.4$ (PBS), dried on blotting paper, and finely chopped. Samples (30 g) were then extracted at room temperature with $150 \mathrm{~mL}$ of methanol/water mixture $(2: 1, \mathrm{v} / \mathrm{v})$. After a cleanup step via centrifugation (3000 $\mathrm{rpm}, 4{ }^{\circ} \mathrm{C}$ for $15 \mathrm{~min}$.), the extracts were filtered through Millex HV 0.45 $\mu \mathrm{m}$ filters (Millipore, Billerica, MA), and then the organic solvent was removed under reduced pressure at $35{ }^{\circ} \mathrm{C}$ before freeze-drying procedure. All extracts were stored at $-80{ }^{\circ} \mathrm{C}$ and recovered with $1 \mathrm{~mL}$ of water immediately before the analysis.

\subsubsection{HPLC-DAD analyses (quantitative analysis)}

Chromatographic separation was performed using an Agilent 1200 liquid chromatograph equipped with mobile-phase online degasser, quaternary pump, and diode array detector (Agilent, Waldbronn, Germany). A Gemini ${ }^{\circledR}$ C18 110A analytical column (150 x 2.00 mm i.d., $5 \mu \mathrm{m}$ ) with pre-column (Phenomenex, Torrance, CA, USA) was used. The mobile phase consisted of formic acid $0.1 \%$ in water (solvent A) and methanol (solvent B) at $0.3 \mathrm{~mL} / \mathrm{min}$ (injected volume $10 \mu \mathrm{L}$ ). The multi-step solvent gradient used was: from $2 \%$ B to $5 \%$ B in 18 $\mathrm{min}$, then to $40 \% \mathrm{~B}$ in $50 \mathrm{~min}$, to $60 \% \mathrm{~B}$ in $10 \mathrm{~min}$, to $100 \% \mathrm{~B}$ in $10 \mathrm{~min}$ with a final plateau of 
$10 \mathrm{~min}$ at $100 \% \mathrm{~B}$; then from $100 \% \mathrm{~B}$ to $2 \% \mathrm{~B}$ in $2 \mathrm{~min}$; equilibration time $10 \mathrm{~min}$. Flow rate 0.3 $\mathrm{mL} / \mathrm{min}$; injection volume $10 \mu \mathrm{L}$. The UV-vis spectra were recorded in the range 200-600 $\mathrm{nm}$ and chromatograms were also acquired at 254, 280, $314 \mathrm{~nm}$, and $370 \mathrm{~nm}$. The HPLC-PDA system was controlled by a personal computer equipped with ChemStation Software version Rev. B.04.01 operating in a Windows XP Professional operating system environment.

Quantification of kaempferol and quercetin derivatives was carried out at $350 \mathrm{~nm}$ using calibration curves established with kaempferol and quercetin as external standard. Stock standard solutions ( $1 \mathrm{mg} / \mathrm{mL})$ of kaempferol and quercetin were prepared by dissolving carefully weighed amounts of each standard compound in methanol. Each standard solution was diluted with methanol:water (50:50) to six final concentrations ranging from 0.02 to $0.5 \mathrm{mg} / \mathrm{mL}$. Each concentration was analyzed in triplicate. Quantification of individual compounds was performed by the external standard method using a six-point regression curve. The peak area was plotted against concentration, and least squares regression analysis was used to fit lines to the data (kaempferol $R^{2}=0.9997$ and quercetin $R^{2}=0.9998$ ).

The amount of each kaempferol and quercetin derivative was expressed as mg of kampferol or quercetin equivalents in $100 \mathrm{~g}$ caper dry weight (DW), respectively.

Analyses were always carried out in triplicate.

\subsubsection{Method validation}

HPLC-PDA method validation was carried out using the kaempferol and quercetin standards. Five standard solutions from 20 to $500 \mu \mathrm{g} / \mathrm{mL}$ were assayed by sequentially injecting each of the five concentrations from lowest to highest three times. Peak area versus concentration plots were obtained and least squares regression analysis was used to fit lines to the data. The following regression lines were obtained: $y=44581 x+257.91$ with a correlation coefficient of 0.998 for kaempferol and $y=61329 x+131.02$ with a correlation coefficient of 0.999 for quercetin, over the concentration range. The relative standard deviations showed acceptable reproducibility, with RSDs ranging from $0.29 \%$ to $1.1 \%$. The LOD and LOQ were determined by testing dilutions of the lowest standard concentrations. The LOD was $5 \mu \mathrm{g} / \mathrm{mL}$ and the LOQ $10 \mu \mathrm{g} / \mathrm{ml}$ for both the analytes. As regards method repeatability, intraday repeatability RSDs $(n=6)$ were $2.20 \%$, $1.25 \%$, and $1.10 \%$ for kampferol and $2.18 \%, 1.20 \%$, and $1.15 \%$ for quercetin at 20,250 , and $500 \mu \mathrm{g} / \mathrm{mL}$, respectively, while interday repeatability RSDs $(3$ days, $\mathrm{n}=9)$ at the same concentrations were $2.10 \%, 1.45 \%$, and $1.30 \%$ for kaempferol, and $2.15 \%, 1.50 \%, 1.40 \%$ for quercetin. The accuracy of the HPLC-PDA method was determined by recovery tests performed using three standard solutions at 20,250, and $500 \mu \mathrm{g} / \mathrm{mL}$ concentrations. Recovery ranges were, 
respectively $96-106 \%, 97-103 \%$, and $96-105 \%$ for the three concentrations of the analytes, with RSDs less than $17 \%$.

\subsubsection{HPLC-MS ${ }^{\mathrm{n}}$ experiments (qualitative analyses)}

The analyses have been carried out using the same column and applying the elution method previously described for the HPLC-PDA analyses. LC-MS data were acquired on Thermo Scientific LCQ FLEET system (LCQ FLEET ion trap mass spectrometer, Surveyor MS Pump/Autosampler/PDA Detector). The injection volume was $5 \mu \mathrm{L}$. The ion trap operated in data-dependent, full scan $(90-1500 \mathrm{~m} / \mathrm{z})$, and $\mathrm{MS}^{\mathrm{n}}$ mode to obtain fragment ions $\mathrm{m} / \mathrm{z}$ with collision energy of $35 \%$ and an isolation width of $3 \mathrm{~m} / \mathrm{z}$. The negative and positive parameters of the ion mode ESI source had previously been optimized by flow injection analysis, using kaempferol and quercetin ( $5 \mathrm{ppm}$ in $0.1 \%$ formic acid-methanol solution, 50:50, v/v) to an ionization voltage of $5.0 \mathrm{kV}$, a capillary temperature of $400{ }^{\circ} \mathrm{C}$, a capillary voltage of $33 \mathrm{~V}$, a sheath gas flow rate of 50 arbitrary units (AU), and an auxiliary gas flow rate of 20 AU.

The Termo Fisher Scientific Xcalibur MS Software Version 2.1 (Thermo Fisher Scientific Inc., Waltham, MA, USA) was used for data acquisition and processing.

Three independent assays were performed to analyze the samples by HPLC/PDA-ESI-MS ${ }^{\mathrm{n}}$; no relevant variations attributable to the nature of the detected fragments or their relative intensities were observed.

\subsubsection{Statistical analysis}

The content of kaempherol and quercetin derivates was put into the S-PLUS 2000 (MathSoft Inc.) software for multivariate analysis. The data set was the content of kaempferol or quercetin equivalents/100g of DW vs origin of collected samples.

\subsection{Results and discussion}

\subsubsection{Chemical characterization of extracts by LC-MS}

HPLC - PDA chromatograms of the tested caper accessions are reported in figure 27.

In Table 3, compound attribution based on UV-VIS and mass spectra, chromatographic behavior, and a comparison with standard compounds and the literature is reported.

The chromatographic retention time and spectral characteristics of each compound were compared to those of the external standard, when available, and when commercial standards 
were not available, the analytes were identified by combining $\mathrm{MS}^{\mathrm{n}}$ data with the respective literature data. Ionization was performed both in positive- and in negative ion mode. Combined use of ionization in the two modes affords extra certainty of the determination of the molecular mass.

Compound 1 produced the molecular ion in positive ionization mode at $\mathrm{m} / \mathrm{z} 361$; its MS/MS fragmentation led to an ion at m/z 199 due to the loss of 162 amu (a hexose mojety). In negative ionization mode an ion at m/z 153 corresponding to the decarboxylation of syringic acid [M-H162-COO] $]^{-}$was also present.

The compound was putatively identified as syringoil-hexoside. Other two small organic acids were present: quinic acid (2) and vanillic acid (6), both identified by comparison with the corresponding standards. Compound 2 showed a molecular ion $[\mathrm{M}-\mathrm{H}]^{-}$at $\mathrm{m} / \mathrm{z} 191$, with $\mathrm{MS}^{2}$ fragments at m/z $173\left[\mathrm{M}-\mathrm{H}-\mathrm{H}_{2} \mathrm{O}\right]^{-}$and at m/z $127\left[\mathrm{M}-\mathrm{H}-\mathrm{CO}-2 \mathrm{H}^{2} \mathrm{O}\right]^{-}$(Gouveia \& Castilho, 2009), while compound 6 had MM $168 \mathrm{Da}$, gave $[\mathrm{M}-\mathrm{H}-\mathrm{COO}]^{-}(\mathrm{m} / \mathrm{z} 123)$ and $\left[\mathrm{M}-\mathrm{H}-\mathrm{COO}-\mathrm{H}_{2} \mathrm{O}\right]^{-}(\mathrm{m} / \mathrm{z}$ $105)$ as $\mathrm{MS}^{2}$ fragments. It was therefore identified as vanillic acid, a phytochemical identified in caper fruit aqueous extract possessing anti-inflammatory effects (H. Zhou, et al., 2010). The occurrence of this acid has been previously reported in caper berries (Francesca et al., 2016).

Compound 4 (MM 284) fragmented given an ion at m/z 151 as base peak [M-132-H] ${ }^{-}$and was putatively identified as a pentose derivative of vanillin. 

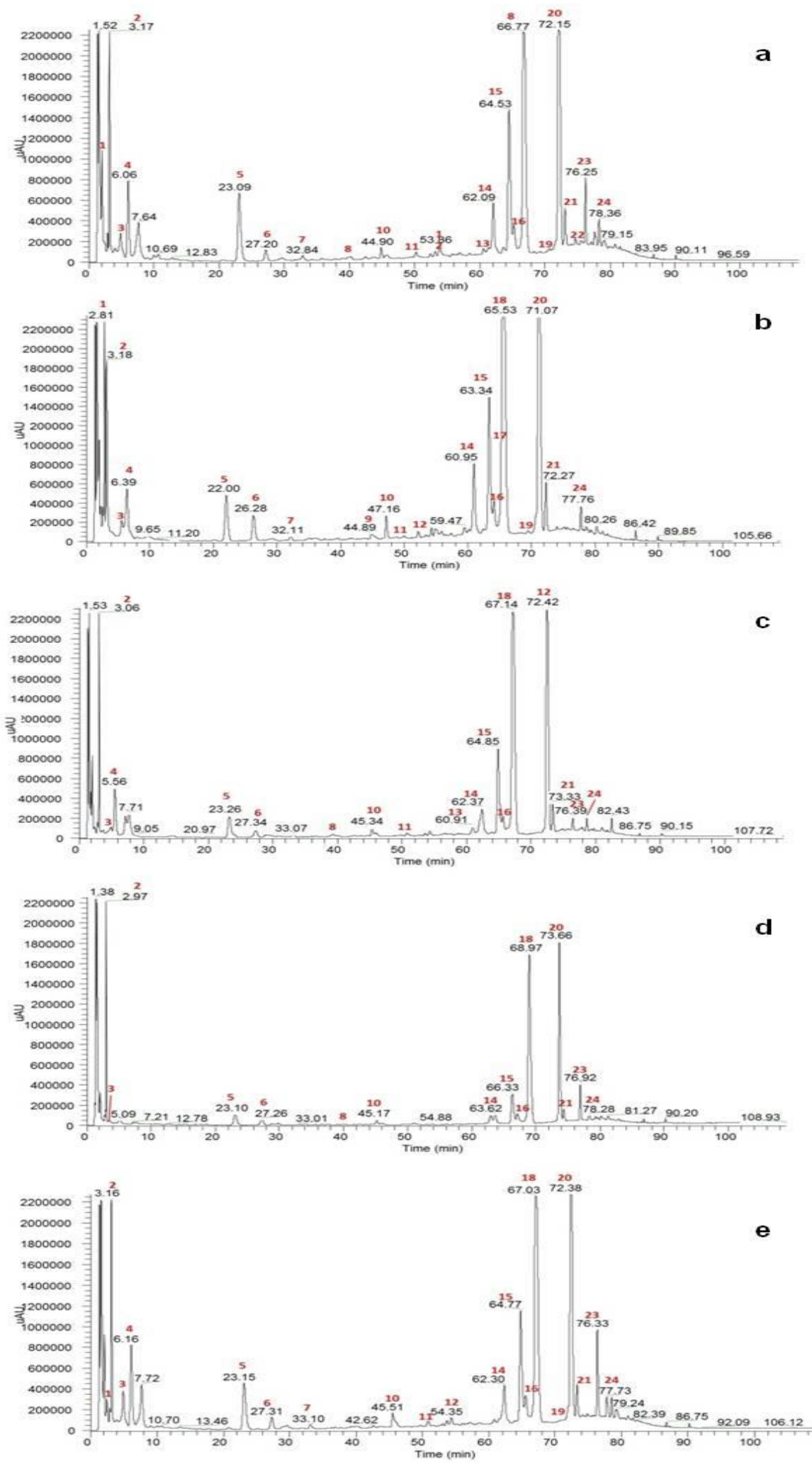

Figure 27. HPLC-PDA chromatograms (200-600 nm) of the tested caper accessions (a-Scauri; b-Barone; c-Rekhale; d-Bugeber; e-Tracino). 
Table 3. Summary of LC-ESI-MS ${ }^{\mathrm{n}}$ data for metabolites identified in capers.

\begin{tabular}{|c|c|c|c|}
\hline Peak No. & $\mathrm{m} / \mathrm{z}$ & $\mathrm{MS}^{\mathrm{n}} m / z$ & Compound \\
\hline \multirow[t]{2}{*}{$1^{\mathrm{b}, \mathrm{c}}$} & $361^{+}$ & $\operatorname{MS}^{2}[361]: 199(100)$ & Syringoil-hexoside \\
\hline & 359 & $\operatorname{MS}^{2}[359]: 197(100), 153(30)$ & \\
\hline $2^{*}$ & 191 & $\operatorname{MS}^{2}[191]:$ 173(40), 127(15), 111(100) & Quinic acid \\
\hline $3^{c}$ & $222^{+}$ & $\operatorname{MS}^{2}[222]: 191(100), 160(70)$ & Cappamensin A \\
\hline $4^{\mathrm{b}}$ & 283 & $\operatorname{MS}^{2}[283]: 151(100)$ & Vanillin pentoside \\
\hline 5 & 332 & $\begin{array}{l}\operatorname{MS}^{2}[332]: 275(15), 259(50), 195(10), 163(20), \\
97(100)\end{array}$ & Glucocapparin \\
\hline $6^{*}$ & 167 & $\operatorname{MS}^{2}[167]: 123(100), 105(65)$ & Vanillic acid \\
\hline $7^{\mathrm{b}, \mathrm{c}}$ & $495^{+}$ & $\operatorname{MS}^{2}[495]: 464(100), 274(40)$ & Isoprincepin \\
\hline $8^{\mathrm{b}, \mathrm{e}}$ & 431 & $\operatorname{MS}^{2}[431]: 285(100), 284(45), 257(60), 255(25)$ & Kaempferol-7-O-rhamnoside \\
\hline $9^{b, c, d, e}$ & 450 & $\mathrm{MS}^{2}[450]: 386(80), 275(45), 195(100), 96(30)$ & Glucoalyssin \\
\hline 10 & $436^{+}$ & $\operatorname{MS}^{2}[436]: 348(45), 291(100), 263(28)$ & Cadabicine \\
\hline $11^{\mathrm{b}, \mathrm{e}}$ & 372 & $\operatorname{MS}^{2}[372]: 275(25), 195(100), 163(20), 96(30)$ & Gluconapin \\
\hline $12^{\mathrm{b}, \mathrm{c}}$ & 463 & $\begin{array}{l}\operatorname{MS}^{2}[463]: 383(10), 285(5), 259(50), 195(100), \\
96(30),\end{array}$ & 4-hydroxy-glucobrassicin \\
\hline $13^{\mathrm{b}, \mathrm{d}, \mathrm{e}}$ & 755 & $\begin{array}{l}\mathrm{MS}^{2}[755]: \text { 609(100), 431(68), 285(10) } \\
\text { MS }^{3}[609]: 285(100), 284(80), 257(65)\end{array}$ & $\begin{array}{l}\text { Kaempferol-3-O-rhamnosyl-7-O-glucosyl- } \\
\text { glucoside }\end{array}$ \\
\hline 14 & 609 & $\begin{array}{l}\mathrm{MS}^{2}[609]: 463(55), 301(100), 300(65), 271(15), \\
\text { 255(25) }\end{array}$ & Quercetin-7- $O$-neohesperidoside \\
\hline 15 & 739 & $\begin{array}{l}\operatorname{MS}^{2}[739]: \text { 593(40), 431(100), 284(5) } \\
\operatorname{MS}^{3}[431]: \text { 285(60), 284(100) }\end{array}$ & $\begin{array}{l}\text { Kaempferol-3- } O \text {-neohesperidoside-7- } O \text { - } \\
\text { rhamnoside }\end{array}$ \\
\hline $16^{\mathrm{e}}$ & 593 & $\operatorname{MS}^{2}[755]:$ 447(35), 285(70), 284(100) & Kaempferol-3-O-neohesperidoside \\
\hline $17^{b, c, d, e}$ & 463 & $\operatorname{MS}^{2}[463]: 301(100), 300(70)$ & Quercetin-7-O-glucoside \\
\hline 18 & 609 & $\begin{array}{l}\mathrm{MS}^{2}[609]: 463(55), 301(60), 300(100), 271(35), \\
255(15)\end{array}$ & Quercetin-3-O-neohesperidoside \\
\hline $19 * \mathrm{c}, \mathrm{d}$ & 447 & $\mathrm{MS}^{2}[477]: 285(60), 284(100), 257(10,255(40)$ & Kaempferol-3-O-glucoside \\
\hline $20^{*}$ & 593 & $\mathrm{MS}^{2}[755]:$ 447(55), 285(100), 284(45) & Kaempferol-7-O-neohesperidoside \\
\hline 21 & 447 & $\begin{array}{l}\mathrm{MS}^{2}[447]: \text { 275(15), 259(60), 227(10), } \\
\text { 195(100),163(10), 97(60) }\end{array}$ & Glucobrassicin \\
\hline $22^{\mathrm{a}, \mathrm{b}, \mathrm{c}}$ & 623 & $\begin{array}{l}\mathrm{MS}^{2}[623]: 477(25), 315(100) \\
\operatorname{MS}^{3}[315]: 300(100)\end{array}$ & Isorhamnetin-7-O-neohesperidoside \\
\hline $23^{\mathrm{a}}$ & 422 & $\begin{array}{l}\mathrm{MS}^{2}[422]: 342(24), 275(100), 259(20), \\
\text { 195(10),96(10) }\end{array}$ & Gluconasturtin \\
\hline 24 & 668 & $\mathrm{MS}^{2}[668]:$ 604(100), 437(10), 421(20) & Glucosides of 9-methylsulfinyl-nonylglucosinolate \\
\hline
\end{tabular}

Compounds are reported in order of elution. *Compared with standard compound; ${ }^{*}$ indicates positive ionization; ${ }^{a}$ Not found in Barone; ${ }^{b}$ not found in Bugeber; ${ }^{\mathrm{c}}$ not found in Rekale; ${ }^{\mathrm{d}}$ not found in Scauri; ${ }^{\mathrm{e}}$ not found in Tracino.

Six kaempferol derivatives were detected of which three present in all fermented capers accessions. Compound 8 showed a molecular ion at $\mathrm{m} / \mathrm{z} 431$ and it was detected in Scauri, Rekhale, and Bugeber capers. In $\mathrm{MS}^{2}$ it showed the base peak at m/z 285 due to the loss of 146 amu, deriving from the fragmentation process of heterolytic cleavage of deprotonated flavonoid glycosided (Lu et al., 2010; Jin et al., 2010); a low abundant secondary ion at $\mathrm{m} / \mathrm{z} 284$ corresponding to the radical aglycone ion and deriving from a hemolytic cleavage was also present. In addition, the $\mathrm{MS}^{2}$ spectrum disclosed an ion at $\mathrm{m} / \mathrm{z} 257$ that was more abundant than the one at $\mathrm{m} / \mathrm{z} 255$. These features are characteristic of kaempferol-7-O-rhamnoside.

Compound 13, found only in Scauri and Rekhale, responded to negative ionization as $\mathrm{m} / \mathrm{z} 755$. The presence of m/z 609 and $\mathrm{m} / \mathrm{z} 431$ due to the loss of a pentose and a disaccharidic residue 
from the precursor ion, respectively, indicates that these two residues are located at different position of the aglycone. Furthermore, a much smaller relative abundance of the product ion at $\mathrm{m} / \mathrm{z} 431$ than the ion at $\mathrm{m} / \mathrm{z} 609$, indicates that the former should be located at the $3-\mathrm{O}$ of the aglycone. $\mathrm{MS}^{3}$ experiment produces ion at $\mathrm{m} / \mathrm{z} 285$ as molecular ion confirming the linkage of disaccharide to the $\mathrm{C} 7$ of the flavonol, and ion at $\mathrm{m} / \mathrm{z} 284$ as secondary ion. The combination of these structural features allowed us to propose kaempferol 3-O-rhamnosyl-7-O-glucosylglucoside structure for this compound (Kachlicki et al., 2008; Kerhoas, \& Stobiecki, 2008; Shahat et al., 2005).

Following the same approach, it was possible putatively identify compound 15 (present in all capers) as kaempferol-3-O-neohesperidoside-7-O-rhamnoside; in fact, the fragmentation gave an ion at $\mathrm{m} / \mathrm{z} 431$ as base peak and ions at m/z 593, 285, and 284 as secondary peaks. The subsequent fragmentation of the ion at $\mathrm{m} / \mathrm{z} 431$ gave a higher intensity for the ion at $\mathrm{m} / \mathrm{z} 284$ than for the ion at $\mathrm{m} / \mathrm{z} 285$, indicating the linkage between rhamnosyl residue and $\mathrm{C} 7$ of the aglycone.

Compounds 16 and 20 had the same molecular mass of 594 Da; based on their similar UV and MS spectra we concluded that they are isobaric compounds. They produced the $\mathrm{MS}^{2}$ base peaks at $\mathrm{m} / \mathrm{z} 284$ and 285, respectively, following the loss of the rhamnosyl-glucose residue (308 amu) from C3 on kaempferol for compound 16 and from C7 for compound 20. The m/z 447 ion corresponding to the loss of rhamnose residue was also present in both spectra and due to fact that the relative abundances of the two ions were strikingly different, a $1 \rightarrow 2$ linkage between the monosaccharides was confirmed (Ma et al., 2001). The fragmentation patterns allowed attribution of compound 16 to kampferol-3-O-neohesperidoside and of compound 20 to kaempferol-7-O-neohesperidoside.

Based on the comparison of retention time, UV-vis spectra, and MS/MS fragments with the commercial standard, kaempferol-3-O-glucoside (19) was identified in Scauri, Barone, and Tracino.

All caper accessions contained three quercetin derivatives: quercetin-7-O-neohesperidoside (14), quercetin-7-O-glucoside (17), and quercetin-3-O-rutinoside (18, rutin). The relative abundance of the radical aglycone ion correlated closely with the glycosylation position and this let us to discriminate between $3-\mathrm{OH}$ and $7-\mathrm{OH}$ position. Furthermore, the relative abundance of the two ions deriving from the loss of rhamnose and glucosyl-rhamnoside let us to discriminate between the presence of neohesperidoside and rutinoside derivatives.

Finally, an isorhamnetin derivative was detected in Scauri and Tracino (22). According to the literature (Carazzone et al., 2013; Stintzing et al., 2004), assignment of the aglycone to 
isorhamnetin was based on $\mathrm{MS}^{3}$ fragmentation. In fact, while formation of a m/z 165 A-ring fragment as the most prominent ion is a peculiarity of rhamnetin, isorhamnetin glycosides produce an intense m/z 300 fragment in the $\mathrm{MS}^{3}$ event. Compound 22 showed in $\mathrm{MS}^{2}$ spectrum a base peak at $\mathrm{m} / \mathrm{z} 315$ formed by the loss of two sugar moieties $1 \rightarrow 2$ linked [M-H-308]- on the same phenolic position, and m/z 300 fragment in the $\mathrm{MS}^{3}$ event; therefore it was identified as isorhamentin-7-O-neohesperidoside. Siracusa et al. (2011) previously reported the presence of an isobaric compound in an aqueous infusion of capers, isorhamnetin-3-O-rutinoside.

The hydrophylic extracts contained also some other secondary metabolites than polyphenols, especially glucosinolates that could be best extracted using aqueous methanol solution at 70-80 ${ }^{\circ} \mathrm{C}$. Compound 3 produced a molecular ion at $\mathrm{m} / \mathrm{z} 222$ in positive ionization mode. It displayed a fragmentation pattern producing a base peak at m/z 191 and a secondary peak with high intensity at $\mathrm{m} / \mathrm{z} 160$ due to the loss of one and two methoxyl group, respectively. By comparison with literature data, it was putatively identified as cappamensin A, a compound with in vitro inhibitory activity of tumor cell replication, isolated from Capparis sikkimensis (Wu et al., 2003). The alkaloid cadabicine (10) showing a pseudomolecular ion at $\mathrm{m} / \mathrm{z} 436\left[\mathrm{M}^{+} \mathrm{H}\right]^{+}$, fragmented leading to $\mathrm{m} / \mathrm{z} 348$ (due to the loss of the neutral group 14-diaminobutane after the cleavage of the ring), m/z 291 as base peak (by the loss of the 3-aminopropene group from $\mathrm{m} / \mathrm{z}$ 348), and $\mathrm{m} / \mathrm{z} 263$, according to literature data (Khatib et al., 2016). Putatively assignment of compound 7 to a sesquineolignan was based on its pattern of fragmentation: $\mathrm{m} / \mathrm{z} 464$ M $^{-}$ $\left.\mathrm{CH}_{2} \mathrm{OH}^{+} \mathrm{H}\right]^{+}$and $\mathrm{m} / \mathrm{z} 274$ (Luecha et al., 2009).

As regards glucosinolate, deprotonated ions are generally decomposed into specific fragments, which correspond to the fragment ions from the thioglucoside (m/z 195, 275, 227, and 163), the side chain, and the sulphate anion $\left(\left[\mathrm{HSO}_{4}\right]^{-}, \mathrm{m} / \mathrm{z} 97\right)$. Due to these features, glucocapparin (5), glucoalyssin (9), gluconapin (11), 4-hydroxy-glucobrassicin (12), glucobrassicin (21), gluconasturtin (23), and glucosides of 9-methylsulfinyl-nonylglucosinolate were identified (24) (Bianco et al., 2012; Lin et al., 2014). Details of the mass spectra of the major fragments registered in negative ionization mode are shown in Table 1. These compounds are largely responsible for the distinctive flavors of capers, and usually glucocapparin is the main representative accounting for about $80-90 \%$ of the total glucosinolate (Matthäus \& Özcan, 2002).

\subsubsection{Kaempferol and quercetin derivatives quantification}

In Table 4 the concentrations of kaempferol and quercetin derivatives in five capers from Pantelleria Island from different areas of collection were reported. Our results agree with those 
reported by Inocencio et al. (Inocencio et al., 2000), indicating capers as very rich source of flavonols.

The levels of both flavonol derivatives varied considerably among the analyzed samples. Kaempferol derivatives are more representative than quercetin derivates with kaempferol-3-Oneohesperidoside-7-O-rhamnoside and kaempferol-7-O-neohesperidoside as predominant compounds.

Table 4. Concentration (mg equivalents/100 g FW caper) of kaempferol and quercetin derivatives in five different caper accessions determined by HPLC-DAD. Values are means $( \pm$ standard deviation) of three samples.

\begin{tabular}{|c|c|c|c|c|c|}
\hline Compound & Scauri & Barone & Rekhale & Bugeber & Tracino \\
\hline Kaempferol-7-O-rhamnoside & $58,94 \pm 0,18$ & - & $14,26 \pm 0,17$ & $7,87 \pm 0,32$ & - \\
\hline $\begin{array}{l}\text { Kaempferol-3-O-rhamnosyl-7-O- } \\
\text { glucosyl-glucoside }\end{array}$ & $48,48 \pm 0,18$ & - & $6,46 \pm 0,15$ & - & - \\
\hline $\begin{array}{l}\text { Kaempferol-3-O-neohesperidoside-7-O- } \\
\text { rhamnoside }\end{array}$ & $266,90 \pm 0,65$ & $232,94 \pm 2,46$ & $55,82 \pm 0,5$ & $85,96 \pm 0,37$ & $12,99 \pm 0,30$ \\
\hline Kaempferol-3-O-neohesperidoside & $21,14 \pm 0,26$ & $14,59 \pm 0,13$ & $11,42 \pm 0,06$ & $5,41 \pm 0,25$ & - \\
\hline Kaempferol-3-O-glucoside & $10,83 \pm 0,09$ & $13,82 \pm 0,25$ & - & - & $2,51 \pm 0,17$ \\
\hline Kaempferol-7-O-neohesperidoside & $267,93 \pm 0,46$ & $190,42 \pm 2,52$ & $175,48 \pm 1,08$ & $104,75 \pm 0,56$ & $226,13 \pm 0,50$ \\
\hline Quercetin-7-O-neohesperidoside & $108,30 \pm 0,84$ & $91,47 \pm 22,91$ & $42,97 \pm 0,43$ & $22,39 \pm 0,23$ & $70,11 \pm 0,66$ \\
\hline \multicolumn{6}{|l|}{ Quercetin-7-O-glucoside } \\
\hline Quercetin-3-O-neohesperidoside & $347,38 \pm 0,58$ & $367,14 \pm 1,01$ & $229,18 \pm 0,58$ & $117,95 \pm 1,45$ & $296,35 \pm 1,11$ \\
\hline
\end{tabular}

As shown in Figure 28, the concentration of kaempferol derivatives in Scauri and Barone is significantly higher then in other accessions $(\mathrm{p}<0.01)$; Rekhale and Tracino showed similar levels, while Bugeber was the poorest. Considering the levels of quercetin derivates, also in this case Scauri and Barone were the richest, showing similar values of concentrations, which were significantly higher than Rekhale and Bugener $(\mathrm{p}<0.01)$.

Our data did not totally agree with those recently reported by Maldini et al (2016); in fact, glucocapparin was the most abundant metabolite present in different part (leaves, buds and flowers) of wild and cultivated C. spinosa collected from different area of Sardinia (Italy), with 
values ranging from 112 to $364 \mathrm{mg} / 100 \mathrm{~g}$ Dry Weight (DW), followed by rutin (the highest value registered was $126 \mathrm{mg} / 100 \mathrm{~g} \mathrm{DW}$ ), 4-hydroxyglucobrassicin (the highest value was 42 $\mathrm{mg} / 100 \mathrm{~g} \mathrm{DW}$ ), and isorhamnetin 3-O-rutinoside (the highest value was $24 \mathrm{mg} / 100 \mathrm{~g} \mathrm{DW}$ ). The different chemical profiles and especially the quantitative analysis results indicated that the polyphenol contents (but also the glucosinolate derivatives contents) in the samples from different origins are dissimilar. To further confirm and explore the components, which are responsible for the classification of capers origin, principal component analysis (PCA), one of most powerful tools in explorative data analysis, was applied in this study (Zhu et al., 2011).
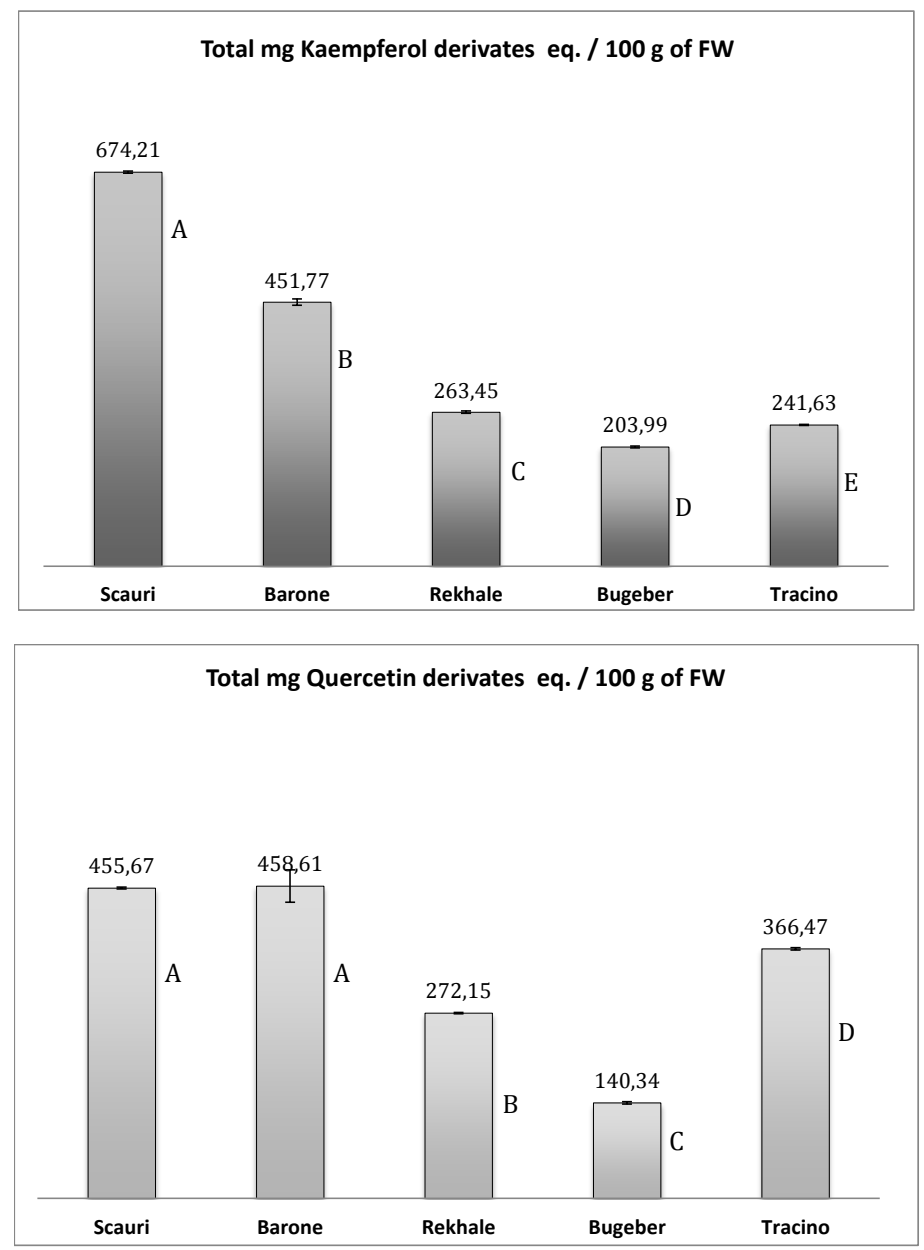

Figure 28. Comparison of kaempferol and quercetin derivates amount in $100 \mathrm{~g}$ of Fresh Weight (FW) of the different accessions. The data are expressed as mean \pm S.D. The statistical differences were evaluated by variance analysis (ANOVA), and means separation was conducted using the Tukey test: $\mathrm{p} \leq 0.01$.

PCA is a statistical approach to facilitate an understanding into the causes and effects indicated by the relationship of multivariate dataset, the core of this method is to generate new principal 
components (PCs) which are independent of the original variables but shows linear combinations of them, each PC consists of a set of values called "score" defining the position of each sample in the new coordinate space, and the other set of values called "loading" that gives the relative contributions of each variable in calculating the scores (Ni et al., 2008; Xie et al., 2008). Content of kaempherol and quercetin derivates detected in the five samples were inputted into the software S-PLUS 2000 (MathSoft Inc.), by this method. After applying PCA, score and loading plots were generated. The score plot shows the samples of capers are clearly divided into two clusters corresponding to the content of analyzed polyphenols (Figure 29); The first component (PC1) explains the $75,2 \%$ of variance while the second component (PC2) the $19,71 \%$. The loading plot, shown in Figure 30, demonstrates that picks 15, 20 and 17+18 might contribute most to separating Barone and Scauri.

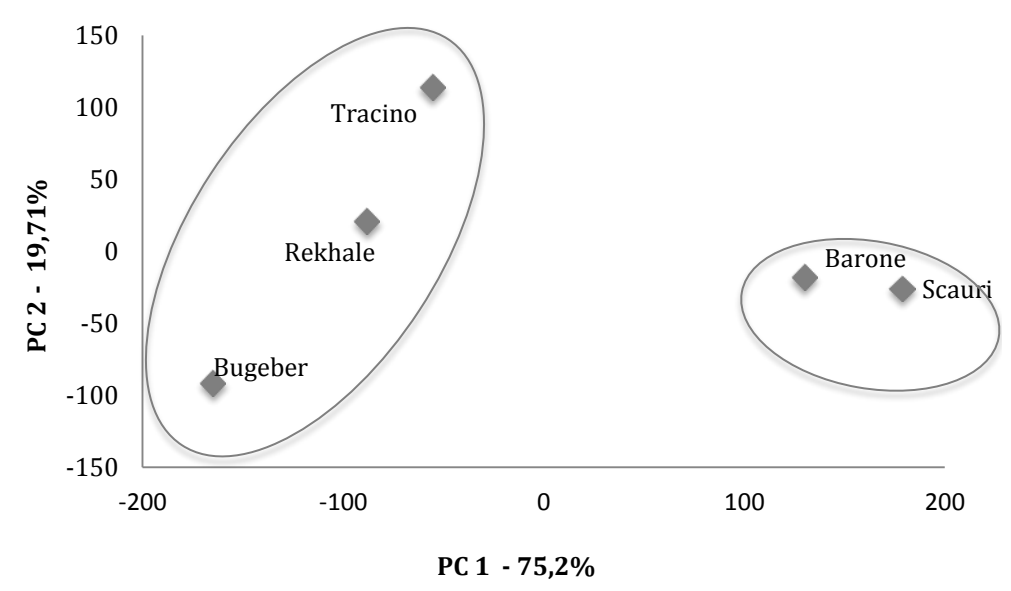

Figure 29. Principal Component Analysis: score plot obtained by covariance method.

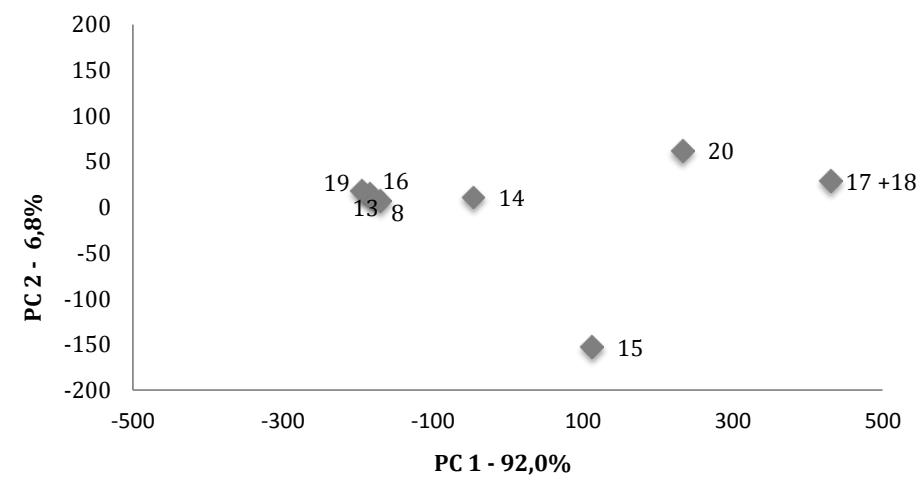

Figure 30. Principal Component Analysis: loading plot obtained by covariance method. 
Correlating this two plot, we can conclude that peaks n. 15-20-17 and 18 (to check the correspondence of peck n. and molecule name see Table n. 3), allow differentiation of Scauri and Barone from other samples tested.

In our study, many bioactive components were detected and high level of quercetin and kaempferol derivates were registered. These polyphenols are known to possess antioxidant activity; however, as the antioxidant activity is a consequence of the synergism between different phenolic compounds and it cannot be attributed specifically to one constituent (Arnous et al., 2002; Lee et al., 2003), commercial standards of the identified compounds in our accessions could be used to study their potential contribution to antioxidant activity, testing them in different assays. The standard compounds could be tested at concentrations selected in a range of values including those reported to occur in plant materials, both alone and also in different mixtures.

\subsection{Conclusion}

Caper is a good source of phenolic compounds, which are known to provide health-improving benefits, due to their various biological activities (antioxidant, anticarcinogenic, antimicrobial, and antimutagenic). The present study reports that capers, unopened flower buds of Capparis spinosa L., collected and processed in Pantelleria Island (Sicily, Italy) represent a good source of antioxidant compounds. This typical Mediterranen food product contains a high level of phenolic compounds, especially in flavonoids content, which explains its high antioxidant activity. This species has been characterized through the detection, isolation and quantitative evaluation of some chemical markers (polyphenols and glucosinolates). The chemical investigation showed a different composition between the five collection zones.

The variations showed by the tested samples regarding the phytochemical composition could be attributed to the chemical-physical properties of the different genotypes, to the composition of the soil and to the influence of other factors, such as geographical coordinates, and solar and windy exposure. 


\section{CHAPTER 3}

\section{Chemical characteristics and Flavor profile of capers (Capparis spinosa L.) by Electronic Nose, SPME/GC-MS, Electronic Toungh tecniques.}

\subsection{Abstract}

C. spinosa $\mathrm{L}$. is one of the most commonly found aromatic plants in Mediterranean cooking. Capers are used in the Mediterranean cuisine as flavoring for meat, vegetable and other foods. This paper presents aroma characteristic and flavor profile of Capparis spinosa L., before and after salting, by GC-MS and Electronic Nose technique. Moreover, Electronic Toungh was used to investigate the concentration of some ions, electric conductivity and $\mathrm{pH}$ by liquid sensors.

Five different caper samples (the floral buds of the plants) from Pantelleria (Italy) were analyzed. Headspace aroma volatiles were extracted and analyzed by SPME/GC-MS and Electronic Nose - $\operatorname{EOS}^{835}$ (Sacmi, Imola-Italy). Fifty compounds were identified. All the data were statistically correlated. Multivariate analysis applied to the volatile and sensory data allowed distinguishing the samples in relation to the area of origin.

\subsection{Introduction}

Attempts to relate sensory analysis data to specific chemicals such as volatile compounds are reported in the literature (Chambers and Koppel, 2013). Flavor analysis usually takes one of two forms, sensory or instrumental. Sensory descriptive methods used for testing are highly reliable and consistent and obviously identify the human perception of flavor. Sensory analysis is the preferred method for odor evaluation (Maarse H., 1991).

Instrumental methods can give a correlation between individual compounds and their flavors. Those methods are based on separation, identification, and quantification of compounds either in headspace or in actual product matrix (Chambers and Koppel., 2013).

C. spinosa $\mathrm{L}$. is one of the most commonly found aromatic plants in Mediterranean cooking: the fresh aerial parts, including the fruit and the flower buds, are present in the vinegar or brined and eaten pickled (Zargari, 1986). The floral buds of this plant are commonly named capers; they are harvested in spring before they blossom and are usually processed in brine. The processed buds have long been used in recipes for salads, pasta, meat, sauces and garnishes to add a pungent 
spicy flavor and aroma to food and have gained a considerable importance in the food industry (Giuffrida et al., 2002).

Capers can not be eaten fresh because of the bitter taste conferred by associates glucosinolates, glucocapparina and glucocleomina. The button flowering, then, collected just before the blossom, is subjected to the stabilization treatment in brine or salt, in order to decrease the content of such ingredient. The stabilization process, by changing the osmolarity of the plant cell, causes the release of myrosinase (thioglucoside-glucohydrolase) enzyme contained in the lysosomes, resulting in enzymatic hydrolysis of glucosinolates, and production, in a simultaneous fermentation process, of few different products. Methyl isothiocyanate is the most abundant; particularly volatile, it is responsible of the smell pungent and spicy aroma and flavor typical of the caper (Ahmed et al., 1972).

Many studies have confirmed that regular consumption of capers prevents the risk of the two major degenerative diseases cause of death: cancer and cardiovascular diseases (Tlili et al., 2011). Responsible of this are the bioactive components contained as isothiocyanates, indoles, and flavonoids, as well as vitamins, beta-carotene and ascorbic acid. Isothiocyanates are aromatic compounds containing sulfur, accountable for the odor characteristic that is emitted, for example, by cooking broccoli (Afsharypuor et al., 1998). The glucosinolates, their hydrolysis products and myrosinase are easily inactivated by heat. In fact, not surprisingly the smell of cabbage is all the more intense the more prolonged is cooking, due to the release of sulfur. This would justify an optimal consumption of these vegetables raw or after steaming. Indoles, characterized by the presence of nitrogen in the molecule also give the product an unpleasant smell. These phenolic compounds, among which the most represented is the indole-3-carbinol, bind to potential carcinogens before they reach their target such as DNA thus indirectly blocking the carcinogenic process and promote the activity of detoxifying enzymes. The indole-3-carbinol helps prevent breast cancer because it decreases the activity of estradiol, the precursor of estrogen and maker of hormone-dependent tumors therefore.

In this section, we present a study concerning the chemical composition of fresh and salted capers using liquid sensors; moreover, sensory and head-space aroma volatiles analysis were performed using SPME-GC-MS and Electronic Nose for the characterization of capers flavors profile.

We present here data concerning different accessions of Capparis spinosa from five different areas of Pantelleria Island $\left(36^{\circ} 47^{\prime 2} 7^{\prime \prime} \mathrm{N} 11^{\circ} 5938^{\prime \prime} \mathrm{E}\right.$ - Trapani, Sicily, Italy): Scauri, Rekhale, Tracino, Barone and Bugeber. 


\subsection{Materials and methods}

\subsubsection{Plant Material}

In our study the local "Cooperativa Agricola Produttori Capperi" provided capers. Harvesting of flower buds occurred in the month of August 2014: an amount of the fresh samples was stored at $-20^{\circ} \mathrm{C}$, and to a second amount of sample was added salt immediately after harvesting. The usual commercial processing procedure for preparing pickled capers consists in a pretreatment in which raw capers are mixed with marine salt (25\% by weight) for about ten days; during this time brine is formed and fermentation takes place. At the end of this stage the brine is discarded and the capers are treated with marine salt (15\% by weight) for another ten days obtaining the finished product. These fermented samples were stored at $4{ }^{\circ} \mathrm{C}$ until time of analysis.

\subsubsection{Electronic Tongue procedure}

Five grams of salted capers were washed with MilliQ water, cut finely with scissors, and after adding $10 \mathrm{ml}$ of MilliQ water, were powdered with the homogenizer. To know basic status of the respective suspension agents used in this study, samples were analyzed using LAQUAtwin meters (Horiba, Kyoto, Japan). Seven parameters were measured: pH, conductivity, and ion content $\left(\mathrm{Ca}^{2+}, \mathrm{NO}^{3-}, \mathrm{K}^{+}, \mathrm{Na}^{+}\right.$and Salt).

\subsubsection{Electronic Nose procedure}

A commercial Electronic Nose, $\operatorname{EOS}^{835}$ (Sacmi, Imola, Italy) equipped with six different MOS (Metal Oxide Semiconductors) sensors (Table 5) has been used for the experiments.

Table 5. MOS Sensor array configuration of the $\operatorname{EOS}^{835}$ (Sacmi Imola, Italy)

\begin{tabular}{ll}
\hline $\mathbf{N}^{\circ}$ Sensor & Material \\
\hline 1 & $\mathrm{SnO}_{2}$ cat $\mathrm{SiO}_{2}$ \\
2 & $\mathrm{SnO}_{2}$ cat $\mathrm{Ag}$ \\
3 & $\mathrm{SnO}_{2}$ cat $\mathrm{Mo}$ \\
4 & $\mathrm{SnO}_{2}$ cat $\mathrm{Ag}$ \\
5 & $\mathrm{WO}_{3}$ \\
6 & $\mathrm{SnO}_{2}$ \\
\hline
\end{tabular}

The $\operatorname{EOS}^{835}$, above described, was used to characterize the aromatic fingerprint of fresh and salted capers. Samples were prepared in triplicate, cutting $2 \mathrm{~g}$ of capers, with scissors and 
placing them in sealed vials. Samples were conditioned in the oven at $40{ }^{\circ} \mathrm{C}$ for 5 minutes under shaking. After reaching the equilibration state, the headspace of the vial (4 ml) was drawn in by using an automated sampling system HT200H (HTA s.r.l., Brescia, Italy). Then, the headspace was injected it into the $\operatorname{EOS}^{835}$, $\mathrm{s}$ injector and carried out by a continuous flow of $10 \mathrm{ml} / \mathrm{min}$ of air to the sensors chamber kept at a constant temperature of $50{ }^{\circ} \mathrm{C}$ and relative humidity of $0 \%$. When the aroma went through the sensors layer, the initial resistance (R0) fell down to a minimum value $(\mathrm{R})$. The measure duration was $34 \mathrm{~min}$ (Before time $=2 \mathrm{~min}$, During time $=2$ min and After time $=30 \mathrm{~min}$ ). A set of six values $\{\mathrm{R} 1-\mathrm{R} 6\}$ was obtained in each measurement and data pre-processing was carried out. The feature Delta $=\mathrm{R} 0-\mathrm{R}$ was extract from the sensors response curve. Principal Component Analysis (PCA) was used as unsupervised statistic method to reduce the dimensional space and plot the data, by a correlation matrix of data using Nose Pattern Editor (Sacmi Imola) and with S-PLUS 2000 (MathSoft Inc.).

\subsubsection{HS-SPME-GC-MS procedure}

The extraction of volatile compounds was carried out by a HS-SPME (headspace solid phase microextraction) method as described by Romeo et al. 2007, using a DVB/CAR/PDMS fiber, with 50/30 $\mu \mathrm{m}$ film thickness (Supelco, Bellafonte, PA, USA); before the analysis the fiber was preconditioned in the injection port of the GC as indicated by the manufacturer.

For each sample, 2 grams of capers were finely chopped and closed into a $20 \mathrm{ml}$ vial equipped with a "mininert" valve (Supelco, Bellafonte, PA, USA). The vial was kept at $40{ }^{\circ} \mathrm{C}$ and the sample was left to equilibrate for $5 \mathrm{~min}$; then, the SPME fiber was exposed for 25 min to the headspace while maintaining the sample at $40{ }^{\circ} \mathrm{C}$. After sampling the SPME fiber was introduced into the GC injector, and was left for 1 min to allow the analytes thermal desorption. The measurements were carried out with a gas chromatographer with mass spectrometer detector (GC-MS) (GCMS-QP2010, Shimadzu) equipped with a capillary column OMEGAWAX (30 m x $0.25 \mathrm{~mm}$ x $0.25 \mu \mathrm{m}$ ) (Supelco). The GC instrument parameters were: column oven temperature $45^{\circ} \mathrm{C}$, injection temperature $250{ }^{\circ} \mathrm{C}$, injection mode splitless, sampling time $1 \mathrm{~min}$, carrier gas Helium, pressure $69 \mathrm{KPa}$, total flow 7,4 $\mathrm{mL} / \mathrm{min}$, column flow 1,24 mL/min, linear velocity 40,3 $\mathrm{cm} / \mathrm{s}$, ion source temperature $230{ }^{\circ} \mathrm{C}$, interface temperature $250{ }^{\circ} \mathrm{C}$, scan interval $0.12 \mathrm{~s}$, mass range 40-300 m/z. The oven temperature was programmed as follows: an isothermal at $45^{\circ} \mathrm{C}$ for $7 \mathrm{~min}$, then an increase to $80{ }^{\circ} \mathrm{C}$ at a rate of $15^{\circ} \mathrm{C} / \mathrm{min}$, and again an increase at $240{ }^{\circ} \mathrm{C}$ at a rate of $5^{\circ} \mathrm{C} / \mathrm{min}$.

The peaks identification was performed by Lib. Nist (GCMS solution Library, Shimadzu) and by comparison with previous studies on capers (Condurso et al. 2015, Romeo et al. 2007 and 
Afsharypuor et al. 1998). Each measurement was repeated three times. The repeatability of the developed method was determined by analyzing three different samples of the same caper batch under identical experimental conditions. The PCA was performed with the software S-PLUS 2000 (MathSoft Inc.) using a correlation matrix.

\subsection{Results and Discussions}

\subsubsection{Chemical Data}

With Electronic Tongue, an array of 7 single liquid sensor (LACQUATwin ${ }^{\circledR}$ ), seven chemical parameters were measured for salted capers: $\mathrm{pH}$, conductivity, and ion content $\left(\mathrm{Ca}^{2+}, \mathrm{NO}^{3-}, \mathrm{K}^{+}\right.$, $\mathrm{Na}^{+}$and Salt). Chemical data are shown in table 6.

Plant cells need many essential mineral ions for their operation. The potassium $\left(\mathrm{K}^{+}\right)$is a cofactor of many enzymes necessary, for example, for the synthesis of proteins. The calcium $\left(\mathrm{Ca}^{2+}\right)$ has regulatory functions, is a component of the cell wall structure, stabilizes the membranes and controls the movements. The vacuole is the largest store of water and solutes in the plant cell. It mainly contains mineral ions such as $\mathrm{K}^{+}, \mathrm{Cl}^{-}, \mathrm{Na}^{+}, \mathrm{Ca}^{2+}, \mathrm{PO}_{4}{ }^{3-}, \mathrm{NO}^{3-}, \mathrm{SO}_{4}{ }^{2-}$, and water-soluble substances such as monosaccharides, disaccharides and trisaccharides. It contains secondary metabolites, alkaloids, terpenoids and phenols and organic acids (citric acid), glycosides and tannins. Store flavonoid pigments (anthocyanins, flavones, flavanols). The flavonoids, pigments that give the typical color of the plants, and substances such as glycosides protect the plant from predators because they serve as animal repellents (therefore the need to process and store sea salt with fresh floral buttons of the caper for make them edible). Finally, the vacuole is fundamental for the ionic balance and for osmosis adjustment of the plant cell by acting as a support in growth of the plant cell.

These macro and micro elements, that the plant absorbs from the soil, are reflected in the chemical composition of the plants. To understand which parameter could help to correlate sample with origin area, statistical analysis was performed.

Table 6. Liquid sensor's data obtained and their standard deviations.

\begin{tabular}{|c|c|c|c|c|c|c|c|}
\hline & $\mathrm{pH}$ & $\mathrm{Na}^{+}(\mathrm{ppm})$ & $\mathrm{NO}_{3}^{-}(\mathrm{ppm})$ & $\mathrm{K}^{+}(\mathrm{ppm})$ & Electric Cond. $\mathrm{mS} / \mathrm{cm}$ & $\mathrm{Ca}^{++}(\mathrm{ppm})$ & Salts(\%) \\
\hline SCAURI & $4,1 \pm 0,0$ & na & $3166,7 \pm 57,7$ & $2066,7 \pm 57,7$ & $65 \pm 3,6$ & $303,3 \pm 5,8$ & $7,1 \pm 0,1$ \\
\hline REKHALE & $4,5 \pm 0,0$ & na & $3233,3 \pm 57,7$ & $1200 \pm 0,0$ & $75,7 \pm 0,6$ & $176,7 \pm 5,8$ & $6,83 \pm 0,12$ \\
\hline TRACINO & $4,1 \pm 0,0$ & na & $3133,3 \pm 57,7$ & $1100 \pm 0,0$ & $71,3 \pm 1,5$ & $120 \pm 0,0$ & $6,33 \pm 0,06$ \\
\hline BARONE & $4,2 \pm 0,0$ & na & $3166,7 \pm 57,7$ & $1300 \pm 0,0$ & $73,3 \pm 3,1$ & $163,3 \pm 5,8$ & $6,13 \pm 0,06$ \\
\hline BUGEBER & $4,3 \pm 0,0$ & na & $3500 \pm 100$ & $653,3 \pm 5,8$ & $81 \pm 1,7$ & $143,3 \pm 5,8$ & $7,06 \pm 0,06$ \\
\hline
\end{tabular}


$\mathrm{Na}^{+}$concentration is not expressed for salted samples because it is out of range of the $\mathrm{Na}^{+}$ sensor.

To verify if the quantitative differences in these phytochemicals could allow discrimination among the samples, a multivariate approach was applied to quantitative data. The PCA was applied to the matrix obtained using the quantitative content of each marker compound in each type of samples. The PCA was performed with the software S-PLUS 2000 (MathSoft Inc.) using a correlation matrix. All parameters influence the sample distribution on the PCA plot (Figure $31)$.

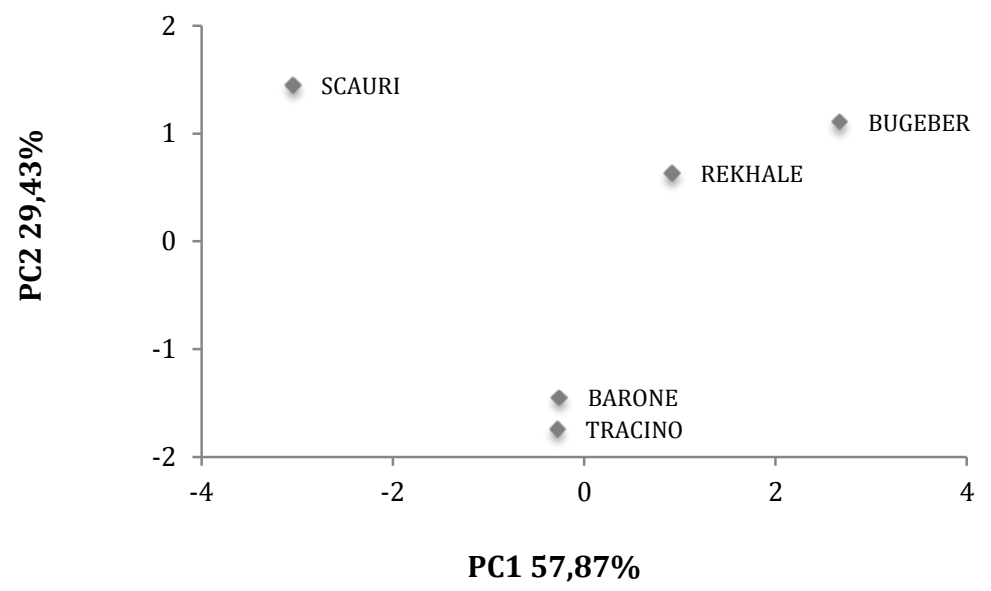

Figure 31. Principal Component Analysis: Score Plot of salted capers. 


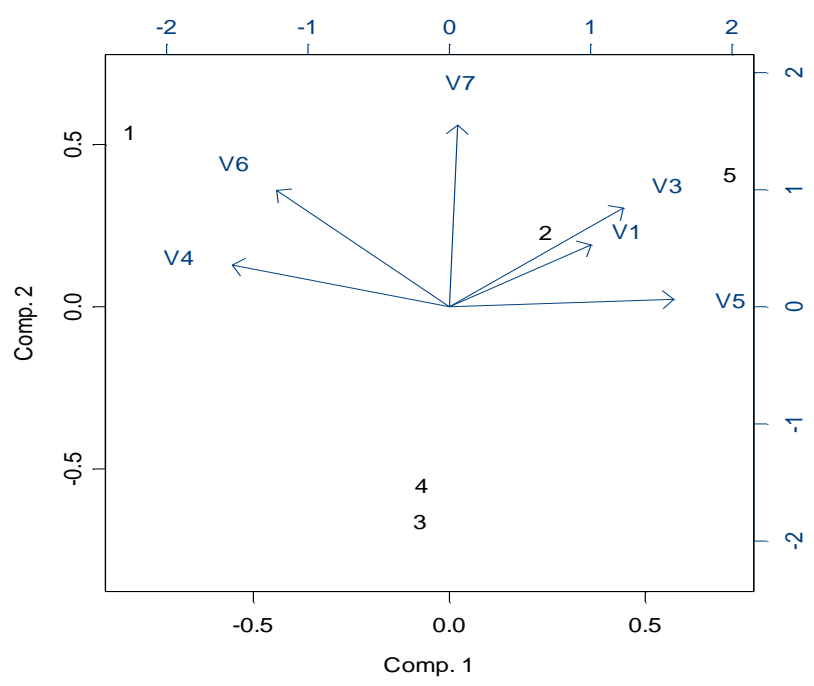

Figure 32. Principal Component Analysis: Biplot of the first and second components of salted capers. Letter "V" indicates a variable $\left(\mathrm{V} 1=\mathrm{Ph}, \mathrm{V} 3=\mathrm{NO}^{3-}(\mathrm{ppm}), \mathrm{V} 4=\mathrm{K}^{+}(\mathrm{ppm}), \mathrm{V} 5=\right.$ conductivity, $\left.\mathrm{V} 6=\mathrm{Ca}^{++}(\mathrm{ppm}), \mathrm{V} 7=\operatorname{Salts}(\%)\right)$, numbers indicate samples $(1=$ Scauri, $2=$ Rekhale, 3=Tracino, 4=Barone, 5= Bugeber).

The first component (PC1) explains the $57,87 \%$ of variance while the second component (PC2) the 29,43\%. As shown, phytochemical values PCA does not allow to reveal significant differences among the geographical origin of the samples.

In order to evaluate the influence of each variable on the classification of the samples, the loading plot obtained for the same dataset was then studied (Figure 32). Sample from Scauri is described better with values of $\mathrm{K}^{+}$and $\mathrm{Ca}^{2+}$, showing the higher value for these two ions. The percentage of salt described with vector number 7, discriminates samples from Tracino and Barone, that shown the lower values $(6,33 \pm 0,06 \%$ and $6,13 \pm 0,06 \%$ respectively). As evidenced from quantitative data and rapidly highlighted from PCA, all caper samples of cultivated $C$. spinosa are not characterized exclusively by liquid sensor.

\subsubsection{Analysis of flavor and aroma volatiles}

Electronic nose could be a very valuable tool to evaluate flavor and aroma volatiles in food. Strengths of the electronic nose include good sensitivity and correlation with data obtained for example with GC-MS. It might have other advantages regarding portability, price, and ease of use. Therefore, it has the potential to move from well-equipped chemical laboratories to industrial routine in-line controls. However, at present ENs shows some downsides that must be overcome. The major limitation of currently available chemical sensor based ENs remains the 
independence (cross-correlation) and selectivity of the sensing devices. Sensors with poor selectivity affect adversely the discriminating power of the array. Moreover, the EN use of semiselective sensors prevents any real identification or quantification of the individual compounds present in the headspace of a food sample, as it can be done with classical analytical techniques, which sometimes can be crucial for the end-user. In the present study, the EN technique was coupled with classical chemical techniques, like gas chromatography with mass spectroscopy (GC-MS) with SPME technique. Figure 33 shows PCA analysis of obtained data using $\operatorname{EOS}^{835}$. The first component (PC1) explains the 90,03\% of variance while the second component (PC2) the 8,2\%. As shown, electronic nose does not allow revealing significant differences among the five samples tested.

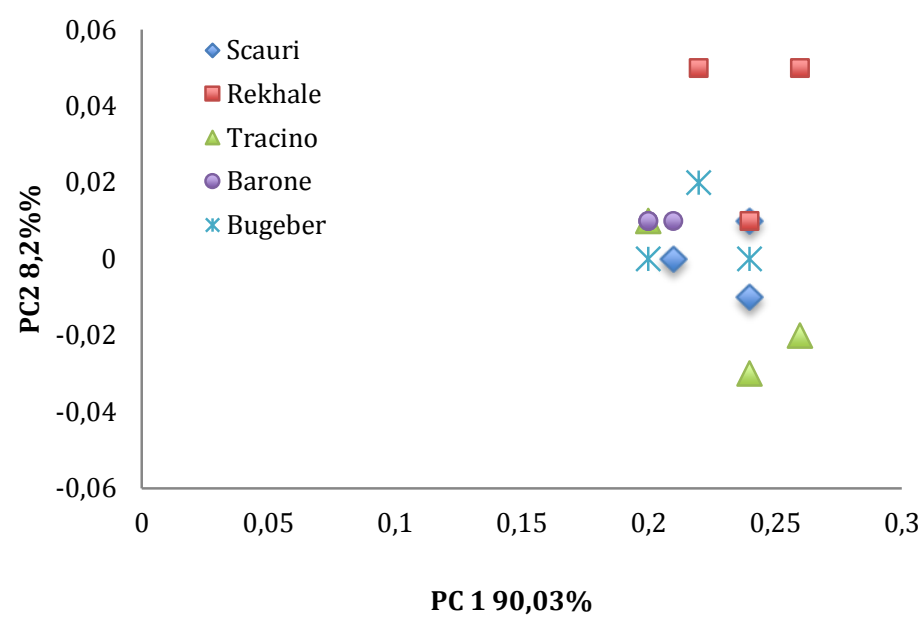

Figure 33. Principal Component Analysis of $\operatorname{EOS}^{835}$ data of salted samples: difference of collection area.

The GC-MS chromatogram of the flavor profile of capers from the island of Pantelleria is shown in Figure 34. We identified 53 different volatile compounds grouped in classes of substances (Table 7). Even if electronic nose not have been underline important difference between five samples analyzed, chromatograms show differences in their molecular patterns. 

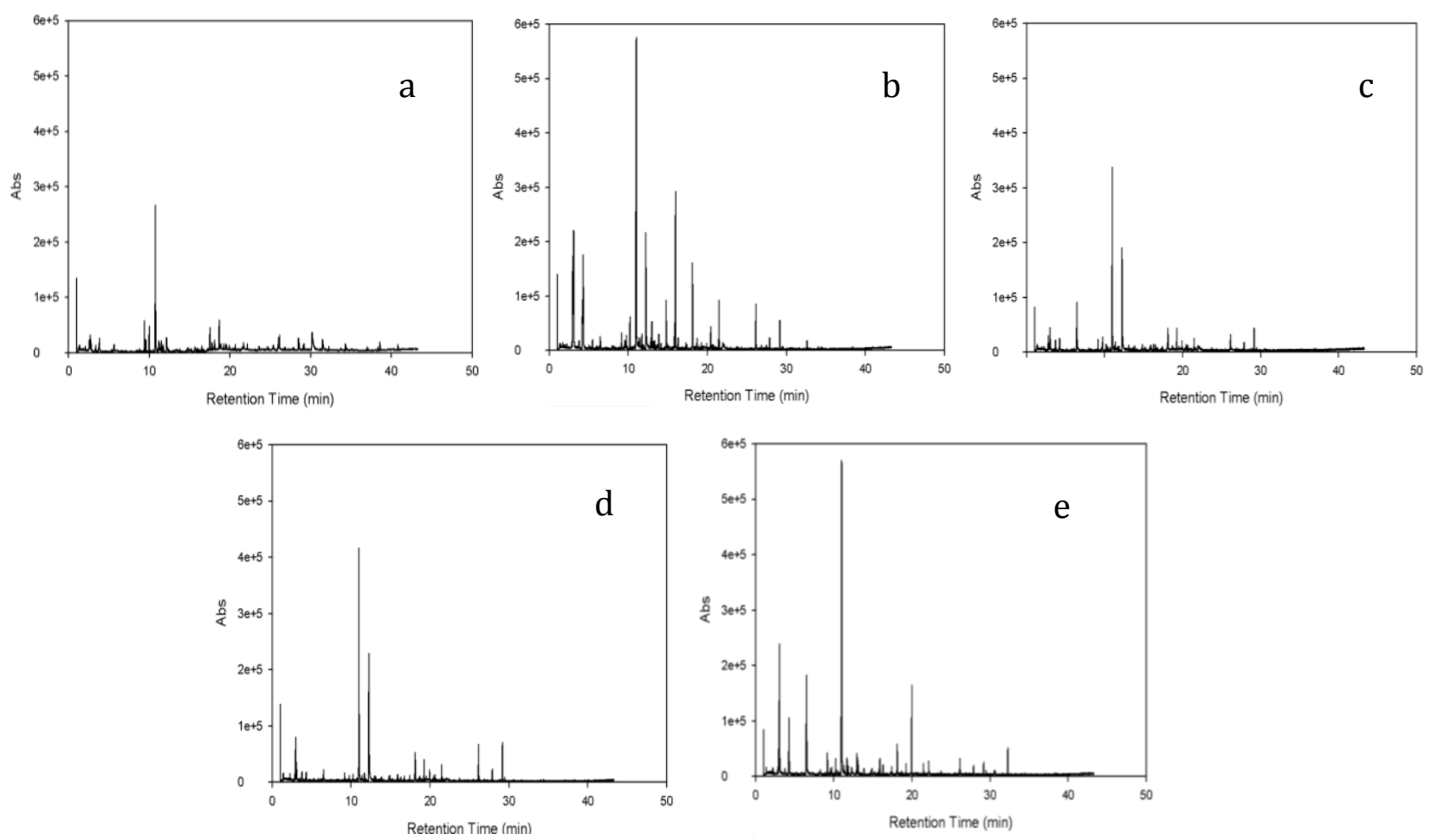

Figure 34. Chromatograms of salted samples: a. Scauri, b. Rekhale, c. Tracino, d. Barone, e. Bugeber. 
Table 7. Volatile compounds identified and their classification in classes of substances.

\begin{tabular}{|c|c|c|}
\hline Compound Name & Retention Time (min) & Class of substances \\
\hline Butanal, 3-methyl- & 2,78 & Aldehydes \\
\hline Isopropyl Alcohol & 2,90 & Alcohols \\
\hline Ethanol & 3,06 & Alcohols \\
\hline Pentanal & 3,60 & Aldehydes \\
\hline Acetonitrile & 4,20 & Azo Compounds \\
\hline Methane, isocyano- & 4,28 & Azo Compounds \\
\hline Butanoic acid, 2-methyl-, ethyl ester & 5,48 & Esters \\
\hline Hexanal & 6,32 & Aldehydes \\
\hline 1-Penten-3-ol & 9,16 & Alcohols \\
\hline Isopropyl isothiocyanate & 9,59 & Sulphur compounds \\
\hline D-Limonene & 9,67 & Terpenes \\
\hline Ethyl cyclohexanepropionate & 9,77 & Esters \\
\hline 1-Butanol, 3-methyl- & 10,18 & Alcohols \\
\hline Methyl isothiocyanate & 10,96 & Sulphur compounds \\
\hline Styrene & 11,35 & Terpenes \\
\hline 3-Octanone & 11,36 & Ketones \\
\hline beta.-Cymene & 11,50 & Terpenes \\
\hline Butane, 1-isothiocyanato- & 11,69 & Sulphur compounds \\
\hline Thiocyanic acid, methyl ester & 11,86 & Sulphur compounds \\
\hline Acetoin & 12,22 & Ketones \\
\hline Isobutyl isothiocyanate & 12,98 & Sulphur compounds \\
\hline 2-Hexen-1-ol, (E)- & 13,02 & Alcohols \\
\hline 2-Heptenal, (E)- & 13,13 & Aldehydes \\
\hline 2-Hexenal, 2-ethyl- & 13,37 & Aldehydes \\
\hline 1-Hexanol & 13,87 & Alcohols \\
\hline Octanoic acid, methyl ester & 15,16 & Esters \\
\hline 3-Octanol & 15,60 & Alcohols \\
\hline Pinacolyl alcohol & 15,79 & Alcohols \\
\hline Octanoic acid, ethyl ester & 15,94 & Esters \\
\hline 1-Octen-3-ol & 16,31 & Alcohols \\
\hline Isomenthone & 16,53 & Ketones \\
\hline Furfural & 16,74 & Aldehydes \\
\hline 2,4-Heptadienal, (E,E)- & 17,41 & Aldehydes \\
\hline 2-Nonyne & 17,79 & Hydrocarbons \\
\hline 1,6-Octadien-3-ol, 3,7-dimethyl- & 18,11 & Alcohols \\
\hline Benzaldehyde & 18,12 & Aldehydes \\
\hline Linalyl isobutyrate & 18,69 & Esters \\
\hline 3,5-Octadien-2-one & 19,24 & Ketones \\
\hline 4-Terpineol & 19,95 & Alcohols \\
\hline 3-Cyclohexen-1-ol, 4-methyl-1-(1-methylethyl)- & 19,96 & Alcohols \\
\hline Benzoic acid, methyl ester & 20,46 & Esters \\
\hline Butyrolactone & 20,66 & Ketones \\
\hline Ethyl benzoate & 21,49 & Esters \\
\hline (+)-alpha.-Terpineol & 21,93 & Terpenes \\
\hline o-Methylphenol & 26,02 & Alcohols \\
\hline Benzyl Alcohol & 26,15 & Alcohols \\
\hline Methyl 6-methylsalicylate & 27,90 & Esters \\
\hline Benzaldehyde, 4-methoxy- & 29,17 & Aldehydes \\
\hline Benzaldehyde, 3-methoxy- & 29,18 & Aldehydes \\
\hline Cinnamaldehyde, (E)- & 29,48 & Aldehydes \\
\hline Octanoic Acid & 30,20 & Acids \\
\hline Thymol & 32,29 & Terpenes \\
\hline
\end{tabular}


A Radar plot is a graphical method of displaying multivariate data in the form of a twodimensional chart of three or more quantitative variables represented on axes starting from the same point.

Radar plot of predominance of chemical classes (Figure 35) shows difference mostly in the content of aldehydes, terpenes, esters and ketones. For aldehydes content for example, samples have the following values: Scauri 6,9\%, Rekhale 7,3\%, Tracino $24,8 \%$, Barone $14,01 \%$, and Bugeber 16,3\%. As regards the aldehydes, hexanal and benzaldehyde (almond, burnt sugar) prevailed in all the samples, and $(E)$ - cinnamaldehyde (cinnamon) was also detected.

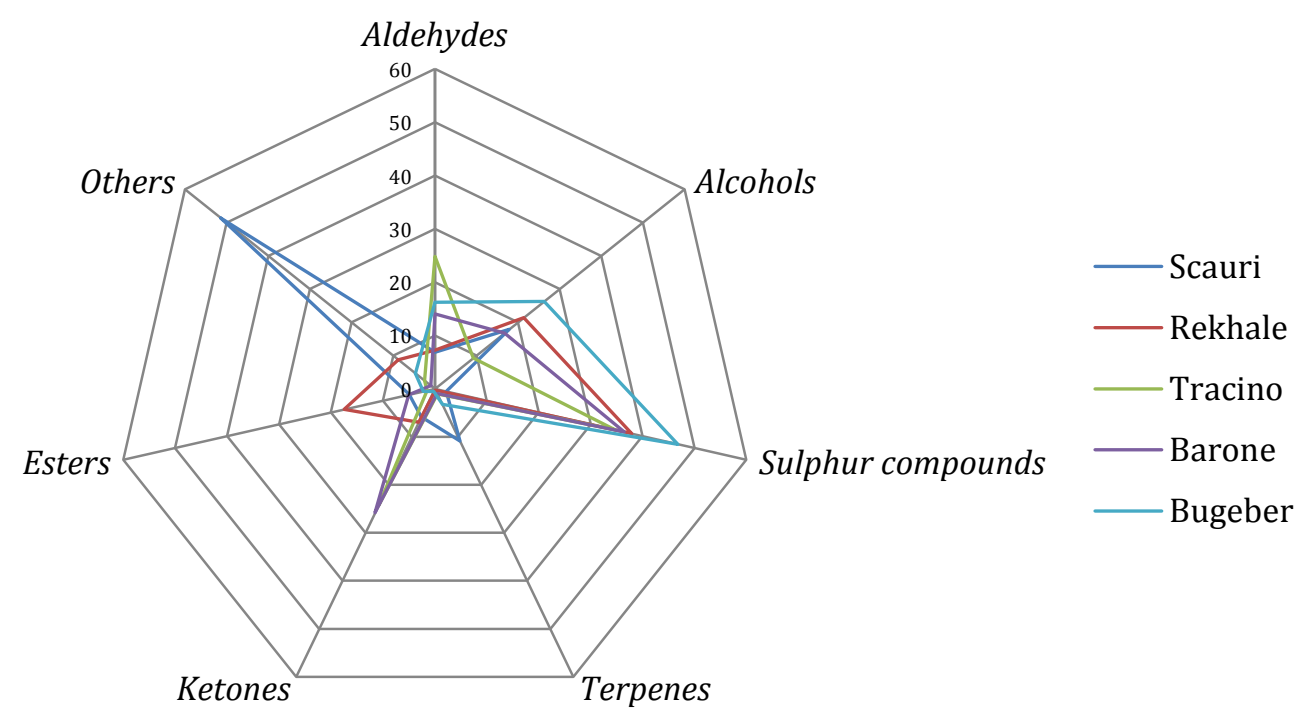

Figure 35. Radar plot of importance of chemical classes in samples analyzed by GC-MS

Cinnamaldehyde and benzaldehyde were the most abundant aldehydes according to Romeo et al., 2007. Cinnamaldehyde commonly used in perfumes for its sweet and fruity scent is also used as fungicide typically applied to the root systems of plants; cinnamaldehyde is an effective insecticide and its scent is also known to repel animals like cats and dogs.

The presence in food of aliphatic aldehydes, acids and alcohols such as hexanal, $(E, E)-2,4-$ heptadienal, hexanoic acid, and 1-octen-3-ol is related to fat oxidation reactions. These substances have been found in a variety of food products including meats and processed meats, fruits, as well as dairy and grain products. More specifically they have been associated with green/grassy/vegetable aromatics in fruits and vegetables (Condurso et al., 2015).

Comparing with the literature data a large number of compounds resulted identified for the first time in our capper buds. 
Previously, Brevard et al. (1992) reported the monoterpene linalool and the sesquiterpene $\beta$ ionone as the only detected terpenes in capers from Morocco. In the present study, five terpenes were identified: D-Limonene, styrene, $\beta$-cymene, $(+)$ - $\alpha$-terpineol and thymol. Limonene (citrus) and $\beta$-linalool (flower, lavender) prevailed. Their structures reveal an isoprenoid-based origin, and they were long assumed to be the products of the oxidative cleavage of carotenoids.

The monoterpenes are often partially responsible for the odor of plants; their production often occurs in non-photosynthetic tissues in non-pigmented plastids known as leucoplast during the relatively brief periods when these cells are metabolically active (Gershenzon \& Croteau, 1990; Auldridge et al., 2006).

Sulphur compounds accounted for the average of $31,6 \%$ of the volatiles, with methylisothiocyanate and benzyl-isothiocyanate as the major ones; both substances having a pungent smell and sharp test. Lower sulphur compounds content, was reported in Scauri 2,18\% and the higher was reported in Bugeber 46,8\%. This can be directly linked with the report by Matthaus and Ozcan (2002), on the high glucocapperin content in the buds of C. spinosa from Turkey, where glucocapperin accounted for the $80 \%$ of the total glucosinolates in those buds. In fact, isothiocyanates (ITCs) encountered in higher plants invariably derive from glucosinolates by enzymatic hydrolysis, which is, schematically shown in Figure 36 for the conversion of glucocapperin into methyl-isothiocyanate. All Capparis species are sources of glucosinolates, and hence of isothiocyanates, with the structurally simplest representative, methyl glucosinolate (glucocapperin) as the apparently most widely distributed one.

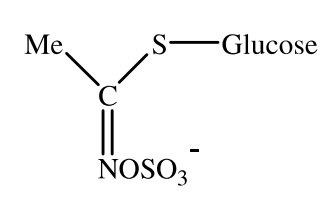

Methyl-glucosinolate

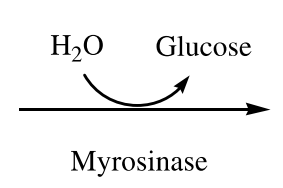

Myrosinase

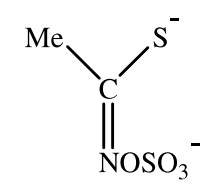

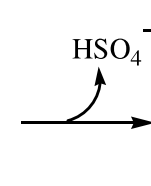

Methyl-isothiocyanate

Figure 36. The myrosinase-catalyzed conversion of methyl-glucosinolate (glucocapperin) to methyl-isothiocyanate (Romeo et al., 2007).

Recently, Zhang (2004) has documented the cancer-preventive activity of a significant number of isothiocyanates, the majority of which occur in plants, especially in cruciferous vegetables. Moreover, glucosinolates via their hydrolysis products are among the most powerful antibiotic substances known from higher plants (Louda \& Mole, 1991), with an established correlation between the content of glucosinolates (isothiocyanates) and disease resistance (Chew, 1988). 
Benzoate and salicylate esters are common components of floral scent and are believed to be important attractants of insect pollinators (Schwab et al., 2008).

Furfuran derivatives were identified with different amount in Pantelleria samples. They account for the burnt sugar/caramel odor of heated carbohydrates. They can be found at low levels in many foods and drinks as a result of thermal treatment; they are also biosynthesized by plants, microorganism and insects although the detailed formation pathways are still unknown (Schwab, 2013). Furfural prevailed in the samples and it has caramel and toasted notes.

PCA performed on amount of each volatile is shown in Figure 37. PCA identifies patterns of correlation among dependent variables and substitutes a new variable, called a factor, for the group of original attributes that were correlated. PCA resulted in a two-dimensional solution accounting for $71,54 \%$ of the total variance in the data, of which $47,13 \%$ was accounted by PC1 and about $24,41 \%$ by PC2. Therefore, almost all the variation in the data is explained by this two-dimensional summary.

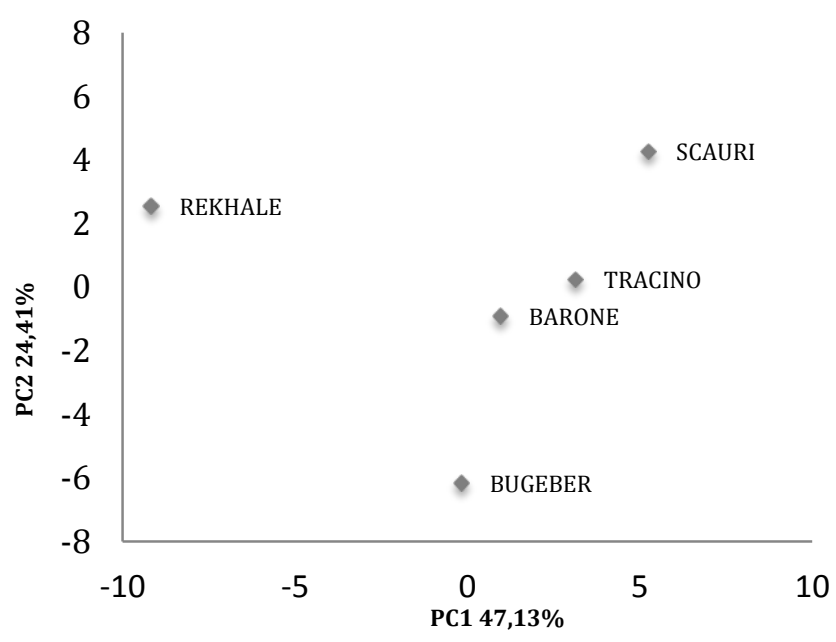

Figure 37. Bidimensional biplot representation of samples according to principal components PC1 and PC2

In particular, the variables that had the greatest impact on PC1 and PC2 making it possible to distinguish caper samples in two different groups: capers from Rekhale were located on the negative side of the PC1, whereas capers from other site of Pantelleria on the positive side of PC1.

In conclusion, the flavor profile of Pantellerian capers as been investigated for the first time, and the potential of the solvent-free HS-SPME extraction technique combined with the GC-MS analysis, as a possible simple routine method for analyzing food flavor, has been shown. Obviously, it should always be taken into consideration that the volatiles that form fruit flavor 
are produced through metabolic pathways during ripening, harvest, post-harvest and storage, and depend on many factors related to the species, variety, environment of cultivation and the type of technological treatment.

\subsection{Conclusion}

In this work, some relevant applications of electronic nose technology and Gas Chromatography have been reviewed. A large number of volatile substances were identified and the sensory profile was determined. Important and useful information to producers and consumers about the sensory characteristics of the capers were provided.

The results demonstrated that volatiles and other chemical descriptors, altogether considered, allowed distinguishing the capers of different geographic origin. Our results could be of great interest for the traceability, which is an important tool to protect national and local foods, linking it to their own territory. All the reported case studies showed promising results, thus confirming that EN coupled with other tools such as GC-MS could represent a rapid mean for controlling and improving the quality of food. However, further investigations to induce more sensitive specific response of the gas sensors may help both in the qualitative and quantitative analysis. The sensory quality, here defined, could help our small local companies to compete on the international market and defense the Italian capers from fraudulent geographic indications. 


\section{CHAPTER 4}

\section{AFLP Markers for the assessment of Genetic Diversity in Capparis spinosa cultivated in Pantelleria Island.}

\subsection{Abstract}

The aim of this investigation was the genetic characterization of four different accessions of Capparis spinosa from Pantelleria Island (Sicily, Italy) and the assessment of any correlation between genetic and morphological diversity. Leaf material for genetic analysis was collected from 4 wild populations belonging the same subspecies, from three different areas of Pantelleria Island: Scauri, Rekale and Tracino. Leaves collected from Tracino were maintained as two different groups (Tracino A and Tracino B) in order to support the morphological difference shown.

In order to determine the genetic diversity within and among populations of Capparis spinosa from Pantelleria Island (Sicily, Italy) AFLPs markers were employed. Moreover, using markers attributes in present study, it was been evaluated AFLP markers capacity. The values of polymorphic information content (PIC), marker index (MI) and the resolving power (RP) demonstrated the utility of the primer combinations used in the present study for discriminating the capers accessions studied in this study. Eight primer combinations were screened for their ability to generate AFLP polymorphic DNA bands. Results provided molecular markers for Capparis spinosa.

Marker attributes like PIC, MI and RP have been determined to evaluate genetic diversity in Capparis spinosa. Further analyses using more accessions and materials from other areas are needed to confirm these results.

\subsection{Introduction}

Capparis spinosa L. (family Capparidaceae) is one of the most common aromatic plants growing wild in the dry regions around the Mediterranean basin. In Italy, this blue-gray spiny plant is intensively cultivated, particularly on small islands around Sicily, such as Pantelleria and the Eolian Salina, which provide 95\% of the national product (Tesoriere et al. 2007).

C. spinosa is a shrub species suffruticosa, able to adapt to fragile or degraded semiarid Mediterranean environments. The plant has a reproductive system mainly allogamous. 
Pollination is usually entomophilous and only a small percentage (1.7\%) of plants has sterile female sexual organs (Shakrishvili et al., 2013).

This shrub is known as caper (English), kabbar (Arab), alcaparra (Spanish), câpre (French), cappero (Italian) and gollaro (Urdu), (Legua et al. 2013).

Of the approximately 250 species existing (Moubasher, et al. 2011), the object of study of this project is $C$. spinosa. Populations typically found in Sicily are C. spinosa subsp. spinosa var. canescens and C. spinosa subsp. rupestris.

The caper has multiple uses in cuisine, for instance immature flower buds pickled in vinegar, sauce or preserved in salt are highly demanded in European countries (Melgarejo et al., 2009).

Furthermore, chemical and biological studies reported the presence of many beneficial compounds (Tlili et al. 2009, Tesoriere et al. 2007) and revealed significant antidiabetic, antisclerosis, antimicrobial, antioxidative, antiinflammatory, immunomodulatory and antiviral activities (Tlili et al. 2011, Fu et al., 2008).

DNA studies related to Capparis are very scarce. Random Amplification of Polymorphic DNA (RAPD) technique have been used for studing the impact of population size on genetic variation in populations of $C$. spinosa (Nosrati et al. 2012), and Amplified Fragment Length Polymorphism (AFLP) fingerprinting technique has been used to determine the relationships among Capparis spp. from Spain, Morocco and Syria (Inocencio et al. 2005).

The aim of the present study was to determine genetic diversity within and among some accessions of $C$. spinosa collected from different areas of Pantelleria Island (Sicily, Italy), using AFLPs markers. Despite the low number of samples disposable, understanding the patterns of genetic diversity of this species is fundamental not only when addressing questions concerning evolutionary processes and the development of conservation strategies, but also as a prerequisite for the efficient use of genetic resources in breeding programs of caper species in Italy (Saifi 2011).

Moreover, using markers attributes in present study it was been evaluated AFLP markers capacity to define differences between capers accessions from different areas of Pantelleria Island, grown under different environmental conditions.

\subsection{Material and Method}

\subsubsection{Plant material and DNA extraction}

A total of 4 accession of Capparis spinosa from Pantelleria Island (Sicily, Italy) were studied. Leaves of randomly selected individuals were collected from three different areas of Pantelleria 
Island called Scauri, Rekale and Tracino. From Tracino, two different accessions were recollected, one with white flowers and other with purple flowers. Leaves were stored at $-80{ }^{\circ} \mathrm{C}$ and then freeze dried.

DNA was extracted using the DNeasy Plant Mini Kit (Qiagen, Valencia, California, USA), following the protocol of the manufacturer. DNA quantity and quality were verified by gel electrophoresis and NanoDrop ${ }^{\circledR}$ ND-1000. DNA samples were stored at $-20{ }^{\circ} \mathrm{C}$ until used. Two independent extractions were performed for each sample.

\subsubsection{AFLP analysis}

Details of AFLP assay, adapter and primer sequences, PCR conditions for pre-selective and selective amplifications, and PCR product electrophoresis were performed according to Vos et al. (1995) and Sorkheh et al. (2007).

Genomic DNA was double digested using first the Tru9 enzyme at $65{ }^{\circ} \mathrm{C}$ and followed by PstI enzyme at $37^{\circ} \mathrm{C}$ (Figure 38). The enzyme Tru9 recognizing sequences of 4 nucleotides will have a cut-off frequency greater than Pst1 which recognizes sequences of six nucleotides.

$$
\begin{aligned}
& \text { 5'-T } \nabla \text { TAA-3' } \\
& \text { 5'-CTGCA } \nabla \text { G-3' } \\
& \text { 3'-AAT } \mathbf{\Delta} \text { T-5' } \\
& \text { 3'-G А ACGTC-5' } \\
& \text { Tru9 site cutting } \\
& \text { PstI site cutting }
\end{aligned}
$$

Figure 38. Nucleotide sequence recognized by restriction enzymes Tru9 and PstI and cutting area.

Tru9 is an isoschizomer of the MseI restriction enzyme, and it is obtained from Escherichia coli that carries the cloned Tru9 I gene from Thermus ruber 9 (source: http://www.sigmaaldrich.com).

PstI is a restriction enzyme of type II produced by the microorganism Providencia stuartii which has a restriction site in double stranded DNA dependent unmethylated sequence, palindromic and asymmetrical about its hydrolase which generates cohesive ends catalytic activity (Carter et al., 1980).

Double-stranded oligonucleotide adapters specific to each site (Adapter Mse and Adapter Pst respectively, Table 8) were ligated at each end of the digested DNA . The adaptor-ligated DNA was diluted 10 times with TE buffer. Then pre-selective amplification was performed with primers complementary to the adaptors and with one selective base at the $3^{6}$ end, MseI adaptor 
$+\mathrm{C}$ and PstI $+\mathrm{A}$ primers respectively, according to Esfahani et al. (2009). Pre-selective amplification was performed in a GeneAmp®PCR System 9700 thermal cycler (Perkin-Elmer Corp- Applied Biosystem, Freemont, CA) in a final volume of $20 \mu 1$, containing $1 *$ PCR, $5 \mu 1$ of DNA ligated with adaptators (diluted 1:5), 2.5 $\mu$ Dream Taq Buffer 10U (ThermoScientific), $2 \mu 1$ $\mathrm{MgCl}_{2} 50 \mathrm{mM}, 1 \mu \mathrm{dNTP}, 0.5 \mu \mathrm{l}$ of each primers (MseI $+1-\mathrm{C}$ and PstI $+1-\mathrm{A}$ ) $10 \mu \mathrm{M}$ and $0.2 \mu \mathrm{l}$ Dream Taq DNA Polymerase 5U/ $\mu$ ( ThermoScientific), using the following temperature profile: $94{ }^{\circ} \mathrm{C}$ for $2 \mathrm{~min}$, than 20 cycles of $94{ }^{\circ} \mathrm{C}$ for $20 \mathrm{sec}, 56{ }^{\circ} \mathrm{C}$ for $30 \mathrm{sec}$ and $72{ }^{\circ} \mathrm{C}$ for $25 \mathrm{sec}$ and finishing with $60{ }^{\circ} \mathrm{C}$ for $30 \mathrm{~min}$.

Table 8. Oligonucleotide adapter and primer names and sequences for selective amplified fragment length polymorphism primer combinations (assay units)

\begin{tabular}{ll} 
Name & \multicolumn{1}{c}{ Sequence } \\
\hline MseI Adapter & 5'-GACGATGAGTCCTGAGTACTCAGGACTCAT-3' \\
PstI Adapter & 5'-GACTGCGTAGGTGCAGAGCATCTGACGCATCC-3' \\
MseI + 1-C & 5'-GATGAGTCCTGAGTAAC-3' \\
PstI + 1-A & 5'-GACTGCGTACATGCAGA-3' \\
MseI + 3-CTA & 5'-GATGAGTCCTGAGTAACTA-3' \\
MseI + 2-CC & 5'-GATGAGTCCTGAGTAACC-3' \\
PstI + 3-ACA & 5'-GACTGCGTACATGCAGACA-3' \\
PstI + 3-ACG & 5'-GACTGCGTACATGCAGACG-3' \\
PstI + 3-AGG & 5'-GACTGCGTACATGCAGAGG-3' \\
PstI + 3-AGC & 5'-GACTGCGTACATGCAGAGC-3' \\
\hline
\end{tabular}

Selective amplifications were carried out using 8 primer combinations (Table 9) in a final volume of $20 \mu \mathrm{l}$, containing $1 * \mathrm{PCR}, 5 \mu \mathrm{l}$ of DNA from pre selective PCR diluted 1:10, $0.2 \mu 1$ Dream Taq Buffer 10U (ThermoScientific), $2 \mu \mathrm{MgCl}_{2} 50 \mathrm{mM}, 1 \mu \mathrm{dNTP}, 1 \mu \mathrm{l}$ of a primers combination $10 \mu \mathrm{M}$ and $0.2 \mu$ Dream Taq DNA Polymerase $5 \mathrm{U} / \mu \mathrm{l}$ (ThermoScientific), using the following temperature profile: $94{ }^{\circ} \mathrm{C}$ for $2 \mathrm{~min}$, than 10 cycles of $94{ }^{\circ} \mathrm{C}$ for $20 \mathrm{sec}, 66^{\circ} \mathrm{C}$ for 30 $\sec \left(-1{ }^{\circ} \mathrm{C}\right.$ each cycle) and $72{ }^{\circ} \mathrm{C}$ for $25 \mathrm{sec}$, than 20 cycles of $94{ }^{\circ} \mathrm{C}$ for $20 \mathrm{sec}, 56^{\circ} \mathrm{C}$ for $30 \mathrm{sec}$ and $72{ }^{\circ} \mathrm{C}$ for $25 \mathrm{sec}$ and finishing with $60^{\circ} \mathrm{C}$ for $30 \mathrm{~min}$.

DNA fragment were separated using an ABI Prism 3130 Genetic Analyzer (Applied Biosystem) and scored as binary traits (present $=1$, absent $=0$ ) using GeneMapper software, version 4.0 (Applied Biosystem). Reproducible and well-resolved AFLP fragments in the size range of 50500 bp were scored. 
Table 9. Primers combination used for selective amplification and marker used to visualize DNA bands.

\begin{tabular}{ll} 
Primers Combination & Marker \\
\hline PstI-ACA/MseI-CTA & FAM \\
PstI-ACG/MseI-CTA & VIC \\
PstI-ACG/MseI-CTA & PET \\
PstI-AGC/MseI-CTA & NED \\
PstI-ACA/MseI-CC & FAM \\
PstI-ACG/MseI-CC & VIC \\
PstI-ACG/MseI-CC & PET \\
PstI-AGC/MseI-CC & NED \\
\hline
\end{tabular}

\subsubsection{Data Analysis}

Pairwise genetic similarities were estimated with the Dice (Sorensen) similarity coefficient $\mathrm{Sij}=$ $2 a /(2 a+b+c)$, where $a$ is the number of bands shared by $i$ and $j, b$ is the number of bands present in $\mathrm{i}$ and absent in $\mathrm{j}$, and $\mathrm{c}$ is the number of bands present in $\mathrm{j}$ and absent in $\mathrm{i}$.

The resulting genetic similarity matrix was used to generate a neighbor-joining phenogram with the Phylip 3.62 package (Felsenstein, 1989). One thousand bootstrapped distance matrices were calculated using the Phyltools 1.32 software (Buntjer 2001) and used to test the stability of the neighbour joining tree.

In order to evaluate the informativeness of the markers employed, some statistics index were calculated.

Polymorphism Information Content (PIC) were calculated for each combination of primers, according to Weir (1990) and Anderson et al., (1993), based on allele frequencies of all of the varieties analyzed as: $\mathrm{PICi}=1-\Sigma \mathrm{P} 2 \mathrm{ij}$, where $\mathrm{Pij}$ is the frequency of the $\mathrm{jth}$ allele for the ith marker locus and summation extends over $\mathrm{n}$ alleles.

The Marker Index (MI) was calculated for each AFLP primer combination as $\mathrm{MI}=\mathrm{PIC}^{*} \mathrm{n} \beta$, where PIC is the mean PIC value, $\mathrm{n}$ the number of bands, and $\beta$ is the proportion of polymorphic bands (Powell et al., 1996).

MI should be expressed using standard formula: $\mathrm{MI}=\mathrm{PIC} \times \mathrm{EMR}$ where, EMR (effective multiplex ratio) is the product of total number of fragments per primer (n) and the fraction of polymorphic fragments $(\beta)(\mathrm{EMR}=\mathrm{n} \beta)$.

Discriminatory power of a given primer combination, i.e., resolving power (RP), was calculated using the formula of Prevost and Wilkinson (1999): $\mathrm{RP}=\sum \mathrm{Ib}$ where, $\mathrm{Ib}$ is the fragment 
informativeness, which is represented on $0-1$ scale by using the formula: $\mathrm{Ib}=1-[2 \times 0.5-\mathrm{p}]$ where, $\mathrm{p}$ is the proportion of the 4 caper genotypes containing fragments.

Percentage of polymorphism was calculated as the proportion of polymorphic bands $\beta$ over the total number of bands n (Martos et al. 2005).

\subsection{Results and Discussions}

\subsubsection{Genetic diversity}

Genetic diversity of 4 Pantellerian cultivated populations of Capparis spinosa was preliminarily studied using eight AFLP selective primer combinations (Table 9).

The number of informative fragments detected per primer combination range from 18 to 52 bands with an average 36,38 bands (Table 10).

Table 10. Number of informative bands for each sample relating to 8 primer combinations.

\begin{tabular}{lccccc}
\hline & Scauri & Rekale & Tracino A & Tracino B & TOTAL \\
\hline Mse CTA x Pst ACA & 8 & 9 & 10 & 10 & 37 \\
Mse CTA x Pst ACG & 9 & 9 & 10 & 10 & 38 \\
Mse CTA x Pst AGG & 9 & 10 & 9 & 11 & 39 \\
Mse CTA x Pst AGC & 7 & 5 & 5 & 6 & 23 \\
Mse CC x Pst ACA & 10 & 9 & 9 & 9 & 37 \\
Mse CC x Pst ACG & 5 & 4 & 4 & 5 & 18 \\
Mse CC x Pst AGG & 14 & 13 & 12 & 13 & 52 \\
Mse CC x Pst AGC & 11 & 12 & 12 & 12 & 47 \\
\hline Mean & & & & & 36,38
\end{tabular}

The eight primer combinations were screened for their ability to generate AFLP polymorphic DNA bands using total genomic DNAs. Based on the band patterns, the AFLP primer combinations Mse-CTA x Pst-ACA generated the highest (6 fragments) number of polymorphic bands, expressed as EMR, while the lowest (2 fragments) were generated by primer combinations Mse-CTA x Pst-ACG, Mse-CTA x Pst-AGG, Mse-CC x Pst-ACG and Mse-CC x Pst-AGG (Table 10).

Details of the informativeness of the markers for each AFLP primers combination are given in Table 11. In order to compare the primer combinations used, an average PIC value for each one was calculated based on the PIC values for all the polymorphic fragments generated. Based on the results, PIC value ranged from 0,796 and 0,925. The highest polymorphic information content was related to primer combination Mse-CC x Pst-AGG which introduces it as a good 
informative primer combination to study genetic diversity between the four accessions of Capparis studied. PIC provides an estimate of the discriminatory power of a marker by taking into account not only the number of alleles, but also their relative frequencies.

MI value was also calculated for all the primer combinations as a feature of marker diversity and it ranged from 0,264 and 2,726 with an average of 1,00 per primer combination. In this case the primer combination Mse CTA x Pst ACA has the highest value of MI and the primer combination Mse-CC x Pst-AGG has a MI value of 0,264.

$\mathrm{RP}$ value is a feature that indicates the discriminatory potential of the marker and in this case it ranged from 1 and 5,5 with an average of 1,94.

Table 11. Characterization of the degree of polymorphism and quality of AFLP data generated with 8 primers combination.

\begin{tabular}{|c|c|c|c|c|c|c|c|}
\hline Primer Combination & $n^{1}$ & $\beta^{2}$ & $\%$ Polymorphic Bands & $\mathrm{PIC}^{3}$ & $\mathrm{EMR}^{4}$ & $\mathrm{MI}^{5}$ & $\mathrm{RP}^{6}$ \\
\hline Mse CTA x Pst ACA & 12 & 0,50 & 50,00 & 0,909 & 6 & 2,726 & 1,5 \\
\hline Mse CTA x Pst ACG & 11 & 0,18 & 18,18 & 0,899 & 2 & 0,327 & 1 \\
\hline Mse CTA x Pst AGG & 11 & 0,18 & 18,18 & 0,902 & 2 & 1,804 & 5,5 \\
\hline Mse CTA x Pst AGC & 8 & 0,38 & 37,50 & 0,843 & 3 & 0,948 & 2,5 \\
\hline Mse CC x Pst ACA & 11 & 0,27 & 27,27 & 0,900 & 3 & 0,736 & 1,5 \\
\hline Mse CC x Pst ACG & 6 & 0,33 & 33,33 & 0,796 & 2 & 0,531 & 1,5 \\
\hline Mse CC x Pst AGG & 14 & 0,14 & 14,29 & 0,925 & 2 & 0,264 & 1 \\
\hline Mse CC x Pst AGC & 13 & 0,23 & 23,08 & 0,919 & 3 & 0,636 & 1 \\
\hline Mean & 10,75 & 0,28 & 27,73 & 0,89 & 2,88 & 1,00 & 1,94 \\
\hline Total & 86,00 & 2,22 & 221,83 & 7,09 & 23,00 & 7,97 & 15,50 \\
\hline
\end{tabular}

${ }^{1}$ Number of bands, ${ }^{2}$ Proportion of Polymorphic Bands, ${ }^{3}$ Polymorphic Index Content, ${ }^{4}$ Effective Multiplex Ratio, ${ }^{5}$ Marker Index, ${ }^{6}$ Resolving Power.

In the figure 39 a comparison of PIC, MI and RP is reported for each primer combinations. Even if there is not a perfect relation between these three statistic indexes, in this preliminary study, the primer combinations Mse CTA x Pst AGG, Mse CTA x Pst ACA and Mse CTA x Pst AGC have the best capacity of underlining genetic differences in the four accessions of capers.

These primer combinations are promising for future analyses. If they are polymorphic with just 4 samples, they probably will be using more, but to confirm this result, analysis of a bigger number of accessions would be necessary. 


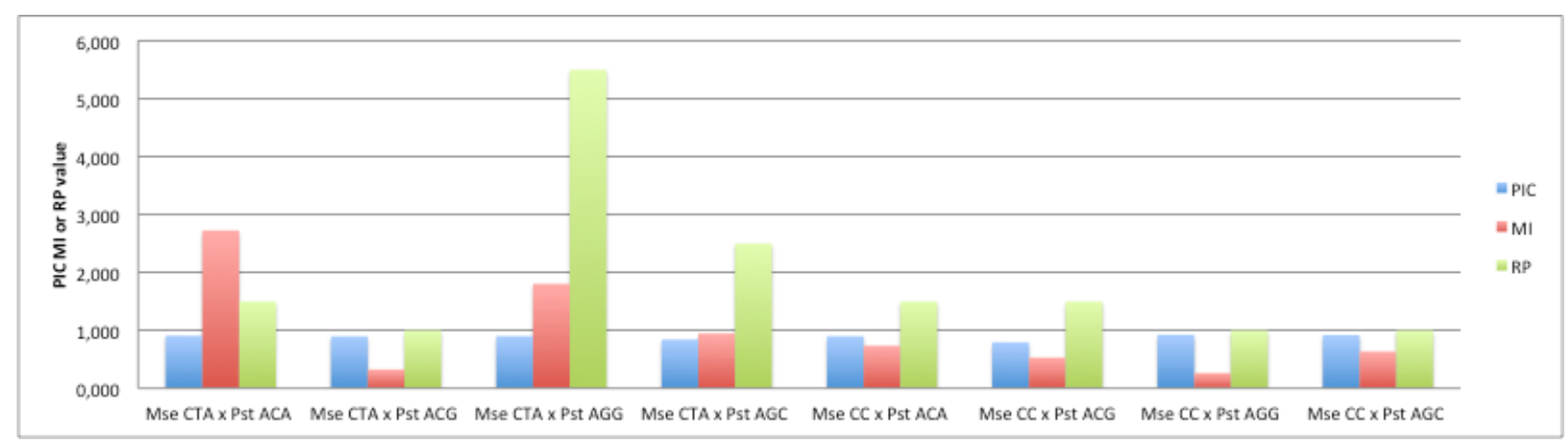

Figure 39. Comparison of statistic index calculated for each primer combinations.

Table 12 shows fragments obtained with primers combination used in present study and which should be considered exclusive bands. Presence of exclusive bands from C. spinosa genotypes from three different areas of Pantelleria Island demonstrates genetic and molecular differentiation not only between plant collected in different areas but also between plants from the same area where phenotypic differences are observated. Mse-CTA x Pst-AGC and Mse-CC x Pst-AGC were very discriminative because each of them produced three exclusive bands.

Table 12. List of exclusive bands for each primer combinations.

\begin{tabular}{lccccc}
\hline & Fragment Size (bp) & Scauri & Rekale & Tracino A & Tracino B \\
\hline Mse CTA x Pst ACA & 180 & 0 & 1 & 1 & 1 \\
Mse CTA x Pst ACG & 287 & 0 & 0 & 1 & 0 \\
& 340 & 0 & 0 & 0 & 1 \\
Mse CTA x Pst AGG & 175 & 0 & 0 & 0 & 1 \\
Mse CTA x Pst AGC & 115 & 1 & 0 & 0 & 0 \\
& 139 & 1 & 0 & 0 & 0 \\
Mse CC x Pst ACA & 228 & 0 & 0 & 0 & 1 \\
Mse CC x Pst ACG & 149 & 1 & 0 & 0 & 0 \\
Mse CC x Pst AGG & 135 & 1 & 0 & 0 & 0 \\
Mse CC x Pst AGC & 350 & 0 & 0 & 0 & 1 \\
& 107 & 1 & 1 & 0 & 1 \\
& 141 & 1 & 0 & 0 & 0 \\
& 116 & 1 & 0 & 0 & 0 \\
& 117 & 0 & 1 & 1 & 1 \\
\hline
\end{tabular}

\subsubsection{Neighbor-joining phenogram data}

As observed in the Neighbor-Joining dendrogram (Figure 40), these four genotype of C. spinosa tend to group according to their origin from three different area of Pantelleria Island. Moreover, 
phenotypic differences within Tracino $3 \mathrm{~A}$ and Tracino $3 \mathrm{~B}$, collected in the same area, is supported by the genetic difference shown.

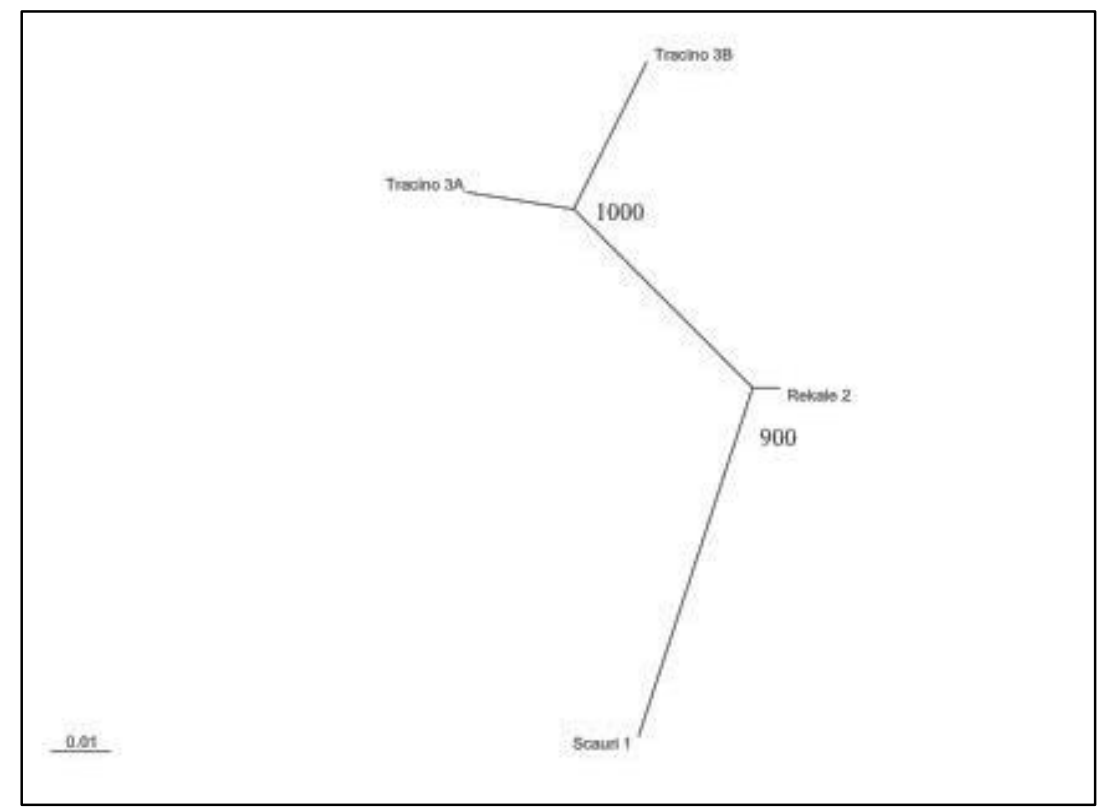

Figure 40. Neighbor-Joining phenogram tree of 4 studied capers varieties revealed by AFLP data based on Nei's coefficient. Numbers indicate the proportion (\%) of 1000 bootstrap samples in which a particular clade was found.

\subsection{Conclusion}

In the present study AFLP technique was used, not only to examine genetic differences between capers from different areas of Pantelleria Island, but also to evaluate AFLP markers capacity to discriminate accessions of this species.

Marker attributes like PIC, MI and RP have been calculated in this work to assess the discriminatory power of AFLP markers for genetic diversity analysis. The AFLP technique studied in C. spinosa has been permitted to reveal genetic variation of the four samples considered.

The results obtained are a motivating force to make additional analysis of other samples from other climatic zones in the Mediterranean. Indeed, knowledge of the genetic structure of these plants, not only should permit to estimate the importance of some evolutionary forces, but also could provide fundamental information for plants such as salutistic and nutraceutical contents. AFLP analysis is demonstrated a good method to archive this goal. 


\section{CONCLUSIONS}

Caper is a good source of phenolic compounds, which are known to provide health-improving benefits, due to their various biological activities (antioxidant, anticarcinogenic, antimicrobial, antimutagenic). The present study reports that capers, salt fermented unopened flower buds of Capparis spinosa L., collected and processed in Pantelleria Island (Sicily, Italy) represent a good source of antioxidant compounds. This typical Mediterranen food product contains a high level of phenolic compounds, especially in flavonoids content, which explains its high antioxidant activity. Values of total phenolic compounds ranged from $843.92 \pm 44.83$ (for Rekhale) to $596.92 \pm 53.15$ (for Bugeber) $\mathrm{mg}$ GAE/100g DW. Values of total flavonoids ranged from 90.31 \pm 0.01 (for Scauri) to $20.65 \pm 0.01$ (for Bugeber) $\mathrm{mg} \mathrm{RE} / 100 \mathrm{~g} \mathrm{DW}$. The total phenols and flavonoids content were considered according the geographic area of caper collection. For the DPPH, capers from Rekhale showed lowest DPPH assay value of $\mathrm{EC}_{50}(1.93 \pm 0.13 \mathrm{mg} \mathrm{DW})$, while Tracino displayed the highest $(2.67 \pm 0.16 \mathrm{mg} \mathrm{DW})$. For the ABTS radical, capers from Rekhale and Barone showed respectively minimum and maximum value of TEAC (4.50 \pm 0.04 and $6.39 \pm 0.02 \mu \mathrm{mol} \mathrm{TE} / \mathrm{g}$ DW respectively).

Actually, ORAC assay was the best test to determine potential antioxidant activity in capers. Sample from Bugeber shown the minimum ORAC value: $231.70 \pm 12.19 \mu \mathrm{mol}$ TE/100 g DW; sample from Scauri shown the maximum ORAC value: $655.98 \pm 58.34 \mu \mathrm{mol} \mathrm{TE} / 100 \mathrm{~g} \mathrm{DW}$. No significant difference of ORAC value was registered for samples from Rekhale, Tracino and Barone.

According to Pearson's correlation coefficients (R2), the correlation between total polyphenols and antioxidant activity was higher for the DPPH assay $(\mathrm{R} 2=0.665)$ and lower for the ABTS assay $(\mathrm{R} 2=0.156)$. Moreover, the correlation between total flavonoids and the antioxidant activity was a higher for the ORAC assay (R2=0.888), lower for the DPPH assay (R2=0.074) and moderate for the ABTS assay $(\mathrm{R} 2=0.594)$. Thus, it can be deduce that: i) the antioxidant capacity of bioactive compounds from caper can be suitably determined by ORAC assay, and ii) flavonoids are polyphenols with very high antioxidant activity.

From capers were identified 24 secondary metabolites, included polyphenols. In particular 15 compounds are present in all of five collections area of capers tested, for example kaempferol-3O-neohesperidoside-7-O-rhamnoside was found in all samples. Other two small organic acids were present: quinic acid and vanillic acid. Typical capers molecules are glucosinolates: glucocapparin, glucoalyssin, gluconapin, 4-hydroxy-glucobrassicin, glucobrassicin, gluconasturtin and glucosides of 9-methylsulfinyl-nonylglucosinolate were identified. 
In this work, some relevant applications of electronic nose technology and Gas Chromatography have been reviewed. A large number of volatiles were identified and the sensory profile was determined. Important and useful information to producers and consumers about the sensory characteristics of the capers were provided.

The results demonstrated that volatiles and other chemical descriptors, altogether considered, allowed distinguishing the capers of different geographic origin. Our results could be of great interest for the traceability, which is an important tool to protect national and local foods, linking it to their own territory.

The variations showed by the five samples tested regarding the phytochemical composition could be attributed to the chemical-physical properties of the different genotypes, to the composition of the soil and to the influence of other factors like geographical coordinates, and solar and windy exposure.

In the present study AFLP technique was used, not only to examine genetic differences between capers from different areas of Pantelleria Island, but also to evaluate AFLP markers capacity to discriminate accessions of this species.

Presence of exclusive bands from C. spinosa genotypes from different areas of Pantelleria Island demonstrates genetic and molecular differentiation not only between plant collected in different areas but also between plants from the same area where phenotypic differences are observed.

In conclusion, this study shows for the first time the composition of compounds with potential capacity antioxidants present in Pantelleria capers, confirming that they contain substantial concentrations of phenolic acids and flavonoids. The results presented here, therefore, indicate that the antioxidant capacity of the capers is probably the combined result of the activity and of the interactions of a wide range of compounds, including phenolic compounds, as well as possibly enzymes and other minor components. Capers, therefore, may be one of the natural products that can be taken into account to maintain a good state of health and to protect against damage caused by free radicals. These considerations could provide new insights in the study of the caper in the Mediterranean quality. The processing and preservation process may be controlled so differently in order to ensure and enhance the nutritional quality of the product and also may be selected within the same area of cultivation sites that provide a richer in minerals produced and / or components antioxidants as well as to further raise the quality of the products distributed by local agricultural cooperative. 


\section{ACKNOWLEDGMENT}

I wish to thank Professor Maria Antonietta Germanà, Dr. Pier Luigi San Biagio and Dr. Valeria Guarrasi, my supervisors to the wide availability accorded me in the realization of this thesis and for having supported me scientifically and morally.

A heartfelt thanks to Professor Manuel Agustì Fonfria, my Spanish supervisor for the opportunity to work with him and with Professor Carlos Mesejo Conejo and Carmina Reig; thanks also for having managed the relationship with the University of Valencia, and and for the opportunity to work with the group of Professor Josè Maria Seguì Simarro, whose kind collaboration is here acknowledged.

I wish to thank Dr. Marisa Badenes for their warm welcome in their lab at the Instituto Valenciano de Investigaciones Agraria (IVIA), for their kind assistance in experiments and data analysis.

I wish to extend a special thanks to the Professor Adele Papetti and her team lab, for guest me in their lab at University of Pavia and for supporting my commitment to outstanding educational sense and human solidarity.

I wish to thank Dr. Daniela Butera, University of Palermo, for her useful technical support.

I would like to acknowledge also Rosario Cappadona from the Cooperativa Agricola Produttori Capperi, a.r.1., Pantelleria (Trapani-Sicily, Italy) for providing caper samples.

Thanks to my mother, my sister and Vincenzo, strength and gravitational center of my world. Thanks to my dad that from heaven he guides me and supports me everyday. 


\section{REFERENCES}

Afsharypuor, S., Jeiran, K., Jazy, A.A. (1998). First investigation of the flavor profiles of leaf, ripe fruit and root of Capparis spinosa var. mucronifolia from Iran. Pharmaceutica Acta Helvetica, 72: 307-9.

Ahmed, Z.F., Rizk, A.M., Hammouda, F.M., Seif El-Nasr, M.M. (1972). Glucosinolates of Egyptian Cupparis species. Phytochemistry 11(25): 256.

Allaith, A.A.A. (2014). Assessment of the antioxidant properties of the caper fruit (Capparis spinosa L.) from Bahrain. Journal of the Association of Arab Universities for Basic and Applied Sciences, DOI: http://dx.doi.org/10.1016/j.jaubas.2014.07.001.

Aliyazicioglu, R., Eyupoglu, O.E., Sahin, H., Yildiz, O., Baltas, N. (2013). Phenolic components, antioxidant activity, and mineral analysis of Capparis spinosa L. African Journal of Biotechnology, 12(47): 6643-6649.

Ali-Shtayeh, M.S., Abu Ghdeib, S.L. (1999). Antifungal activity of plant extracts against dermatophytes. Mycoses, 42: 665-672.

Al-Said, M.S., Abdelsattar, E.A., Khalifa, S.I.; El-feraly, F.S. (1988). Isolation and identification of an anti-inflammatory princople from Capparis spinosa. Pharmazie, 43: 640-641.

Amenta, M., Ballistreri, G., Fabroni, S., Romeo, F.V., Spina, A., Rapisarda, P. (2015) Qualitative and nutraceutical aspects of lemon fruits grown on the mountainsides of the Mount Etna: A first step for a protected designation of origin or protected geographical indication application of the brand name 'Limone dell'Etna'. Food Research International 74: 250-259.

Ames, B.N., Gold, L.S., Willett, W.C. (1995). The causes and prevention of cancer. Proceedings of the National Academy of Sciences of the United States of America. 92:5258- 5265.

Anderson, J.A., Churchill, J.E., Autrique, S.D., Tanksley, S., Sorrells, M.E., (1993). Optimizing parental selection for genetic linkage maps. Genome 36: 181-188. 
Antolovich, M., Prenzler, P.D., Patsalides, E., McDonald, S., Robards, K. (2001).Methods for testing antioxidant activity. The Analyst, 127: 183-198.

Ao, M.Z., Gao, Y.Y., Yu, L.J. (2007). Advances in studies on constituents and their pharmacological activities of Capparis spinosa. Chinese Traditional and Herbal Drugs, 38(3): 463.

Ardanaz, N., Pagano, P.J. (2006). Hydrogen peroxide as a paracrine vascular mediator: regulation and signalling leading to dysfunction. Experimental Biology and Medicine 231:237251.

Argentieri, M., Macchia, F., Papadia, P., Fanizzi, F. P., \& Avato, P. (2012). Bioactive compounds from Capparis spinosa subsp. rupestris. Industrial Crops and Products, 36(1): 6569.

Arnous, A., Makris, D.P., Kefalas, P. (2002). Correlation of pigment and flavanol content with antioxidant properties in selected aged regional wines from Greece. Journal of Food Composition and Analysis, 15(6): 655-665.

Auldridge, M.E., McCarty, D.R., Klee, H.J. (2006). Plant carotenoid cleavage oxygenases and their apocarotenoid products. Current Opinion in Plant Biology, 9: 315-321.

Barbera, G., Di Lorenzo, R. (1984). The caper culture in Italy. Acta Horticolturae, 144: 167-71.

Beal MF (2005). Less stress, longer life. Nature Medicine, 11:598-599.

Bianco, G., Lelario, F., Battista, F. G., Bufo, S. A., Cataldi, T. R. (2012). Identification of glucosinolates in capers by LC-ESI-hybrid linear ion trap with Fourier transform ion cyclotron resonance mass spectrometry (LC-ESI-LTQ-FTICR MS) and infrared multiphoton dissociation. Journal of Mass Spectrometry, 47(9): 1160-1169. 
Blanca, J.M., Prohens, J., Anderson, G.J., Zuriaga, E., Caiñzares, J., Nuez, F. (2007). AFLP and DNA sequence variation in an Andean domesticate, pepino (Solanum muricatum, Solanaceae): implications for evolution and domestication. American Journal of Botany 94(7): 1219-1229.

Bohn, M., Utz, H., Melchinger, A. (1999). Genetic similarities among winter wheat cultivars determined on the basis of RFLPs. AFLPs and SSRs and their use for predicting progeny variance. Crop Science 39:228-237.

Bonina, F., Puglia, C., Ventura, D., Aquino, R., Tortora, S., Sacchi, A., Saija, A., Tomaino, A., Pellegrino, M., de Capariis, P. (2002). In vitro antioxidant and in vivo photoprotective effects of a lyophilized extract of Capparis spinosa L. buds. Journal of cosmetic science, 53(6): 321-336.

Botes, L., Van der Westhuizen, F.H., Loots, D.T. (2008). Phytochemical contents and antioxidant capacities of two aloe greatheadii var. davyana Extracts. Molecules, 13: 2169-2180.

Botstein, D., White, R.L., Skolnick, M., Davis, R.W., (1980). Construction of a genetic linkage map in man using restriction fragment length polymorphisms. The American Journal of Human Genetics, 32(3):314-331.

Bottema, S., Hansen, J. (1992). The Palaeoethnobotany of Franchthi Cave. Journal Storage.

Brevard, H., Brambille, M., Chaintreau, A., Marion, J.P. (1992). Occurrence of elemental sulphur in capers (Capparis spinosa L.) and first investigation of the flavour profile. Flavour \& Fragrance Journal, 7: 313-321.

Buntjer, J.B.V (1997). Phylogenetic computer tools, version 1.3. Wageningen University, Wageningen, Netherlands.

Cadenas, E. (1997). Basic mechanisms of antioxidant activity. Biofactors, 6: 391-397.

Cagnasso, S., Falasconi, M., Previdi M. P. (2010). Rapid screening of alicyclobacillus acidoterrestris spoilage of fruit juices by electronic nose: a confirmation study. Journal of Sensors, Article ID 143173. 
Calis, I., Kuruuzum-Uz, A., Ruedi, P. (1999). 1H-indole-3-acetonitrile glycosides from Capparis spinosa fruits. Phytochemistry, 50: 1205- 1208.

Cao, Y., Li, X., Zheng, M. (2010). Capparis spinosa protects against oxidative stress in systemic sclerosis dermal fibroblasts. Archives of Dermatological Research, 302: 349-355.

Carter, J.A., Chaterd, K.F., Bruton, C.J., (1980). A comparison of DNA cleavage by the restriction enzymes SalPI and PstI. Nucleic Acids Research, 8(21):4943-4954.

Chambers, E. IV, Koppel, K. (2013). Associations of Volatile Compounds with Sensory Aroma and Flavor: The Complex Nature of Flavor. Molecules, 18:4887-4905.

Chew, F.S. (1988). Searching for defensive chemistry in the Cruciferae. Chemical mediation of coevolution, 81-112. San Diego, CA: Academic Press.

Cicerale, S., Lucas, L., Keast, R. (2012). Antimicrobial, antioxidant and anti-inflammatory phenolic activities in extra virgin olive oil. Current Opinion in Biotechnology, 23(2): 129-135.

Cíž, M., Cížová, H., Denev, P., Kratchanova, M., Slavov, A. (2010). Different methods for control and comparison of the antioxidant properties of vegetables. Food Control, 21: 518-523.

Condurso, C., Mazzaglia, A., Tripodi, G., Cincotta, F., Dima, G., Lanza, C.M., Verzera, A., (2015). Sensory analysis and head-space aroma volatiles for the characterization of capers from different geographic origin. Journal of Essential Oil Research, 1041-2905.

Dancey, C., Reidy, J. (2004). Statistics without maths for psychology: using SPSS for windows. London: Prentice Hall.

Davies, K.J.A., Ursini, F. (1995). The oxygen paradox. Cooperativa Libraria Editrice dell'Università di Padova, University press, 88-7178-374-3, Padova, Italy.

Davies, K.J.A. (1995). Oxidative stress: the paradox of aerobic life. Biochemical Society Symposia 61:1-31. 
Deepak, M.K., Surendra, S.K., Mahabaleshwar, V.H., Hanhong, B. (2015). Significance of Antioxidant Potential of Plants and its Relevance to Therapeutic Applications. International Journal of Biological Sciences, 11(8): 982-991.

Del Río, L.A., Sandalio, L.M., Corpas, F.J., Palma, J.M., Barroso, J.B. (2006). Reactive oxygen species, reactive nitrogen species in peroxisomes. Production, scavenging, and, role in cell signaling. Journal of Plant Physiology, 141: 330-35.

Domitrović, R., Jakovac, H., Marchesi, V.V., Sain, I., Romić, Z., Rahelić, D. (2012). Preventive and therapeutic effects of oleuropein against carbon tetrachloride-induced liver damage in mice. Pharmacological Research 65(4):451-64.

Dröge, W. (2002). Free radicals in the physiological control of cell function. Physiological Reviews

82: 47-95.

Dudonné, S., Vitrac, X., Coutière, P., M., Mérillon, J.M. (2009). Comparative Study of Antioxidant Properties and Total Phenolic Content of 30 Plant Extracts of Industrial Interest Using DPPH, ABTS, FRAP, SOD, and ORAC Assays. Journal of Agricolture and Food Chemistry, 57: 1768-1774.

Embuscado, M.E. (2015). Spices and herbs: Natural sources of antioxidants - a mini review. Journal of Functional Foods, 18: 811-819

Esposito, K., Marfella, R., Ciotola, M., Di Palo, C., Giugliano, F., Giugliano, G., D'Armiento, M., D'Andrea, F., Giugliano, D. (2004). Effect of a mediterranean-style diet on endothelial dysfunction and markers of vascular inflammation in the metabolic syndrome: a randomized trial. The Journal of the American Medical Association, 292(12):1440-6.

European Union (EU) Regulation (EC) No. 1107/96

Feher, J. (1985). Free radical reactions in medicine. Berlin Springer Verlag. 
Felsenstein, J. (1989). PHYLIP—phylogeny inference package, version 3.2. Cladistics 5: 164166.

Fici, S., (2014). A taxonomic revision of the Capparis spinosa group (Capparaceae) from the Mediterranean to Central Asia. Phytotaxa, 174 (1): 001-024.

Fici, S., Gianguzzi, L. (1997). Diversity and conservation in wild and cultivated Capparis in Sicily. Bocconea, 7: 437-443.

Francesca, N., Barbera, M., Martorana, A., Saiano, F., Gaglio, R., Aponte, M., Moschetti, G., Settanni, L. (2016). Optimised method for the analysis of phenolic compounds from caper (Capparis spinosa L.) berries and monitoring of their changes during fermentation. Food Chemistry, 196: 1172-1179.

Fu, X.P., Wu, T., Abdurahim, M., Su, Z., Hou, X.L., Aisa, H.A., (2008). New spermidine alkaloids from Capparis spinosa roots. Phytochemistry Letters, 1:59-62.

Gardener, H., Wright, C.B., Gu, Y., Demmer, R.T., Boden-Albala, B., Elkind, M.S., Sacco, R.L., Scarmeas, N. (2011). Mediterranean-style diet and risk of ischemic stroke, myocardial infarction, and vascular death:the Northern Manhattan Study. The American Journal of Clinical Nutrition. 94(6):1458-64.

Germanò, M.P., De Pasquale, R., D’Angelo, V., Catania, S., Silvari, V., Costa, C. (2002). Evaluation of Extracts and Isolated Fraction from Capparis spinosa L. Buds as an Antioxidant Source. Journal of Agricolture and Food Chemistry, 50: 1168-1171.

Gershenzon, J., Croteau, R. (1990). Regulation of monoterpene biosynthesis in higher plants. Biochemistry of the mevalonic acid pathway to terpenoids; recent advances phytochemistry 24 : 99-160.

Giomaro, G., Karioti, A., Bilia, A.R., Bucchini, A, Giamperi, L., Ricci D., Fraternale D. (2014) Polyphenols profile and antioxidant activity of skin and pulp of a rare apple from Marche region (Italy). Chemistry Central Journal, 8: 45. 
Giuffrida, D., Salvo, F., Ziino, M., Toscano, G., Dugo, G. (2002). Initial investigation on some chemical constituents of capers (Capparis spinosa L.) from the island of Salina. Italian Journal of Food Science, 14(1):25-33.

Gull, T., Anwar, F., Sultana, B., Cervantes Alcayde, M.A., Nouman W. (2015). Capparis species: A potential source of bioactive and high-value components: Review Article. Industrial Crops and Products 67: $81-96$.

Handa, S.S., Sharma, A., Chakraborti, K.K. (1986). Natural products and plants as liver protecting drugs. Fitoterapia 57: 307-349.

Haciseferoğullari, H., Özcan, M.M., Duman, E. (2011). Biochemical and technological properties of seeds and oils of Capparis spinosa and Capparis ovata plants growing wild in Turkey. Journal of Food Processing and Technologies, 2: 6.

Halliwell, B. (1991). Reactive oxygen species in living systems: source, biochemistry, and role in human disease. The American Journal of Medicine 91:14-22

Halliwell, B., Gutteridge, J.M. (1989). Free radicals in Biology and Medicine. Oxford, Oxford University Press, UK.

Hashem, F.A., Motawea, H., El-Shabrawy, A.E., Shaker, K., El-Sherbini, S. (2011). Myrosinase Hydrolysates of Brassica oleraceae L. Var. italica Reduce the Risk of Colon Cancer. Phytotherapy Research. doi: 10.1002/ptr.3591.

Higton, R.N., Akeroyd, J.R. (1991). Variation in Capparis spinosa L. in Europe. Botanical Journal of the Linnean Society, 106: 104-112.

Ho, C.S., Lam, C.W.K., Chan, M.H.M., Cheung, R.C.K., Law, L.K., Lit, L.C.W., Ng, K.F., Suen, M.W.M., Tai, H.L. (2003). Electrospray Ionisation Mass Spectrometry: Principles and Clinical Applications. The Clinical Biochemist Reviews, 24(1): 3-12.

Huang, D., Ou, B., Prior, R.L. (2005). The chemistry behind antioxidant capacity assays. Journal of Agricolture and Food Chemistry, 53: 1841-1856. 
Kalita, D., and Jayanty, S.S. (2014) Comparison of Polyphenol Content and Antioxidant Capacity of Colored Potato Tubers, Pomegranate and Blueberries. Journal of Food Processing and Technologies, 5: 8. [http://dx.doi.org/10.4172/2157-7110.1000358]

Ignarro, L.J. (2000). Introduction and overview. Nitric Oxide in Biology and Pathobiology, 3-19, Accademic press, San Diego.

Inocencio, C., Cowan, R.S., Alcaraz, F., Rivera, D. Fay, M.F. (2005). AFLP fingerprinting in Capparis subgenus Capparis related to the commercial sources of capers. Genetic Resources and Crop Evolution 52: 137-144.

Inocenio, C., Rivera, D., Alcaraz, F., Tomas-Barber, F.A. (2000). Flavonoid content of commercial capers (Capparis spinosa, $C$. sicula and $C$. orientalis) produced in Mediterranean countries. European Food Research and Technologies 21:70-4.

Janick, J., Paull, R.E. (2006). The encyclopedia of fruits and nuts. Edited by Janick J, Purdue University, USA, and Paull RE., University of Hawaii at Manoa, USA. 228-231.

Kolomvotsou, A.I., Rallidis, L.S., Mountzouris, K.C., Lekakis, J., Koutelidakis, A., Efstathiou, S., Nana-Anastasiou, M., Zampelas, A. (2013). Adherence to Mediterranean diet and close dietetic supervision increase total dietary antioxidant intake and plasma antioxidant capacity in subjects with abdominal obesity. European Journal of Nutrition, 52(1):37-48.

Korkina, L.G. (2007). Phenylpropanoids as naturally occurring antioxidants: from plant defense to human health. Cellular and molecular biology, 53: 15-25.

Krinsky, N.I. (1992). Mechanism of action of biological antioxidants. Proceedings of the Society for Experimental Biology and Medicine, 200: 248-254.

Louda, S., Mole, S. (1991). Glucosinolates: chemistry and ecology. In G. A. Rosenthal, \& M. R. Berenbaum (Eds.), Herbivores: Their interactions with secondary plant metabolites, 123-164. San Diego, California. 
Lee, K.W., Kim, Y.J., Lee, H.J., Lee, C.Y. (2003). Cocoa has more phenolic phytochemicals and a higher antioxidant capacity than teas and red wine. Journal of Agricultural and Food Chemistry, 51(25): 7292-7295.

Legua, P., Martínez, J.J., Melgarejo, P., Martínez, R., Hernández, F. (2013). Phenological growth stages of caper plant (Capparis spinosa L.) according to the Biologische Bundesanstalt, Bundessortenamt and Chemical scale. Annals of Applied Biology. 163:135-141.

Levizon, E., Drilias, P., Kyparissis, A. (2004). Exceptional photosynthetic performance of Capparis spinosa L. under adverse conditions of Mediterranean summer. Photosynthetica, 42:229-35.

Liochev, S.I., Fridovich, I. (1994). The role of $\mathrm{O}_{2}{ }^{*}$, in the production of ${ }^{\circ} \mathrm{OH}$ : in vitro and in vivo. Free Radical Biology and Medicine. 16:29-33.

Maarse, H. (1991). Introduction. In Volatile Compounds in Foods and Beverages, 1st ed.; Maarse H., Ed.; Marcel Dekker Inc.: New York, NY, USA, 1-39.

Martosa, V., Royob, C., Rharrabtia, Y., Garcia del Morala, L.F. (2005). Using AFLPs to determine phylogenetic relationships and genetic erosion in durum wheat cultivars released in Italy and Spain throughout the 20th century. Field Crops Research 91:107-116.

Matos, R.S., Baroncini, L.A., Précoma, L.B., Winter, G., Lambach, P.H., Caron Kaiber, F., Précoma, D.B. (2012). Resveratrol causes antiatherogenic effects in an animal model of atherosclerosis. Arquivos Brasileiros De Cardiologia 98(2):136-42.

Matthaus, B., Özcan M. (2002). Glucosinolate composition of young shoots and flower buds of capers (Capparis species) growing wild in Turkey. Journal of Agricultural and Food Chemistry, 50: 7323-7325.

Melgarejo, P., Legua, P., Martínez, J.J., Martínez-Font, R., Hernández, F., (2009). Preliminary characterization of Sixty one caper clones (Capparis spinosa L.). Acta Horticulturae, 818:155160 . 
Miller, N.J., Rice-Evans, C.A. (1996). Spectrophotometric determination of antioxidant activity. Redox Report 2: 161-171.

Molyneux, P. (2004). The use of the stable free radical diphenylpicrylhydrazyl (DPPH) for estimating antioxidant activity. Songklanakarin Journal of Food Science and Technology, 26: 211-219.

Moubasher, H., Abd El-Ghani, M.M., Kamei, W., Mansi, M., El-bous, M., (2011). Taxonomic considerations among and within some Egyptian taxa of Capparis and related genera (Capparaceae) as revealed by RAPD fingerprinting. Collectanea Botanica, 30:29-35 ISSN: 0010-0730 doi: 10.3989/collectbot.2011.v30.003

Muminovic, J., Melchinger, A., Lubberstedt, T. (2004). Genetic diversity in cornsalad (Valerianella locusta) and related species as determined by AFLP markers. Plant Breeding 123:460-466.

Nei, M., Li, W.H. (1979). Mathematical model for studying genetic variation in terms of restriction endonucleases. Proceedings of the National Academy of Sciences, USA 76: 52695273.

Nosrati, H., Hosseinpour Feizi, M.A., Mazinani, M., Haghighi, A.R., (2012). Effect of population size on genetic variation levels in Capparis spinosa (Capparaceae) detected by RAPDs. EurAsian Journal of Bio-Sciences 6:70-75.

Ou, B., Hampisch-Woodill, M., Prior, L. (2001). Development and validation of an improved oxygen radical absorbance capacity assay using fluoresceina as the fluorescent probe. Journal of Agricultural and Food Chemistry 49: 4619-4626.

Özcan, M., Akgul, A. (1998). Influence of species harvest date and size on composition of capers (capparis spp.) flower buds. Nahrung, 42: 102-105.

Pandey, K.B., Mishra, N., Rizvi, S.I. (2009). Plant polyphenols as dietary antioxidants in human health and disease. Oxidative Medicine and Cellular Longevity 2(5): 270-278. 
Pardo M., Sberveglieri G. (2004). Electronic olfactory systems based on metal oxide semiconductor sensor arrays. MRS Bulletin 29(10):703-701.

Persaud, K., Dodd, G.H. (1982). Analysis of discrimination mechanisms in the mammalian olfactory system using a model nose. Nature, 299: 352-355.

Pezet, R., Cuenat, Ph. (1996). Resveratrol in Wine: Extraction From Skin During Fermentation and Post-fermentation Standing of Must From Gamay Grapes. American Journal of Enology and Viticolture, 47: 287-290.

Powell, W., Morgante, M., Andre, C., Hanafey, M., Vogel, J., Tingey, S., Rafalsky, A. (1996). The comparison of RFLP, RAPD, AFLP and SSR (microsatellite) markers for germplasm analysis. Molecular Breeding. 2: 225-238.

Prevost, A., Wilkinson, M.J. (1999). A new system of comparing PCR primers applied to ISSR fingerprinting of potato cultivars, Theoretical and Applied Genetics, 98: 107-112.

Prior, R.L., Hoang, H., Gu, L., Wu, X., Bacchiocca, M., Howard, L., Hampsch-Woodill, M., Huang, D., Ou, B., Jacob, R. (2003). Assays for hydrophilic and lipophilic antioxidant capacity (oxygen radical absorbance capacity (ORACFL)) of plasma and other biological and food samples. Journal of Agricultural and Food Chemistry 51: 3273-3279.

Pryor, W.A., Houk, K.H., Foote, C.S., Fukuto, J.M., Iganrro, L.J., Squadrito, G.L., Davies, K.J.A. (2006). Free radical biology and medicine: it's a gas man!. The American Journal of Physiology - Regulatory, Integrative and Comparative Physiology, 291: 491- 511.

Pryor, W.A. (1986). Oxyradicals and related species: their formation, lifetimes and reactions. Annual Review of Physiology 48:657-667.

Pugnaire, F.I., Esteban, E. (1991). Nutritional adaptations of caper shrub (Capparis ovata Desf) to environmental stress. Journal of Plant Nutrition, 12:151-61. 
Quideau, S., Deffieux, D., Douat-Casassus, C., and Pouysgu, L. (2011). Plant Polyphenols: Chemical Properties, Biological Activities, and Synthesis. Angewandte Chemie International Edition, 50: 586 - 621 .

Rapisarda, P., Lo Bianco, M., Pannuzzo, P., Timpanaro, N. (2008). Effect of cold storage on vitamin $\mathrm{C}$, phenolics and antioxidant activity of five orange genotypes [Citrus sinensis (L.) Osbeck]. Postharvest Biology and Technology 49: 348-354.

Regulation 20/03/2006 n.510 - 06/510/CE - G.U.E. 31/03/2006 n. 93.

Regulation (CE) n.628/2008.

Romeo, V., Ziino, M., Giuffrida, D. (2007). Flavour profile of capers (Capparis spinosa L.) from the Eolian Archipelago by HS-SPME/GC-MS. Food Chemistry,101:1272-8.

Saeed Tarkesh, E., Behrouz, S., Ghlolamreza, B. (2009). AFLP markers for the assessment of genetic diversity in european and North American potato varieties cultivated in Iran. Crop Breeding and Applied Biotechnology 9: 75-86.

Saifi, N., Ibijbijen, J., Echchgadda, G. (2011). Genetic diversity of caper plant (Capparis ssp.) from North Morocco. Journal of Food, Agriculture \& Environment 9, (3\&4): 299-304.

Sathyanarayana, N., Leelambika, M., Mahesh, S., Jaheer, M. (2011). AFLP assessment of genetic diversity among Indian Mucuna accessions. Physiologyand Molecular Biology of Plants. 17(2):171-180.

Sauer, H. (2001). Reactive Oxygen Species as intracellular messengers during cell growth and differentiation. Cellular Physiology and Biochemistry 11:173-186.

Shahidi, F., Naczk, M. (1995). Food phenolics, sources, chemistry, effects, applications. Lancaster, PA: Technomic Publishing Co Inc,. 
Shalaby, E.A., Shanab, S.M.M., (2013). Comparison of DPPH and ABTS assays for determining antioxidant potential of water and methanol extracts of Spirulina platensis . Indian Journal of Geo-Marine Sciences, 42: 556-564.

Shakrishvili, N., Osishvili, L., (2013). Sexual phenotype of Capparis herbacea (Capparaceae). Turkish Journal of Botany 37: 682-689.

Schafer, F.Q., Buettner, G.R. (2001). Redox environment of the cell as viewed through the redox state of the glutathione disulfide/glutathione couple. Free Radical Biology \& Medicine, 30: $1191-1212$.

Schaller, E., Bosset, J.O., Escher, F. (1998). Electronic noses and their application to food. Food Science and Technology 31: 305-316.

Schwab, W., Davidovich-Rikanati, R., Lewinsohn, E. (2008). Biosynthesis of plant-derived flavor compounds. Plant Journal, 54:712-732

Schwab, W. (2013). Natural 4-Hydroxy-2, 5-dimethyl-3 (2H)- furanone (Furaneol®). Molecules, 18:6936-6951.

Sies, H. (1985). Oxidative stress: introductory remarks. Oxidative Stress 1-8, Academic press, London.

Simon, I., Bârsan, N., Bauer, M., Weimar, U. (2001). Micromachined metal oxide gas sensors: opportunities to improve sensor performance. Sensors and Actuators B: Chemical, 73: 1-26.

Singleton, V.L., Orthofer, R., Lamuela-Raventos, R.M. (1999). Analysis of total phenols and other oxidation substrates and antioxidants by means of Folin-Ciocalteu reagent. Oxidants and Antioxidants, Pt A, 299: 152-178.

Siracusa, L., Kulisic-Bilusic, T., Politeo, O., Krause, I., Dejanovic, B., Ruberto, G. (2011). Phenolic Composition and Antioxidant Activity of Aqueous Infusions from Capparis spinosa L. and Crithmum maritimum L. before and after Submission to a Two-Step in Vitro Digestion Model. Journal of Agricultural and Food Chemistry, 59: 12453-12459. 
Sorkheh, K., Shiran, B., Gradziel, T.M., Epperson, B.K., Martýnez- Gomez, P., Asadi, E. (2007). Amplified fragment length polymorphism as a tool for molecular characterization of almond germplasm: genetic diversity among cultivated genotypes and related wild species of almond, and its relationships with agronomic traits. Euphytica 156: 327-344.

Stuehr, D.J. (1999). Mammalian nitric oxide synthases. Biochimica et Biophysica Acta. 1411:217-230.

Tatikonda, L., Suhas Wani, P., Kannan, S., Beerelli, N., Thakur Sreedevi, K., David Hoisington, A., Devi, P., Rajeev Varshney, K. (2009). AFLP- based molecular characterization of an elite germplasm collection of Jatropha curcas L., a biofuel plant. Plant Science. 176:505-513.

Tesoriere, L., Butera, D., Gentile, C., Livrea, M.A. (2007), Bioactive Components of Caper (Capparis spinosa L.) from Sicily and Antioxidant Effects in a Red Meat Simulated Gastric Digestion. Journal of Agricultural and Food Chemistry. 55:8465-8471.

Thaipong, K., Boonprakob, U., Crosby, K., Cisneros-Zevallos, L., Byrne, D.H. (2006). Comparison of ABTS, DPPH, FRAP, and ORAC assays for estimating antioxidant activity from guava fruit extracts. Journal of Food Composition and Analysis 19: 669-675.

Tlili, N., Elfalleh, W., Saadaoui, E., Khaldi, A., Triki, S., Nasri, N. (2011). The caper (Capparis L.): ethnopharmacology, phytochemical and pharmacological properties. Fitoterapia, 82:93101.

Tlili, N., Munne-Boscch, S., Nasri, N., Saadaqui, E., Khaldi, A., Triki, S. (2009). Fatty acids, tocopherols and carotenoids from seeds of Tunisian caper " Capparis spinosa'. Journal of Food Lipids, 16:452-464.

Tlili, N., Nasri, N., Saadaoui, E., Khaldi, A., Triki, S. (2009). Carotenoid and tocopherol composition of leaves, buds and flowers of Capparis spinosa grown wild in Tunisia. Journal of Agricultural and Food Chemistry, 57: 5381-5. 
Tlili, N., Nasri, N., Khaldi, A., Triki, S., Munne-Bosch, S. (2011). Phenolic compounds, tocopherols, carotenoids and vitamin $\mathrm{C}$ of commercial caper. Journal of Food Biochemistry 35(2):472 - 483.

Valko, M., Rhodes, C.J., Moncola, J., Izakovic, M., Mazura, M. (2006). Free radicals, metals and antioxidants in oxidative stress-induced cancer. Chemico-Biological Interactions, 160: 1-40.

Vos, P., Hogers, R., Bleeker, M., Reijans, M., Van der Lee, T., Hornes, M., Frijters, A., Pot, J., Peleman, J., Kuiper, M., Zabeau, M. (1995) AFLP: a new technique for DNA fingerprinting. Nucleic Acids Research 23: 4407-4414.

Wang, H., Cao, G., Prior, R.L. (1996). Total antioxidant capacity of fruits. Journal of Agricultural and Food Chemistry, 44:701-705.

Wink, D.A., Hanbauer, I., Krishna, M.C., DeGraff, W., Gamson, J., Mitchell, J.B. (1993). Nitric oxide protects against cellular damage and cytotoxicity from reactive oxygen species. Proceedings of the National Academy of Sciences 90:9813-9817.

Yaniv, Z., Dafni, A., Friedman, J., Palevitch, D. (1987). Plants used for the treatment of diabetes in Israel. Journal of Ethnopharmacology, 19: 145-151.

Zargari, A. (1986). (4th ed.). Medicinal plants (Vol. 1). Tehran: Tehran University Publications, $249-252$.

Zhang, Y. (2004). Cancer-preventive isothiocyanates: measurement of human exposure and mechanism of action. Mutation Research, 555: 173-190.

Zima, T.S., Fialova, L., Mestek, O., Janebova, M., Crkovska, J., Malbohan, I., Stıpek, S., Mikulıkova, L., Popov, P. (2001). Oxidative stress, metabolism of ethanol and alcohol-related diseases. Journal of Biomedical Science, 8: 59-70.

Zhishen, J., Mengcheng, T., Jianming, W. (1999). Determination of flavonoid contents in mulberry and their scavenging effects on superoxide radicals. Food Chemistry, 64: 555-559. 
Zhu, S.L., Dou, S.S, Liu, X.R., Liu, R.H., Zhang W.D., Huang H.L., Zhang, Y., Hu, Y.H., Wang, S.P. (2011). Qualitative and Quantitative Analysis of Alkaloids in Cortex Phellodendri by HPLC-ESI-MS/MS and HPLC-DAD. Chemical Research in Chinese Universities, 27(1): 38-44. 